\title{
Cathode Design for High Energy Molten Salt Lithium-Oxygen Batteries
}

\author{
Thesis by \\ Dylan D. Tozier \\ In Partial Fulfillment of the Requirements for the \\ Degree of \\ Doctor of Philosophy

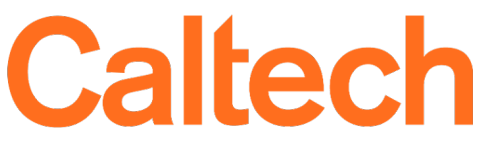

CALIFORNIA INSTITUTE OF TECHNOLOGY

Pasadena, California

2018

Defended May 31, 2018 
(C) 2018

Dylan D. Tozier ORCID: 0000-0001-9489-8824

All rights reserved 


\section{ACKNOWLEDGEMENTS}

Just over seven years ago I somehow stumbled into Prof Ajayan's lab at Rice University. I had never even considered going to grad school, but my time in his lab working with Akshay Mathkar sent me down the path to Caltech. Throughout this time, I've met some extraordinary people, my advisor Julia being one of them. I admire your infectious enthusiasm, and you've made doing research at Caltech a wonderful experience. To the rest of the Greer Group, I am always amazed by how you can be both so good at science and so much fun. I couldn't have asked for better group members. To everyone over at Liox, you have been fantastic collaborators and like a second group to me. I've learned so much from you all, and I can't believe how lucky I was to get to work as closely with you as I did. To the many other amazing people I have had the pleasure to work with, Betar, Carol, Nathan, and others I'm sure I am leaving out, I appreciate how generous you were with your time. It's people like you who make Caltech the great place that it is. To all the current and former members of Steuben House, thank you for the good times. It's been like coming home to family, and I would be hard pressed to find a better group of people to live with. To Patricia, thanks for putting up with me all these years. I guess this means it's your turn to go to grad school. And finally, to my parents who have encouraged and supported me every step of the way, it's hard to believe that the last time I wasn't a student, you were making homework for me to do with Garrett so I wouldn't feel left out. I guess I'm finally finished. Mom and Dad, thanks for everything. 


\begin{abstract}
State of the art commercial lithium ion batteries use cathodes such as lithium cobalt oxide which rely on insertion and removal of lithium ions from a host material. However, insertion cathode materials are limited in their capacity, and replacing them with a cathode that employs growth and dissolution of new phases could significantly increase a battery's energy density. For example, oxygen and sulfur cathodes have been widely researched to this end, with both cases involving the growth of a lithium-rich compound on a current collector/catalyst support.

We begin by describing the effect of using a molten salt electrolyte in a lithiumoxygen battery. In particular, we focus on how the electrochemical performance and discharge product, lithium peroxide, differ from that of a traditional organic electrolyte. In addition, we discuss the enhanced peroxide solubility in a molten salt and its implications for lithium peroxide growth and coulombic efficiency. Finally, we address the cell death of a galvanostatically cycled battery.

We then introduce a similar phase-forming conversion chemistry, whereby a molten nitrate salt serves as both an active material and the electrolyte. Molten nitrate salts were previously studied as an active material in a primary lithium battery where lithium oxide irreversibly forms as nitrate reduces to nitrite. We will describe how the use of a nanoparticle heterogeneous catalyst allows the reversible growth and dissolution of micron-scale lithium oxide crystals in this system.

After introducing these molten salt lithium batteries, we address the effect of cathode geometry on electrochemical performance. In particular, we note that the growth of such large, solid phase species on the surface of the catalyst support imposes new design restrictions when optimizing a cathode for energy density. As a proof of concept, we design and implement an architected electrode with large pore volume and relatively small surface area, comparing it with the more typical geometries of thin films and nanoparticles.
\end{abstract}




\section{PUBLISHED CONTENT AND CONTRIBUTIONS}

1. Giordani, V., Tozier, D., Tan, H., Burke, C. M., Gallant, B. M., Uddin, J., Greer, J. R., McCloskey, B. D., Chase, G. V. \& Addison, D. A Molten Salt LithiumOxygen Battery. Journal of the American Chemical Society 138, 2656-2663. doi: 10.1021/jacs.5b11744 (2016).

D. Tozier assisted with battery assembly and electrochemical analysis, performed the ex situ characterization, and participated in the writing of the manuscript.

2. Addison, D., Tozier, D., Tan, H., Uddin, J., Gallant, B. M., McCloskey, B. D., Greer, J. R., Chase, G. V. \& Giordani, V. A New Rechargeable Battery: Lithium Oxide Growth through Molten Salt Nitrate Reduction. (In Preparation).

D. Tozier assisted with battery assembly and electrochemical analysis, performed the ex situ characterization, and wrote much of the manuscript.

3. Tozier, D., Giordani, V., Chase, G. V., Addison, D. \& Greer, J. R. The Role of Battery Cathode Architecture in Conversion Reaction Chemistries. (In Preparation).

D. Tozier fabricated and characterized the samples, assembled the batteries, performed the electrochemical analysis, and wrote the manuscript. 


\section{TABLE OF CONTENTS}

Acknowledgements ................. iii

Abstract .............................. iv

Published Content and Contributions . . . . . . . . . . . . . . v v

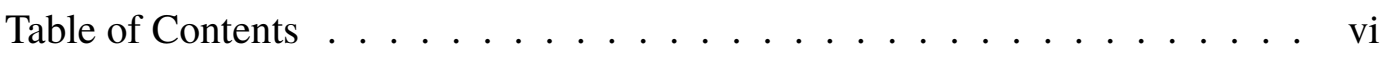

List of Illustrations . . . . . . . . . . . . . . . . vii

List of Tables . . . . . . . . . . . . . . . . . . . ix

Chapter I: Introduction $\ldots \ldots \ldots \ldots$

1.1 A Brief History of Batteries . . . . . . . . . . . . . . 1

1.2 The Lithium-Oxygen Battery . . . . . . . . . . . . . . . . 4

1.3 Thesis Overview . . . . . . . . . . . . . . . . . 10

Chapter II: A Molten Salt Lithium-Oxygen Battery . . . . . . . . . . . . . 11

2.1 Molten Salt Electrolytes . . . . . . . . . . . . . . . . . 12

2.2 Oxygen Electrochemistry in a Molten Salt . . . . . . . . . . . . 13

2.3 Lithium Peroxide and Wulff Constructions . . . . . . . . . . . . 18

2.4 Battery Cycling Performance and Cell Death . . . . . . . . . . . . 26

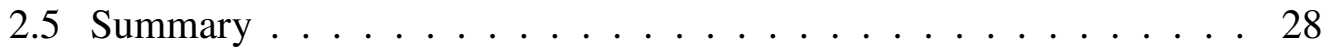

Chapter III: A Nitrate Reduction Battery . . . . . . . . . . . . . . . . . . . . . . . . . . 30

3.1 Nitrate Reduction Chemistry . . . . . . . . . . . . . . . 31

3.2 Catalysis of Nitrite Oxidation . . . . . . . . . . . . . . 33

3.3 Lithium Oxide as a Discharge Product . . . . . . . . . . . . . 37

3.4 Nitrate to Nitrite and Back Again . . . . . . . . . . . . . . . . . 42

3.5 Battery Cycling Performance . . . . . . . . . . . . . . . . 45

3.6 Summary . . . . . . . . . . . . . . . . . . 46

Chapter IV: Role of Cathode Architecture in Conversion Reaction Chemistries 48

4.1 Capacity Limitations . . . . . . . . . . . . . . . . . . . . . . 49

4.2 Fabrication of Architected Electrodes . . . . . . . . . . . . . 53

4.3 Electrochemical Surface Area of Nickel Electrodes . . . . . . . . . . 57

4.4 Performance of Architected Electrodes . . . . . . . . . . . . . 62

4.5 Commercial Foam Electrode Comparison . . . . . . . . . . . . . 66

4.6 Summary . . . . . . . . . . . . . . . . 71

Chapter V: Summary and Outlook . . . . . . . . . . . . . . . . . 72

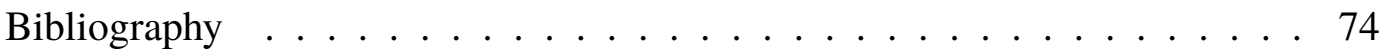

Appendix A: Detailed Cell Construction . . . . . . . . . . . . . . . 82

Appendix B: Ion Exchange Chromatography Calibration and Calculation . . . 85

Appendix C: Nanoscribe Speed Optimization _ . . . . . . . . . . . . . . . 88

Appendix D: Wetting of Architected Electrodes . . . . . . . . . . . . 91 


\section{LIST OF ILLUSTRATIONS}

Number Page

1.1 Lithium-ion battery schematic . . . . . . . . . . . . . 3

1.2 Lithium-oxygen battery schematic . . . . . . . . . . . 5

1.3 Typical lithium-oxygen first cycle ............. 6

1.4 Typical morphologies of $\mathrm{Li}_{2} \mathrm{O}_{2} \ldots \ldots \ldots$. . . . . . . . . 7

1.5 Growth mechanisms of $\mathrm{Li}_{2} \mathrm{O}_{2} \ldots \ldots \ldots$. . . . . . . . . 8

1.6 Gutmann acceptor and donor number of solvents . . . . . . . . . . 9

2.1 Cyclic voltammetry of oxygen reduction and evolution . . . . . . . . 14

2.2 Galvanostatic cycling of oxygen reduction and evolution . . . . . . 16

2.3 Mass spectrometry of lithium-oxygen charge process . . . . . . . 18

2.4 X-ray diffraction of lithium-oxygen cathode across one cycle . . . . 19

2.5 Wulff construction schematic . . . . . . . . . . . . . 20

2.6 Wulff construction of $\mathrm{Li}_{2} \mathrm{O}_{2} \ldots \ldots \ldots . \ldots 21$

2.7 Morphology of oxygen cathode discharge product . . . . . . . . . . . 22

2.8 Elemental map of oxygen cathode discharge product . . . . . . . . 23

2.9 Elemental map of oxygen cathode after full cycle . . . . . . . . . . 23

2.10 Linear sweep voltammograms of $\mathrm{Li}_{2} \mathrm{O}_{2}$ oxidation . . . . . . . . . . 25

2.11 Cycling behavior of lithium-oxygen battery . . . . . . . . . . 26

2.12 X-ray diffraction of cycled lithium-oxygen battery . . . . . . . . . . 27

2.13 Scanning electron microscopy of cycled lithium-oxygen battery . . . 27

3.1 Nitrate reduction first cycle on a Super P carbon cathode . . . . . . . 32

3.2 Nitrate reduction schematic . . . . . . . . . . . . . . 32

3.3 Catalysis comparison for nitrate reduction reversibility . . . . . . . 33

3.4 Galvanostatic intermittent titration technique of nitrate reduction . . . 34

3.5 X-ray photoelectron spectroscopy of nickel nanoparticles . . . . . . . 35

3.6 Transmission electron microscopy of nickel nanoparticles . . . . . . 36

3.7 Lithium-doped nickel oxide as a catalyst . . . . . . . . . . . . . . 38

3.8 X-ray diffraction of nitrate reduction cathode across one cycle . . . . 39

3.9 Transmission electron microscopy of nitrate reduction cathode . . . . 39

3.10 Morphology of nitrate reduction cathode discharge product . . . . . . 40

3.11 Elemental map of nitrate reduction cathode discharge product . . . . 41

3.12 Raman spectroscopy of nitrate reduction electrolyte across one cycle . 42 
3.13 Charging profile of newly constructed cells preloaded with $\mathrm{Li}_{2} \mathrm{O}$. . . 43

3.14 Ion exchange chromatography of nitrate/nitrite solution . . . . . . . 45

3.15 Cycling behavior of nitrate reduction battery . . . . . . . . . . 46

4.1 Surface of fully discharge cathodes . . . . . . . . . . . . 51

4.2 Example structured nickel electrodes . . . . . . . . . . . . . 52

4.3 Model of lattice electrode unit . . . . . . . . . . . . . . . . . . . 54

4.4 Fabrication of polymer lattice . . . . . . . . . . . . . . . . 55

4.5 Sputtered nickel film coating a polymer lattice . . . . . . . . . 56

4.6 Nickel lattice electrode . . . . . . . . . . . . . . . . . . . 57

4.7 Surface electrochemistry of nickel . . . . . . . . . . . . . . 58

4.8 Electrochemical surface area of sputtered nickel . . . . . . . . . . 60

4.9 Electrochemical surface area of lattice electrode . . . . . . . . . 61

4.10 Cyclic voltammetry of nitrate reduction on different cathodes . . . . 62

4.11 Galvanostatic discharge of nitrate reduction on different cathodes . . 64

4.12 Nitrate reduction discharge product on lattice electrode . . . . . . . . 64

4.13 Foam electrode morphologies . . . . . . . . . . . . . . 67

4.14 Cyclic voltammetry of nitrate reduction on foam cathodes . . . . . 68

4.15 Galvanostatic discharge of nitrate reduction on foam cathodes . . . . 69

A.1 Picture of Swagelok cell . . . . . . . . . . . . . 83

B.1 Ion exchange chromatography nitrate calibration scans . . . . . . 85

C.1 Nanoscribe parameter sweep . . . . . . . . . . . . . . . . 89

D.1 Wettability of lattice electrode . . . . . . . . . . . . 91

D.2 Wetting of a lattice electrode . . . . . . . . . . . . 92 


\section{LIST OF TABLES}

Number Page

1.1 Theoretical energy density of batteries . . . . . . . . . . . . 4

2.1 Molten salt electrolyte compositions . . . . . . . . . . . . 13

4.1 Acid bath for nickel surface cleaning . . . . . . . . . . . . 59

4.2 Normalized discharge capacity of nitrate reduction on different cathodes 65

4.3 Structure properties of discharged foam cathodes . . . . . . . . 69 


\section{Chapter 1}

\section{INTRODUCTION}

The ability to store energy and release it as needed plays a surprisingly important role in our lives, so much so that we often forget how integral energy storage has become to a modern lifestyle. For instance, this thesis is written on a laptop, a device that is only possible due to significant advancements in battery technology over the course of decades. And as the performance of batteries has grown over the years, so too has the range of applications where they can play a part. While today it may seem inevitable that electric vehicles are set to replace their gasoline counterparts as automakers announce electrified lineups and countries announce electrification goals[1], it is easy to forget that just 10 years ago Tesla released their first electric vehicle to a skeptical public. Such a dramatic change in perspective is largely thanks to the precipitous drop in battery prices over that time period[2]. Along a similar vein, renewable energy sources such as wind and solar have begun to provide a significant portion of the power in our electric grid, but their intermittency has created a need for large scale, cheap energy storage. We are already seeing batteries begin to play a role in this space, and the improvement of existing battery chemistries and development of new ones will only see their part grow. Between consumer electronics, electric vehicles, grid storage, and many more, the range of applications for batteries, in addition to the demands on them, is only growing. The scope of this thesis is dedicated to understanding some of these new battery chemistries, but to fully do so, it is instructive to look back at how we got to where we are today.

\subsection{A Brief History of Batteries}

For the purposes of this thesis, it is best to divide the history of batteries into three simple categories: before, during, and after lithium-ion batteries. As this is

a brief history, many chemistries will be overlooked. A commonality across all of these battery chemistries is that the underlying physics is the same: an electrolyte separates two electrodes where redox reactions occur, one an oxidation and the other a reduction, and the difference in reduction potential of the two reactions is the voltage across the battery. 


\section{Before Lithium-Ion}

The first true battery was invented in 1800 by Alessandro Volta, after whom the unit Volt is named[3]. While electrochemistry was not understood at the time, his voltaic stack was a true electrochemical cell consisting of zinc and copper electrodes separated by a sulfuric acid electrolyte, giving the half cell reactions of Equation 1.1 .

$$
\begin{aligned}
& \mathrm{Zn}+\mathrm{SO}_{4}^{2-} \rightarrow \mathrm{ZnSO}_{4}+2 e^{-} \\
& 2 \mathrm{H}^{+}+2 e^{-} \rightarrow \mathrm{H}_{2}
\end{aligned}
$$

Similar batteries were used through much of the 1800s until the development of the lead-acid battery, the first rechargeable battery, in 1859[4]. The ability to reuse these batteries led to an expanded range of applications for batteries, and the lead-acid chemistry is still widely used today.

After the development of the lead-acid battery, many other primary and reversible chemistries came into use, including zinc-carbon, nickel-cadmium, alkaline, and nickel-metal hydride to name a few. However, a battery with larger energy density was desired, and lithium became a heavily researched battery constituent due to its low atomic mass and reduction potential. While lithium batteries were commercialized as primary batteries, developing a reversible chemistry proved challenging.

\section{The Lithium-Ion Battery}

Beginning in the 1970s, several groups performed the work necessary to develop the lithium-ion battery, with Stanley Whittingham demonstrating the reversible intercalation of lithium[5, 6], John Goodenough the $\mathrm{LiCoO}_{2}$ cathode[7], and Rachid Yazami the reversible intercalation of lithium into a graphite anode[8]. Building off of these works, Sony was able to commercialize the lithium-ion battery in 1991, first with a hard carbon anode, and later a graphite one.

The operation of the lithium-ion battery is significantly different than the rechargeable batteries that preceded it. Both electrodes employ a lithium intercalation mechanism, a process by which lithium ions reversibly enter and exit a host crystal structure. Typical positive electrodes are transition metal oxides such as $\mathrm{LiCoO}_{2}$ and $\mathrm{LiFePO}_{4}$ [9], and the typical negative electrode is a carbon such as graphite or amorphous carbon. Because the reduction potential of lithium insertion into these carbons is close to that of lithium (ca. $0.2 \mathrm{~V} \mathrm{vs} \mathrm{Li} / \mathrm{Li}^{+}$) and the reduction potential of lithium insertion into one of these transition metal oxides is around $3-4.5 \mathrm{~V}$ vs 
$\mathrm{Li} / \mathrm{Li}^{+}$, the cell potential is far too large to use an aqueous electrolyte. As a result, an organic electrolyte such as a mixture of lithium hexafluorophosphate salt in an ethylene carbonate and diethyl carbonate solution ( $\mathrm{LiPF}_{6}$ in EC/DEC) is used[10]. A schematic of the discharge process in such a lithium-ion battery is shown in Figure 1.1 , with the lithium ions leaving the host structure of the negative electrode and entering the host structure of the positive electrode, and the charge process sees the reverse happen.

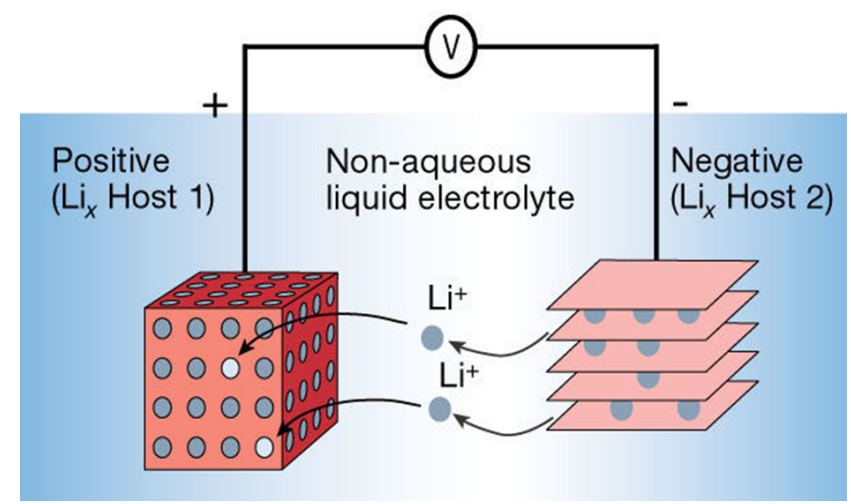

Figure 1.1: Lithium-ion battery schematic. Adapted from [10].

The lithium-ion chemistry makes a compelling battery for several reasons, but chief among them is its achievable energy density. Since its implementation in 1991, many new transition metal oxides cathodes (LMO, NMC, and NCA to name a few) have been developed, allowing this energy density to continue to grow. The capacity of a typical graphite anode is ca. $300 \mathrm{mAh} / \mathrm{g}$, and that of a typical transition metal oxide is approaching $200 \mathrm{mAh} / \mathrm{g}$, allowing a real full cell energy density over 250 $\mathrm{Wh} / \mathrm{kg}[11]$. This is an impressive value, considering that the first Sony lithium-ion battery in 1991 achieved an $80 \mathrm{Wh} / \mathrm{kg}$ energy density[12]. There is still plenty of rich work being done to continue improving the lithium-ion battery, such as the implementation of silicon anodes[13], $5 \mathrm{~V}$ cathodes[14], and lithium-rich transition metal oxide cathodes[15].

\section{Beyond Lithium-Ion}

While the progress in lithium-ion batteries has been quite impressive over the last couple decades, there is still a desire for larger energy density, cheaper, and safer batteries. As a result, research groups have looked beyond the typical intercalation chemistries of the lithium-ion battery. This can take many forms: replacing the graphite anode with silicon or lithium metal, replacing the liquid inorganic elec- 
trolyte with an aqueous or solid one, replacing the transition metal oxide cathode with a conversion reaction chemistry, or moving away from lithium altogether, replacing it with a cheaper or multivalent ion. Each of these options is a field in its own right. This thesis will focus on chemistries that replace the intercalation based transition metal oxide cathode with one that does not require a host structure for lithium, and Table 1.1 compares the theoretical energy density of current and future intercalation cathodes with two of the more prominent "beyond lithium-ion" cathode chemistries. By removing the mass of the host intercalation structure, far higher theoretical energy densities can be achieved.

\begin{tabular}{|c|c|c|c|}
\hline Cathode & $\begin{array}{l}\text { Theoretical } \\
\text { specific capacity } \\
\left(\mathrm{mAh} \mathrm{g}^{-1}\right)\end{array}$ & $\begin{array}{l}\text { Avg. discharge } \\
\text { potential } \\
(\mathrm{V} v \mathrm{vs} \mathrm{Li} / \mathrm{Li}+)\end{array}$ & $\begin{array}{l}\text { Theoretical } \\
\text { specific energy } \\
\left(\mathrm{Wh} \mathrm{kg}^{-1}\right)\end{array}$ \\
\hline $\begin{array}{l}\mathrm{LiCoO}_{2} \\
(\mathrm{LCO})\end{array}$ & 164 & 3.8 & 625 \\
\hline $\begin{array}{l}\mathrm{LiMn}_{1.5} \mathrm{Ni}_{0.5} \mathrm{O}_{4} \\
\text { (high-voltage spinel) }\end{array}$ & 147 & 4.7 & 690 \\
\hline $\begin{array}{l}\mathrm{LiNi}_{0.8} \mathrm{Co}_{0.15} \mathrm{Al}_{0.05} \mathrm{O}_{2} \\
(\mathrm{NCA})\end{array}$ & 195 & 3.8 & 740 \\
\hline $\begin{array}{l}\mathrm{LiNi}_{0.33} \mathrm{Mn}_{0.33} \mathrm{Co}_{0.33} \mathrm{O}_{2} \\
(\mathrm{NMC})\end{array}$ & 166 & 3.8 & 620 \\
\hline $\begin{array}{l}\mathrm{Li}_{1.2} \mathrm{Ni}_{0.15} \mathrm{Mn}_{0.55} \mathrm{Co}_{0.10} \mathrm{O}_{2} \\
(\mathrm{LMR}-\mathrm{NMC})\end{array}$ & 267 & 3.65 & 970 \\
\hline $\begin{array}{l}\mathrm{Li}_{2} \mathrm{~S} \\
\text { (lithium-sulfur) }\end{array}$ & 1168 & 2.15 & 2510 \\
\hline $\begin{array}{l}\mathrm{Li}_{2} \mathrm{O}_{2} \\
\text { (lithium-oxygen) }\end{array}$ & 1168 & 2.8 & 3330 \\
\hline
\end{tabular}

Table 1.1: Theoretical energy density of batteries, as paired with a lithium metal anode. Adapted from [16].

\subsection{The Lithium-Oxygen Battery}

The large theoretical energy density of lithium-oxygen batteries makes them an attractive candidate for research, because if even a small fraction of that theoretical value were practically realized, it would compete well with state of the art lithiumion chemistries. The first demonstration of the lithium-oxygen battery chemistry was in 1996[17], and it has been well studied since, leading to a good understanding of the underlying mechanisms and appreciation for what still needs to be solved. 


\section{Oxygen as a Cathode}

When using oxygen as a cathode, the discharged state of the battery is less clear than it is for a well structured intercalation one. For instance, one might imagine that lithium oxide $\left(\mathrm{Li}_{2} \mathrm{O}\right)$ is the discharged state. And this would be a good thing, as each mole of oxygen gas could host 4 moles of lithium. However, as suggested by Table 1.1, the discharged state is in fact lithium peroxide $\left(\mathrm{Li}_{2} \mathrm{O}_{2}\right)$, giving 2 moles lithium for each mole oxygen. Figure 1.2 is a simple schematic describing this discharge process when paired with a lithium metal anode (as is typical in lithium-oxygen research).

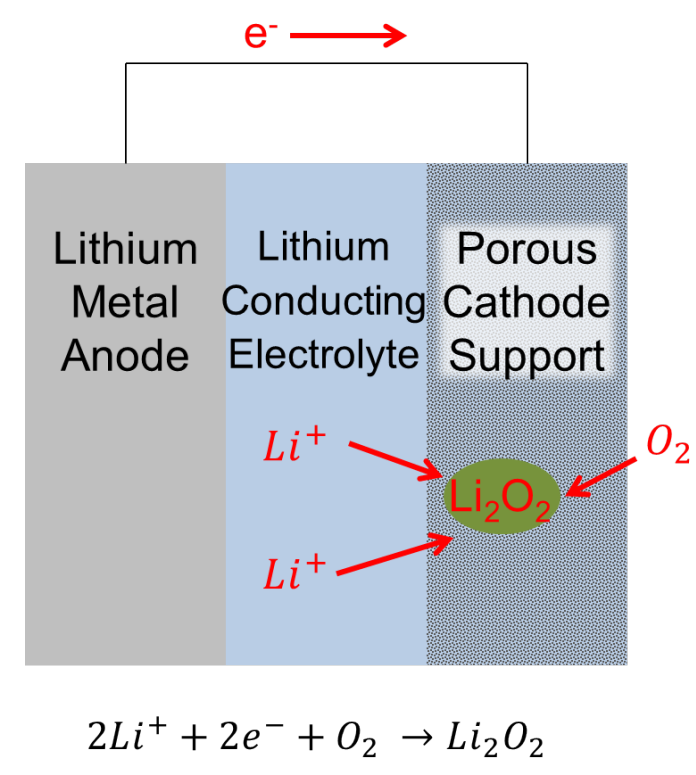

Figure 1.2: Lithium-oxygen battery schematic.

Note that a porous cathodic current collector, often a high surface area carbon, must support the growth of the discharge product while also allowing diffusion of oxygen from the gas phase to the electrode surface. In addition, this simple schematic obfuscates the complex process of bringing together two lithium ions and an oxygen molecule to the surface of the electrode where a two electron redox process must take place. Due to this complexity, the possibility of a one step reaction is untenable, and Equation 1.2 describes the generally accepted series of reactions[18].

$$
\begin{aligned}
\mathrm{O}_{2}+e^{-} & \rightarrow \mathrm{O}_{2}^{-} \\
\mathrm{O}_{2}^{-}+\mathrm{Li}^{+} & \rightarrow \mathrm{LiO}_{2} \\
2 \mathrm{LiO}_{2} & \rightarrow \mathrm{Li}_{2} \mathrm{O}_{2}+\mathrm{O}_{2}
\end{aligned}
$$


Unlike the three step oxygen reduction reaction (ORR) on discharge, the oxygen evolution reaction (OER) on charge is a single step evolution of oxygen. Regardless of the reaction steps, the thermodynamic standard potential for the overall reaction of Equation 1.2 is $2.96 \mathrm{~V}$ [19]. However, when performing this chemistry in an actual battery, there is typically a significant overpotential on both discharge and charge. Figure 1.3 shows the first cycle of lithium-oxygen batteries with different carbons serving as the cathodic current collector.

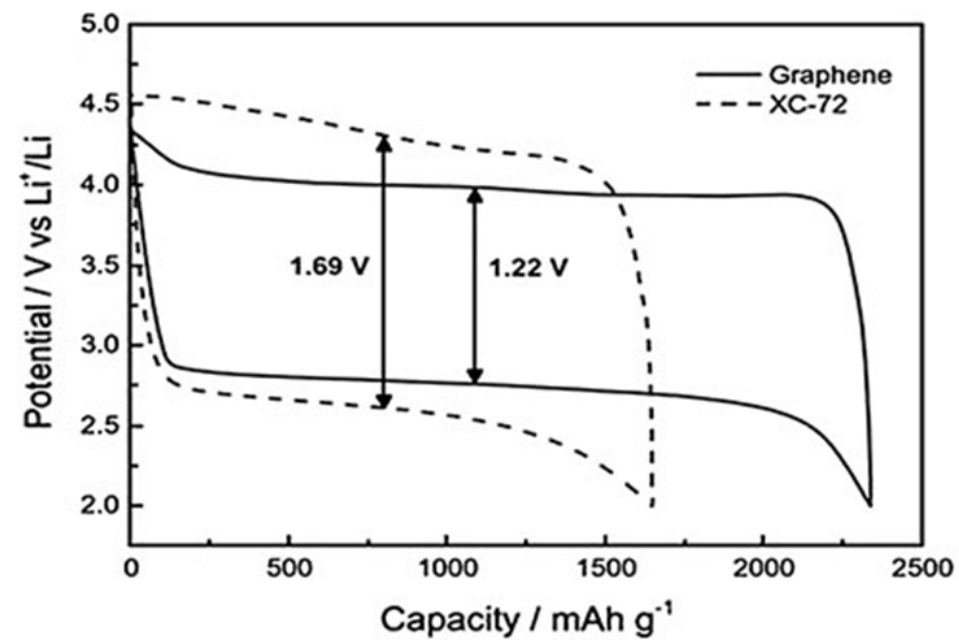

Figure 1.3: Typical lithium-oxygen first cycle. $0.1 \mathrm{~mA} \mathrm{~cm}^{-2}$. Adapted from [20].

This large overpotential suggests a few things: the mechanism of $\mathrm{Li}_{2} \mathrm{O}_{2}$ growth on discharge and dissolution on charge is probably complicated; the wide operating potential window both reduces the round-trip energy efficiency of the battery and lends the system to unwanted side reactions; and an effective catalyst for the reaction, or some other mechanism of reducing the overpotential, is necessary for the lithiumoxygen battery to be a successful secondary battery.

\section{Lithium Peroxide Growth Mechanisms}

While Equation 1.2 describes the chemistry involved in forming $\mathrm{Li}_{2} \mathrm{O}_{2}$, it does not address how it is supported by the cathodic current collector. In particular, it gives no understanding of the morphology of $\mathrm{Li}_{2} \mathrm{O}_{2}$ as it grows, the mechanism of $\mathrm{Li}_{2} \mathrm{O}_{2}$ growth, or the relationship between this morphology and the performance of the battery. There are a wide range of morphologies reported throughout literature[2123], and Figure 1.4 gives a few typical examples of them.

It is worth noting that $\mathrm{Li}_{2} \mathrm{O}_{2}$ is insulating, so one would expect the thin film morphology in Figure 1.4 due to the inability of electrons to leave the surface of the 

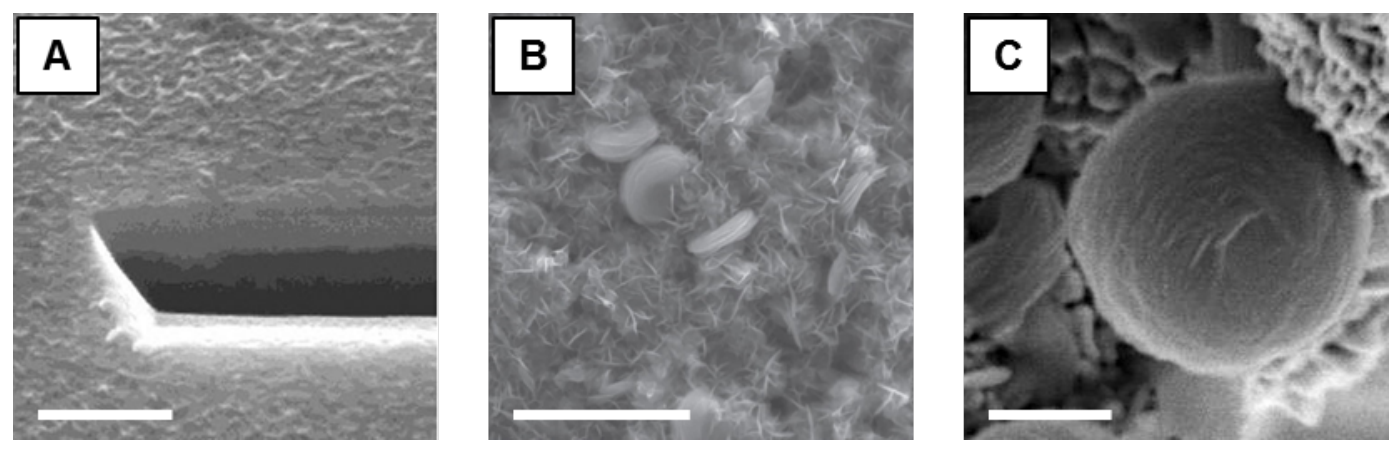

Figure 1.4: Typical morphologies of $\mathrm{Li}_{2} \mathrm{O}_{2}$. (A) Thin film (scale bar: $300 \mathrm{~nm}$ ), (B) platelet (scale bar: $1 \mu \mathrm{m}$ ), and (C) toroid (scale bar: $300 \mathrm{~nm}$ ). Adapted from [24], [25], and [26], respectively.

electrode once an insulating layer has formed. However, other morphologies are also observed, including "toroid" structures on the scale of a micron, and the growth of these larger particles should significantly increase the amount of $\mathrm{Li}_{2} \mathrm{O}_{2}$ hosted by the cathode, in turn increasing the battery's capacity. If all the chemical reactions in Equation 1.2 happened at the surface of the electrode, this morphology would not be possible. This curious observation of large, electrochemically grown, yet insulating crystals was difficult to explain until the recent development of more detailed growth mechanisms[25, 27].

A schematic detailing the two potential growth mechanisms of $\mathrm{Li}_{2} \mathrm{O}_{2}$ is shown in Figure 1.5. In the surface growth mechanism, the first two steps of Equation 1.2 occur on the surface of the electrode, with a second reduction reaction then taking place at the electrode. Since the entire ORR takes place on the electrode surface, electrons must tunnel through any insulating $\mathrm{Li}_{2} \mathrm{O}_{2}$ already present, resulting in a film thickness no larger than about 5-10 $\mathrm{nm}$ [28]. In the solution mediated growth mechanism, the first two steps of Equation 1.2 also take place on the surface of the electrode. However, here the intermediate species, lithium superoxide $\left(\mathrm{LiO}_{2}\right)$, is at least sparingly soluble in the electrolyte, and as a result, the disproportionation reaction can take place away from the electrode surface. This allows the final step in Equation 1.2 to occur in a location which does not have access to an electron, therefore enabling the growth of micron scale insulating particles through an electrochemical process.

Then the $\mathrm{Li}_{2} \mathrm{O}_{2}$ growth mechanism is dictated by the electrolyte, namely how well the electrolyte can solvate the $\mathrm{LiO}_{2}$ intermediate species. In other words, the extent of Lewis acidity and basicity of the electrolyte will determine which growth 


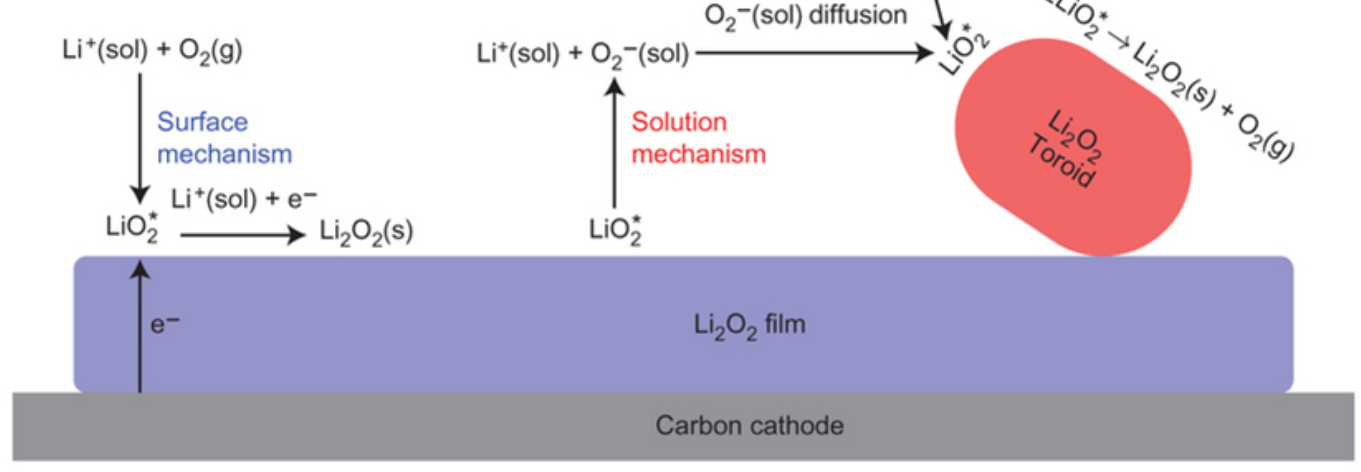

Figure 1.5: Growth mechanisms of $\mathrm{Li}_{2} \mathrm{O}_{2}$. Adapted from [25].

mechanism occurs. A quantitative measure of this can be given by the Gutmann acceptor and donor numbers, which essentially dictate how well a solvent can donate or accept electrons[29]. Figure 1.6 gives the acceptor and donor numbers for some commonly used lithium-oxygen electrolyte solvents such as dimethoxyethane (DME) and dimethyl sulfoxide (DMSO) as well as impurities such as water. When using DME as an electrolyte solvent, the surface growth mechanism takes place and the capacity is poor, but when using DMSO or having a water impurity in DME, the solution mediated growth mechanism predominates and the capacity is far greater[27]. This suggests that finding an electrolyte with large acceptor and donor numbers would increase the solvation of $\mathrm{LiO}_{2}$, and thus give an even larger discharge capacity.

An interesting result of the importance of $\mathrm{LiO}_{2}$ solvation is the role that a trace amount of water can play in the electrolyte[30]. Increasing the water content from an anhydrous rated $<4 \mathrm{ppm}$ concentration to $1000 \mathrm{ppm}$ can increase the discharge capacity by a factor of 10[31]. While this water impurity can act as an enabler of the solution mediated growth process, it also can serve as an example of the role that side reactions can play in the lithium-oxygen chemistry. In a similar approach, researchers have attempted using soluble catalysts, known as redox mediators, to encourage solution mediated growth without requiring solvation of $\mathrm{LiO}_{2}[32,33]$.

\section{Instability and Side Reactions}

As with any secondary battery chemistry, the ability to reversibly cycle a lithiumoxygen battery is predicated on avoiding side reactions that consume active parts of the battery. For example, the development of carbonate electrolytes in lithium-ion 


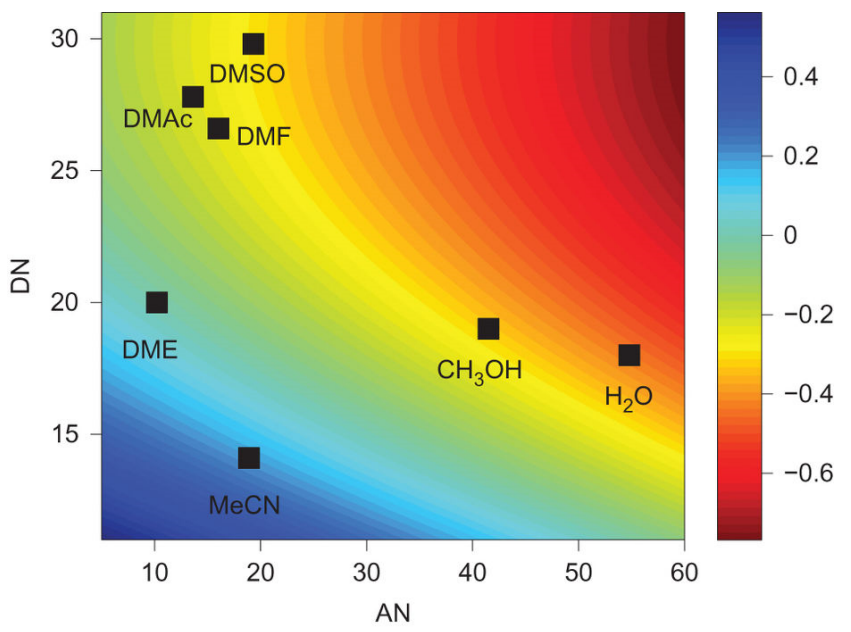

Figure 1.6: Gutmann acceptor and donor number of solvents. Free energy of $\mathrm{LiO}_{2}$ dissolution, relative to DME. Adapted from [25].

batteries allowed the formation of a stable solid electrolyte interphase (SEI) on a graphite anode, preventing further decomposition through exfoliation and allowing graphite to intercalate reversibly[34]. Along a similar vein, it is important to select the appropriate electrolyte and cathode material for a lithium-oxygen battery to cycle reversibly.

As described above, water impurities can play a significant role in the lithiumoxygen battery. While it can enhance the solubility of $\mathrm{LiO}_{2}$, it can also engage in a side reaction, forming lithium hydroxide $(\mathrm{LiOH})$, which is an irreversible reaction in this system[30]. In addition to water impurities, degradation of the organic electrolyte can lead to a wide range of irreversible decomposition products[35]. An expansive search for organic electrolytes has yet to find one that does not suffer from degradation[36-41]. Interestingly, it is thought that $\mathrm{LiO}_{2}$ is a primary culprit, considering the reactivity of the superoxide radical to organic species. This leads to the unfortunate situation where increasing the capacity through the solution mediated growth mechanism also leads to irreversibility due to superoxide attack of the electrolyte.

In addition to electrolyte degradation, the high surface area carbons often employed as the cathode catalyst or the support for other catalysts also suffers from side reactions. In particular, lithium carbonate $\left(\mathrm{Li}_{2} \mathrm{CO}_{3}\right)$ is a common side product which is irreversible on charge[42, 43]. Searching for electrodes which are both catalytic to ORR and OER while also being immune to these side reactions is an active area of research[44-46]. 
The accumulation of these side products which are not removed during OER lead to a passivation of the cathode as insulating species prevent electrons from reaching the electrolyte. When enough of these side products have accumulated, the cell can no longer function and the discharge capacity rapidly approaches zero in an event called "sudden cell death"[42].

The instabilities of both the cathode and electrolyte mentioned above, in addition to a host of other practical complications not mentioned here, demonstrate the difficulties associated with successfully implementing a lithium-oxygen battery. This quick review has only covered the aspects of the lithium-oxygen battery most relevant for this thesis, and there are several excellent, thorough reviews for further reading[16, $19,47,48]$. The complexity of the lithium-oxygen chemistry is a long way from that first primary battery of Volta described in Equation 1.1. However, this lends it to being a rich area of research with many problems to solve.

\subsection{Thesis Overview}

The aim of this thesis is to give a deeper understanding of battery cathodes that employ a phase forming conversion reaction chemistry, and in doing so, provide design guidelines so that one could optimize such a cathode. The first chapter of this thesis has provided a brief introduction to the current state of battery research and then given a detailed look into the lithium-oxygen battery. The second chapter will probe the effects of operating a lithium-oxygen battery with a molten salt electrolyte, noting the implications this gives for the chemistry more broadly. The third chapter will introduce nitrate reduction chemistry, which is similar to the lithium-oxygen battery, and demonstrate its ability to serve as a secondary battery. The fourth chapter will use this nitrate reduction chemistry to explore the effects of cathode structure on battery performance, drawing conclusions which can be more broadly applied to other battery chemistries. Finally, the fifth chapter will reflect on the implications of this thesis and the direction of the field moving forward. 
Chapter 2

\title{
A MOLTEN SALT LITHIUM-OXYGEN BATTERY
}

\author{
Adapted with permission from
}

1. Giordani, V., Tozier, D., Tan, H., Burke, C. M., Gallant, B. M., Uddin, J., Greer, J. R., McCloskey, B. D., Chase, G. V. \& Addison, D. A Molten Salt LithiumOxygen Battery. Journal of the American Chemical Society 138, 2656-2663. doi: 10.1021/jacs.5b11744 (2016).

(C) 2016 American Chemical Society

\section{Chapter Abstract}

Despite the promise of extremely high theoretical capacity $\left(2 \mathrm{Li}+\mathrm{O}_{2} \rightarrow \mathrm{Li}_{2} \mathrm{O}_{2}\right.$, $1675 \mathrm{mAh}$ per gram of oxygen), many challenges currently impede development of lithium-oxygen battery technology. Finding suitable electrode and electrolyte materials remains the most elusive challenge to date. A radical new approach is to replace volatile, unstable and air-intolerant organic electrolytes common to prior research in the field with alkali metal nitrate molten salt electrolytes and operate the battery above the liquidus temperature $\left(>80{ }^{\circ} \mathrm{C}\right)$. In this chapter we demonstrate an intermediate temperature lithium-oxygen battery using a lithium anode, a molten nitrate-based electrolyte (e.g., $\mathrm{LiNO}_{3}-\mathrm{KNO}_{3}$ eutectic) and a porous carbon oxygen cathode with high energy efficiency ( $95 \%)$ and improved rate capability because the discharge product, lithium peroxide, is stable and moderately soluble in the molten salt electrolyte. The results, supported by essential state-of-the-art electrochemical and analytical techniques such as in situ pressure and gas analyses, scanning electron microscopy, rotating disk electrode voltammetry, demonstrate that $\mathrm{Li}_{2} \mathrm{O}_{2}$ electrochemically forms and decomposes upon cycling with discharge/charge overpotentials as low as $50 \mathrm{mV}$. We show that the cycle life of such batteries is limited only by carbon reactivity and by the uncontrolled precipitation of $\mathrm{Li}_{2} \mathrm{O}_{2}$, which eventually becomes electrically disconnected from the oxygen electrode. 


\subsection{Molten Salt Electrolytes}

The Introduction Chapter demonstrated both the potential of lithium-oxygen batteries as a replacement for lithium-ion ones and the many challenges that must still be overcome for them to be practically realized. In particular, finding sufficiently stable electrolytes in the presence of the active lithium-oxygen cathode electrochemistry has been the most elusive challenge to date. In addition, the insulating and insoluble nature of $\mathrm{Li}_{2} \mathrm{O}_{2}$ passivates the cathode surface, limiting discharge capacity to a small fraction of the large theoretical capacity provided by the lithium-oxygen electrochemistry.

The approach described in this chapter is to replace unstable aqueous or organicbased electrolytes common in prior lithium-oxygen battery research with an organicfree molten alkali metal nitrate electrolyte and operate the battery above the eutectic melting point, typically between 80 and $200{ }^{\circ} \mathrm{C}[49]$. Research on molten nitrate electrolytes for lithium batteries and thermal batteries traces back to the late 1970s when it was observed that the reaction between metallic lithium and the nitrate anion generated a SEI composed of $\mathrm{Li}_{2} \mathrm{O}$ that was sufficiently stable for primary cells and rechargeable cells with limited cycle life[50, 51]. However, reports on oxygen electrode behavior in these electrolyte mixtures are somewhat lacking. Previous works reported that equilibria between superoxide, peroxide, and oxide forms of reduced oxygen could coexist in the molten salt electrolyte with high reversibility at a platinum rotating disk electrode[52,53]. Stability toward lithium, low melting point relative to other inorganic salts, high thermal stability above $500{ }^{\circ} \mathrm{C}$, nonvolatility, high ionic conductivity and acceptable electrochemical stability window (typically between 2.2 and $3.8 \mathrm{~V}$ vs $\mathrm{Li} / \mathrm{Li}^{+}$on amorphous carbon black electrodes) are attractive features that make the molten nitrate and nitrite class of electrolytes interesting for lithium-oxygen batteries.

Furthermore, we hypothesize that $\mathrm{LiO}_{2}$ and $\mathrm{Li}_{2} \mathrm{O}_{2}$ discharge products will have enhanced solubility in this electrolyte compared to room temperature organic electrolytes, because previous work on molten salts as solvents have found them to have acceptor numbers $>100$, a value well off the chart in Figure 1.6[54]. Together with improved electrode kinetics at elevated temperature, we anticipate high reversibility and higher rate capability for the oxygen electrode.

The composition and relevant material properties of molten salts used in this work are described in Table 2.1. All salts were purchased from Sigma-Aldrich and vacuum dried for at least one week before use. The chosen compositions correspond to 
the eutectic composition of the described mixture. Melting point was measured by differential scanning calorimetry (DSC), lithium cation transference number by the Bruce and Vincent method[55], and ionic conductivity at $150{ }^{\circ} \mathrm{C}$ by using a conductivity cell of known cell constant suitable for elevated temperature measurements.

\begin{tabular}{lllll}
\hline & $\begin{array}{l}\text { Chemical } \\
\text { composition } \\
(\mathrm{mol} \%)\end{array}$ & $\begin{array}{l}\text { Melting } \\
\text { point } \\
\left({ }^{\circ} \mathrm{C}\right)\end{array}$ & $\begin{array}{l}\text { Lithium } \\
\text { transference } \\
\text { number }\end{array}$ & $\begin{array}{l}\text { Ionic } \\
\text { conductivity } \\
\left.(\mathrm{mS} \mathrm{cm})^{-1}\right)\end{array}$ \\
\hline $\begin{array}{l}\mathrm{LiNO}_{3}- \\
\mathrm{KNO}_{3}\end{array}$ & $42-58$ & 125 & 0.68 & 88 \\
$\mathrm{LiNO}_{3}-$ & $37-39-24$ & 90 & 0.28 & 115 \\
$\mathrm{KNO}_{2}-$ & & & & \\
$\mathrm{CsNO}_{3}$ & & & & \\
\hline
\end{tabular}

Table 2.1: Molten salt electrolyte compositions, with measurements of conductivity properties at $150{ }^{\circ} \mathrm{C}$.

\subsection{Oxygen Electrochemistry in a Molten Salt}

A combination of cyclic voltammetry $(\mathrm{CV})$ and galvanostatic cycling are used to compare the electrochemical behavior of a traditional organic electrolyte with the molten salt electrolytes described in Table 2.1. These experiments were performed in Swagelok cells with known volume that are paired with a pressure sensor and valve to allow filling the head-space with gas and connecting the cell to a mass spectrometer. Cathodes consisted of about $5 \mathrm{mg}$ of Super $\mathrm{P}$ carbon and PTFE binder 95:5 mass ratio pressed onto a stainless steel mesh. A glass microfiber separator was impregnated with about $300 \mathrm{mg}$ of molten salt electrolyte and vacuum dried overnight at $200{ }^{\circ} \mathrm{C}$. For organic electrolytes, the separator was simply wet with purchased premixed electrolyte. Anodes were a simple lithium foil. All assembly took place in a glovebox, then the cells were filled with oxygen after a leak test, and finally placed in an oven to be held at the operating temperature. A detailed description of the cell design and assembly is given in the appendix.

\section{Cyclic Voltammetry}

Figure 2.1 compares CVs of oxygen reduction at a Super $\mathrm{P}$ carbon cathode in a conventional lithium-oxygen battery electrolyte, $0.1 \mathrm{M} \mathrm{LiClO}_{4}-\mathrm{DMSO}$, and a $\mathrm{LiNO}_{3}-\mathrm{KNO}_{3}$ eutectic, at 30 and $150{ }^{\circ} \mathrm{C}$, respectively. As expected, results indicate that in the common organic electrolyte, oxygen reduction to form $\mathrm{Li}_{2} \mathrm{O}_{2}$ is a highly irreversible electrochemical process, as only a strong cathodic current and no anodic 

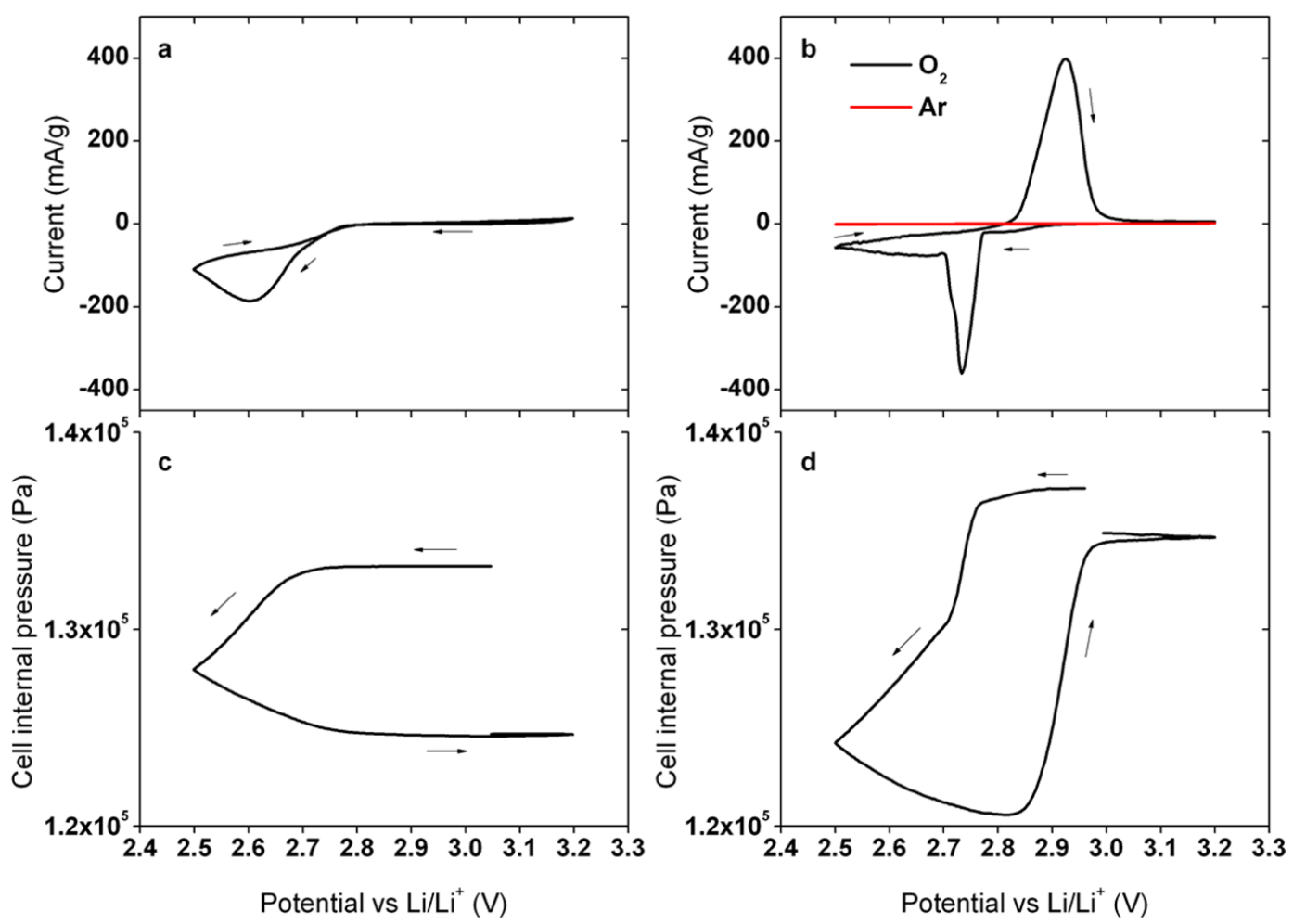

Figure 2.1: Cyclic voltammetry of oxygen reduction and evolution. (a,c) $0.1 \mathrm{M}$ $\mathrm{LiClO}_{4}-\mathrm{DMSO}$ at $30{ }^{\circ} \mathrm{C}$ and $(\mathrm{b}, \mathrm{d}) \mathrm{LiNO}_{3}-\mathrm{KNO}_{3}$ eutectic at $150{ }^{\circ} \mathrm{C}$. Working electrode: Super $\mathrm{P}$ porous carbon $\left(\mathrm{A}=0.785 \mathrm{~cm}^{2}\right)$, carbon loading $\sim 5 \mathrm{mg} / \mathrm{cm}^{2}$. Counter and reference electrodes: lithium metal. Scan rate: $0.05 \mathrm{mV} / \mathrm{s}$. Voltage window: $2.5-3.2 \mathrm{~V}$ vs $\mathrm{Li} / \mathrm{Li}^{+}$. Current density expressed in $\mathrm{mA}$ per $\mathrm{g}$ of carbon.

current is observed in the operating potential window. Previous results have shown that high anodic potentials $\left(>3.8 \mathrm{~V}\right.$ ) are necessary to oxidize $\mathrm{Li}_{2} \mathrm{O}_{2}$ in DMSObased electrolytes, although at these potentials, a substantial fraction of the $\mathrm{Li}_{2} \mathrm{O}_{2}$ oxidation current results in parasitic decomposition of the electrolyte. On the other hand, $\mathrm{CV}$ s performed in the oxygen-saturated $\mathrm{LiNO}_{3}-\mathrm{KNO}_{3}$ eutectic at $150{ }^{\circ} \mathrm{C}$ shows high reversibility with Qa/Qc ratio of $\sim 0.9$ (anodic charge Qa and cathodic charge Qc were obtained by integrating the "current vs time" plot derived from the $\mathrm{CV}$; Qa/Qc would ideally equal 1). To verify nitrate electrolyte electrochemical stability in the operating voltage window, we performed the same CV experiment under argon gas (without any oxygen present) and did not observe any faradaic currents. Furthermore, pressure monitoring clearly demonstrates gas is consumed upon reduction (cathodic scan) and generated upon oxidation (reverse, anodic scan). Mass spectrometry on the head-space following the CV indicates that only oxygen, and no other gas, is evolved during the anodic scan. As expected, no pressure rise is 
observed during the anodic CV scan of a DMSO-based battery, as no anodic current is observed, indicating that no product is being oxidized. The standard electrode potential $\left(\mathrm{E}^{0}\right)$ for the electrochemical formation of $\mathrm{Li}_{2} \mathrm{O}_{2}\left(2 \mathrm{Li}^{+}+\mathrm{O}_{2}+2 e^{-} \rightleftharpoons \mathrm{Li}_{2} \mathrm{O}_{2}\right)$ can be calculated from the free energy of formation, and is generally considered to be $\sim 2.96 \mathrm{~V}$ vs $\mathrm{Li} / \mathrm{Li}^{+}$at $30{ }^{\circ} \mathrm{C}$. However, operating the battery as $150{ }^{\circ} \mathrm{C}$ gives a calculated potential of $\sim 2.83 \mathrm{~V}$ vs $\mathrm{Li} / \mathrm{Li}^{+}$, which agrees with the median potential, measured from the $\mathrm{CV}$.

It is important to note that quasi-reversible CVs are observed at a carbon oxygen electrode in the molten salt eutectic, with cathodic peak to anodic peak separation of about $200 \mathrm{mV}$. Typical CVs for conventional organic electrolytes at room temperature usually display anodic peaks in the 3.4-4.5 V window, which are attributed to side reactions (e.g., solvent decomposition) alongside direct $\mathrm{Li}_{2} \mathrm{O}_{2}$ oxidation. Greater currents are obtained when using the molten salt electrolyte, which likely is a result of less cathode passivation due to the higher solubility of intermediate $\mathrm{LiO}_{2}$ and discharge product $\mathrm{Li}_{2} \mathrm{O}_{2}$. The high cathodic peak potential for oxygen reduction in the melt $\left(\sim 2.73 \mathrm{~V} \mathrm{vs} \mathrm{Li} / \mathrm{Li}^{+}\right)$is likely a result of a combination of the following effects: (i) improved electrode kinetics from elevated temperature operation, (ii) lower internal cell resistance as a result of high ionic conductivity of the molten salt, (iii) improved intermediate solubility (as will be conclusively shown later), such as $\mathrm{LiO}_{2}$, which in turn reduces $\mathrm{Li}_{2} \mathrm{O}_{2}$ induced electrode passivation[56, 57]. Consistent with a $\mathrm{Q} a / \mathrm{Qc}$ ratio of $\sim 0.9$, a slight inefficiency in the pressure profile for the nitrate electrolyte is attributed to $\mathrm{Li}_{2} \mathrm{O}_{2}$ precipitating in the separator, away from the current collector carbon, and becoming electrically disconnected. Some dissolved $\mathrm{Li}_{2} \mathrm{O}_{2}$ may also have traveled across the electrolyte and been reduced to $\mathrm{Li}_{2} \mathrm{O}$ on the lithium metal. No particular effort had been made to optimize the porous volume and electrode architecture to date. These results constitute a significant step forward in the search for stable electrolyte materials. We anticipate that the $\mathrm{LiO}_{2}$ or $\mathrm{Li}_{2} \mathrm{O}_{2}$ could react with carbon at the operating temperature of these batteries to generate $\mathrm{Li}_{2} \mathrm{CO}_{3}$ at the surface of carbon. This is consistent with oxygen consumption/evolution inefficiencies observed during the $\mathrm{CV}$.

\section{Galvanostatic Cycling}

In a similar vein as the $\mathrm{CV}$ scans of Figure 2.1, Figure 2.2 compares galvanostatic cycles of oxygen reduction at a Super $\mathrm{P}$ carbon cathode in a conventional lithiumoxygen battery electrolyte, $0.1 \mathrm{M} \mathrm{LiClO}_{4}-\mathrm{DMSO}$, and a molten salt electrolyte. However, in this case the molten salt is a $\mathrm{LiNO}_{3}-\mathrm{KNO}_{2}-\mathrm{CsNO}_{3}$ eutectic mixture, and 

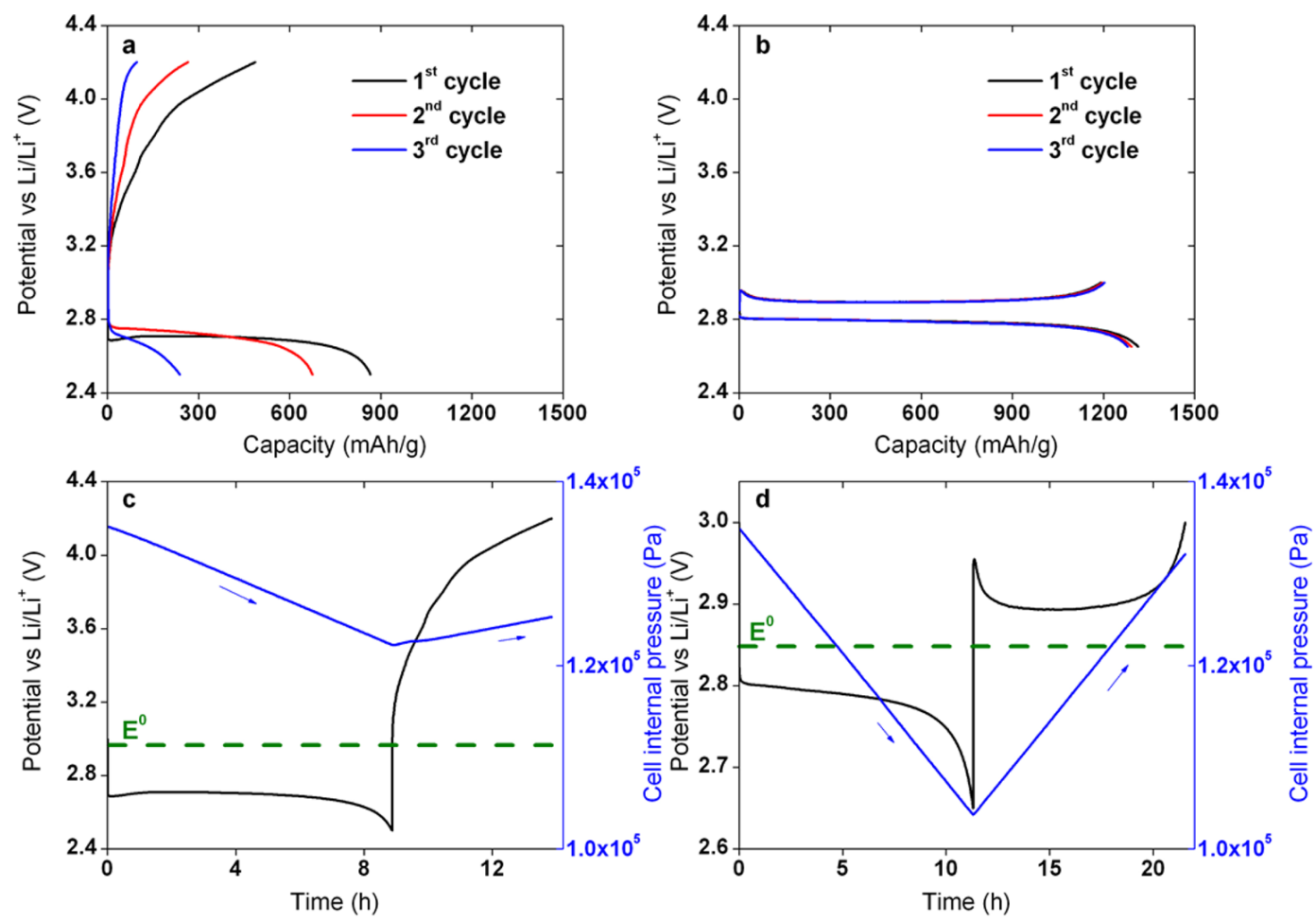

Figure 2.2: Galvanostatic cycling of oxygen reduction and evolution with pressure profiles measured in $(\mathrm{a}, \mathrm{c}) 0.1 \mathrm{M} \mathrm{LiClO}_{4}-\mathrm{DMSO}$ at $30{ }^{\circ} \mathrm{C}$ between 2.5 and $4.2 \mathrm{~V}$ and (b,d) $\mathrm{LiNO}_{3}-\mathrm{KNO}_{2}-\mathrm{CsNO}_{3}$ molten salt electrolyte at $120^{\circ} \mathrm{C}$ between 2.65 and 3.0 V. Positive electrode: Super P carbon:PTFE 95:5 wt \%, current: 0.25 mA ( 80 $\mathrm{mA} / \mathrm{g}$ carbon). Electrolyte loading: $150 \mu \mathrm{L}$. Carbon loading: $\sim 4 \mathrm{mg} / \mathrm{cm}^{2}$. Pressure profiles depicted in (c) and (d) are for the first cycle of the battery. Battery capacity expressed in $\mathrm{mAh}$ per $\mathrm{g}$ of carbon. $\mathrm{E}^{0}$ represents the thermodynamic potential for the reaction $2 \mathrm{Li}^{+}+2 e^{-}+\mathrm{O}_{2} \rightleftharpoons \mathrm{Li}_{2} \mathrm{O}_{2}$ at $30{ }^{\circ} \mathrm{C}$ (c) and $120^{\circ} \mathrm{C}$ (d)

they operate at 30 and $120{ }^{\circ} \mathrm{C}$, respectively. The ternary mixture of nitrate/nitrite salts has a lower melting point compared to the lithium/potassium nitrate binary mixture, and therefore allowed the operation of the battery at a lower temperature. The battery that uses the organic electrolyte has poor capacity retention and high voltage hysteresis, whereas the battery using the molten nitrate/nitrite salts can be cycled between 2.65 and $3.0 \mathrm{~V}$ with remarkably low voltage hysteresis $(\sim 0.1 \mathrm{~V})$ and good capacity retention. Consistent with the $\mathrm{CV}$ data, a $\sim 10 \%$ irreversible capacity loss is observed in the molten nitrate/nitrite battery. The voltage profile comparison for the first three cycles of the batteries clearly demonstrates the superior behavior of the molten salt lithium-oxygen battery compared to prior state of the art in terms of (i) dramatically reduced voltage gap, (ii) excellent capacity retention, and (iii) clear end of half cycle based on voltage turn-down on discharge and turn-up on 
charge. The challenge will be to couple the molten nitrate electrolytes with stable cathode materials to achieve long cycle life. Pressure monitoring in the organic electrolyte battery during cycling clearly shows that only a small fraction of oxygen consumed during discharge is evolved during charge. Side reactions govern the electrochemistry and account for rapid capacity fade in the DMSO-based battery. Many authors have reported high chemical instability of DMSO solvent in the lithium-oxygen battery[36, 58].

Figure $2.2 \mathrm{~d}$ demonstrates that oxygen can be consumed and subsequently evolved with relatively high efficiency ( $\Delta$ Pcharge/ $\Delta$ Pdischarge $\approx 90 \%$ ) when recharging the molten salt battery, with identical slopes of pressure variation within the battery during discharge and charge. Enhanced $\mathrm{LiO}_{2} / \mathrm{Li}_{2} \mathrm{O}_{2}$ solubility in the melt leads to electrical disconnection and carbon decomposition, and are thought to be responsible for the $\sim 10 \%$ irreversible pressure loss during cycling. We found the stoichiometry for the battery reaction, often reported as $\mathrm{e}^{-} / \mathrm{O}_{2}$ molar ratio in the literature, to be 2.0 by combining coulometry and gas analysis, for both discharge (ORR) and charge (OER) half-cycles. Oxygen partial pressure, internal battery volume, and operating temperature are all carefully controlled parameters. Molar ratios that deviate from 2.0 are indicative of parasitic processes occurring during cycling, often related to a reaction between the electrolyte (or the electrode) and reduced forms of oxygen. Gas analysis by mass spectrometry of the battery head-space is routinely performed to ensure $\mathrm{O}_{2}$ (mass 32 ) is the only gaseous species formed during cycling. Typically, gases such as $\mathrm{CO}(28), \mathrm{CO}_{2}$ (44), $\mathrm{NO}(30)$ and $\mathrm{NO}_{2}$ (46) are monitored by mass spectrometry. These would arise from oxidation reactions of the carbon electrode material and the electrolyte materials, namely nitrite and nitrate.

\section{Gas Analysis of Charging Process}

Figure 2.3 shows in situ gas analysis performed during a lithium-oxygen battery charge half-cycle in $\mathrm{LiNO}_{3}-\mathrm{KNO}_{3}$ electrolyte at $150{ }^{\circ} \mathrm{C}$. The battery was first discharged under oxygen to roughly $30 \%$ depth of discharge $(\sim 400 \mathrm{mAh} / \mathrm{g})$. Then, during open circuit voltage (OCV) between discharge and charge, the valve connecting the battery to the mass spectrometer was opened and the gases were allowed to flow from the battery head-space directly into the mass spectrometer chamber. The charge half-cycle was therefore carried out under a vacuum which would not be possible with common organic electrolytes due to solvent volatility. As the electrode

begins to recharge, oxygen mass 32 signal increases and remains steady throughout the entire charge, which is consistent with the pressure data observed in Figure 2.2d. 
Other gases, such as carbon dioxide (mass 44) and nitric oxide (mass 30) remain at background levels.

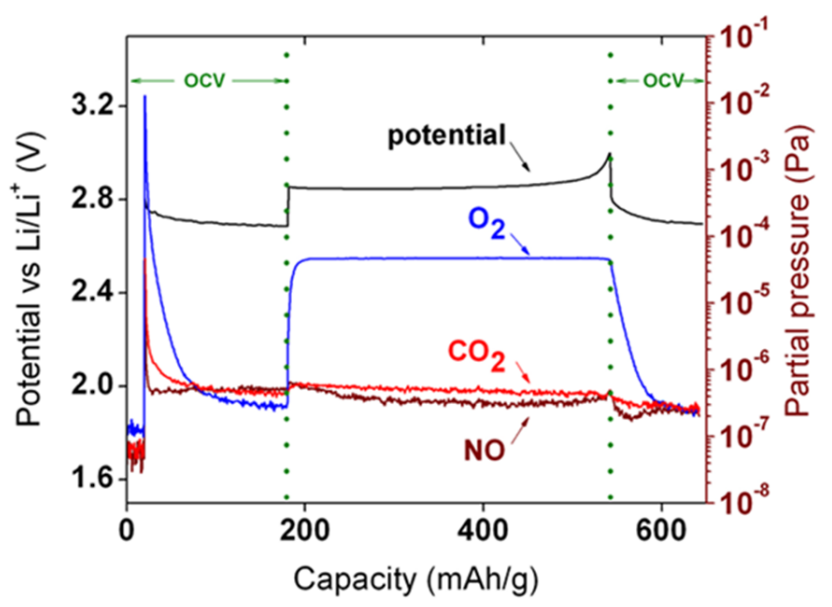

Figure 2.3: Mass spectrometry of lithium-oxygen charge process. Battery employed a $\mathrm{LiNO}_{3}-\mathrm{KNO}_{3}$ molten salt electrolyte, a Super $\mathrm{P}$ carbon:PTFE cathode, and was charged at $150{ }^{\circ} \mathrm{C}, \sim 80 \mathrm{~mA} / \mathrm{g}$, to a $3.0 \mathrm{~V}$ cutoff. Capacity expressed in $\mathrm{mAh}$ per $\mathrm{g}$ of carbon.

\subsection{Lithium Peroxide and Wulff Constructions}

Confident in the reversibility in both the electrochemistry and gas analysis afforded by a molten salt electrolyte, a combination of X-ray diffraction (XRD), scanning electron microscopy (SEM), and energy-dispersive X-ray spectroscopy (EDS) are used to characterize the discharge product grown on the cathode. Typically, the cathode was extracted from heated batteries inside an argon-filled glovebox and rinsed with N-Methylacetamide (NMA) solvent to remove residual nitrate and nitrite salts.

\section{X-ray Diffraction}

After extraction from the battery following the procedure described above, carbon electrodes were then sealed in Kapton tape for protection against air contamination. Diffraction was performed on a PANalytical X'Pert Pro X-ray powder diffractometer with $\mathrm{Cu} \mathrm{K} \alpha 1$ radiation.

XRD patterns of the carbon electrode before discharge, following a $\sim 1400 \mathrm{mAh} / \mathrm{g}$ discharge under $\mathrm{O} 2$ to $2.6 \mathrm{~V}$ cathodic cutoff, and after a completed cycle (electrode fully recharged to $3.0 \mathrm{~V}$ ) are depicted in Figure 2.4. The XRD results clearly demonstrate that crystalline $\mathrm{Li}_{2} \mathrm{O}_{2}$ forms on the carbon surface during discharge and can subsequently be oxidized upon battery charge. XRD also reveals the 


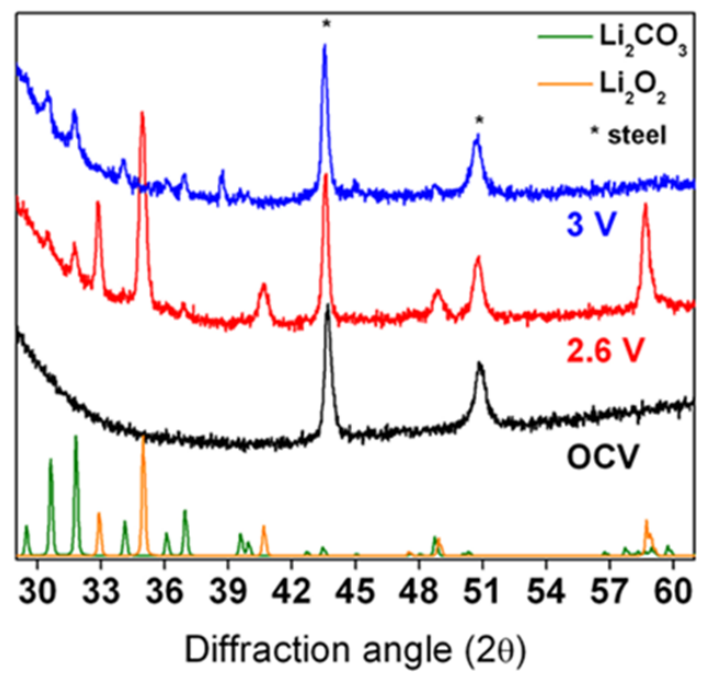

Figure 2.4: X-ray diffraction of lithium-oxygen cathode across one cycle. Scans taken following an OCV period (before discharge), a single discharge to $2.6 \mathrm{~V}$, and a discharge/charge cycle between 2.6 and $3.0 \mathrm{~V}$, in $\mathrm{LiNO}_{3}-\mathrm{KNO}_{3}$ molten salt electrolyte at $150{ }^{\circ} \mathrm{C}$ with Super P carbon cathode.

presence of $\mathrm{Li}_{2} \mathrm{CO}_{3}$ alongside $\mathrm{Li}_{2} \mathrm{O}_{2}$, confirming sustained reaction between carbon and the oxygen reduction products. In addition, this $\mathrm{Li}_{2} \mathrm{CO}_{3}$ side product remains after charge.

\section{Wulff Constructions}

Before analyzing the discharge product morphologies observed in this molten salt electrolyte, it is worthwhile to give a brief review on Wulff constructions. In particular, this section will describe the underlying theory, geometrical construction, and necessary conditions of Wulff constructions.

A simple summary of the theory and proof for a Wulff construction is provided here. For the detailed version of the proof on which this section is based, see [59]. The surface energy of a crystal with $i$ atoms (the difference between the free energy of $i$ atoms in an infinite crystal and the free energy of the $i$ atoms in this crystal) is given by Gibbs[60] to be

$$
\Delta G_{i}=\sum_{j} \gamma_{j} O_{j}
$$

where $\gamma_{j}$ is the surface energy of $j$ th face, and $O_{j}$ its area. Minimizing this energy 
for a constant volume gives

$$
\sum_{j} \gamma_{j} \delta O_{j}=0
$$

Now choose a point inside the crystal. Drawing perpendiculars $h_{j}$ from each face to this point, the volume of this crystal (assuming the crystal is convex) can be given as

$$
V=\frac{1}{3} \sum_{j} h_{j} O_{j}
$$

Taking a small change in crystal shape at constant volume, after some algebra which is omitted here, yields the expression

$$
\sum_{j} h_{j} \delta O_{j}=0
$$

Combining Equations 2.2 and 2.4 with an arbitrary constant $\lambda$ gives

$$
\sum_{j}\left(h_{j}-\lambda \gamma_{j}\right) \delta O_{j}=0
$$

Because the small change in crystal shape was arbitrary, so is $\delta O_{j}$, requiring $h_{j}-$ $\lambda \gamma_{j}=0$ for all $j$. Then $h_{j}=\lambda \gamma_{j}$, and the length of this perpendicular line is proportional to the surface energy of the face it corresponds to, proving the idea proposed by Wulff[61].

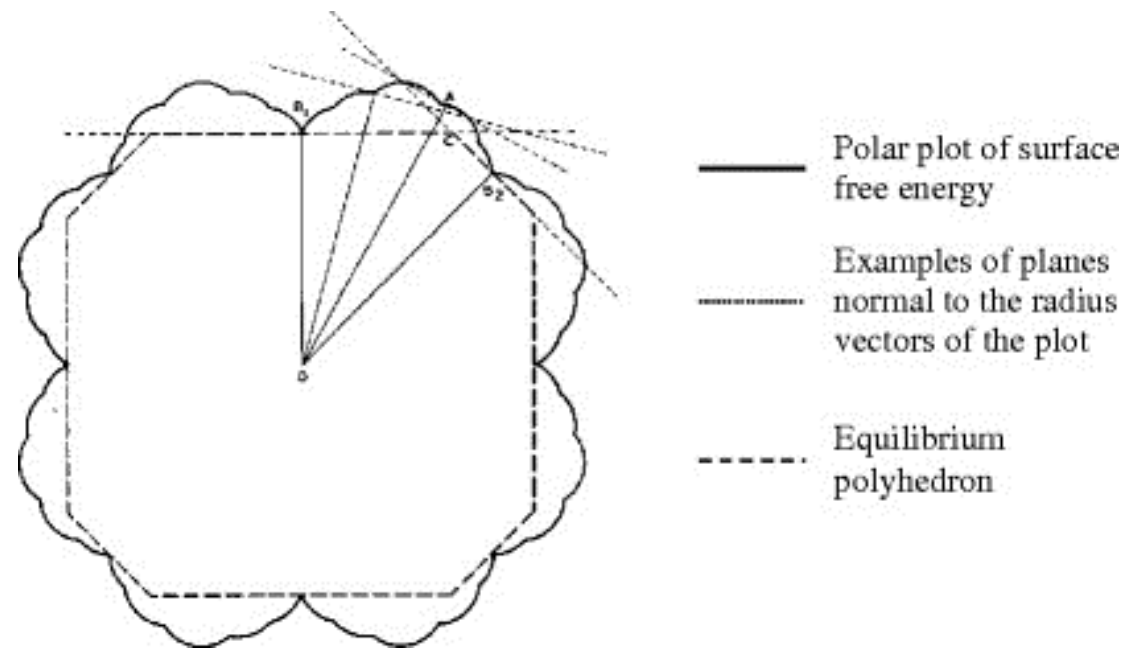

Figure 2.5: Wulff construction schematic. Adapted from [62].

Turning the idea of this derivation backwards, one can construct the shape of a crystal with minimized surface energy. Begin with a plot of surface energy for every 
crystal orientation, $\gamma(i j k)$. Draw a line (representing the $h_{j}$ of above) from the origin to each point on this plot. At this intersection, construct the plane perpendicular to this $h_{i j k}$ (representing the $O_{j}$ of above). The crystal with minimum surface energy is then the one bounded by all of these planes. A schematic of this process in two dimensions is shown in Figure 2.5.

While this construction represents a minimization of the surface energy, and thus the thermodynamic equilibrium crystal shape, like many topics in materials science, a competition between thermodynamics and kinetics determines the physically realized outcome. For instance, several groups have performed Wulff constructions of $\mathrm{Li}_{2} \mathrm{O}_{2}[63,64]$, and Figure 2.6 gives a representative example. By comparison to the previously observed morphologies of $\mathrm{Li}_{2} \mathrm{O}_{2}$ shown in Figure 1.4, it appears that the equilibrium hexagonal structure is not achieved in a lithium-oxygen battery for either the surface or solution mediated growth mechanisms. This suggests that the kinetics of the system are playing a significant role in determining the crystal morphology.

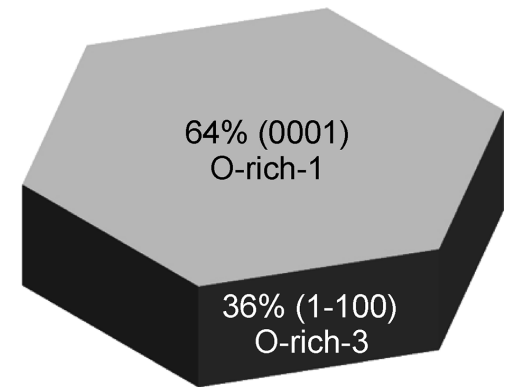

Figure 2.6: Wulff construction of $\mathrm{Li}_{2} \mathrm{O}_{2}$. Adapted from [63].

\section{Microscopy and Elemental Analysis}

After extraction from the battery following the procedure described above, carbon electrodes were briefly exposed to air ( $\sim 30$ seconds) as they were loaded into an SEM vacuum chamber. SEM analysis was performed in a Versa 3D DualBeam focused ion beam (FIB) microscope (FEI), and the elemental analysis with a ZEISS 1550VP FESEM microscope equipped with an Oxford X-Max SDD X-ray energy dispersive spectrometer.

Figure 2.7 shows SEM images of the carbon electrode surface before and after a discharge under oxygen to $2.6 \mathrm{~V}$ at $80 \mathrm{~mA} / \mathrm{g}$ in a $\mathrm{LiNO}_{3}-\mathrm{KNO}_{3}$ molten salt. Typically, large particles ranging from $500 \mathrm{~nm}$ to several microns were observed at the carbon surface of the discharged cathode. These particles are much larger than 

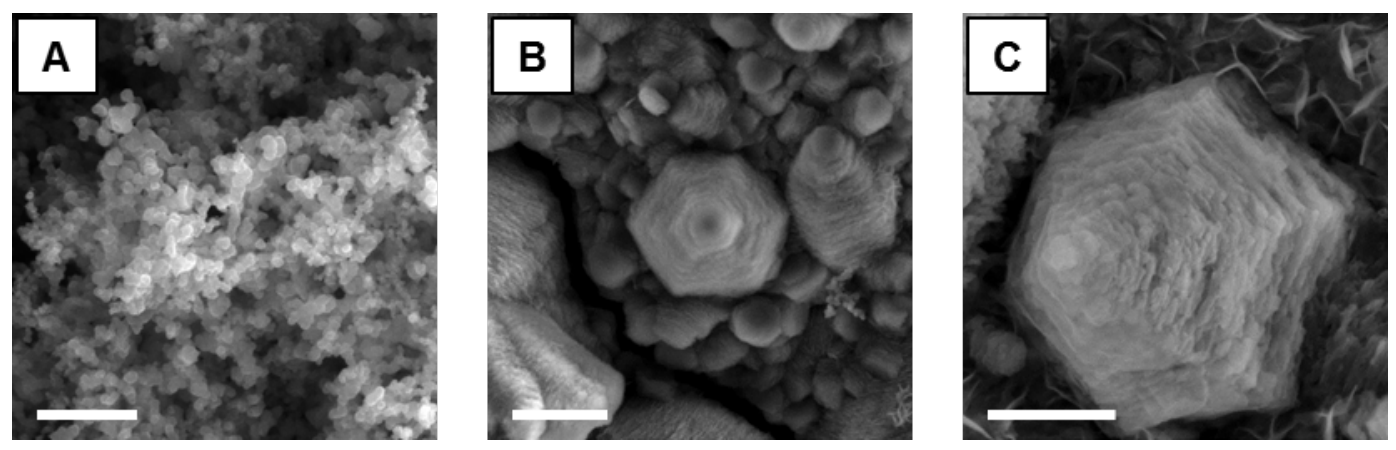

Figure 2.7: Morphology of oxygen cathode discharge product, taken with SEM. (A) Super P carbon nanoparticles before discharge (scale bar: $250 \mathrm{~nm}$ ). (B,C) Cathode following $\sim 1400 \mathrm{mAh} / \mathrm{g}$ discharge under oxygen to $2.6 \mathrm{~V}$ cutoff (scale bar: $1 \mu \mathrm{m}$ and $500 \mathrm{~nm}$, respectively).

the ones grown in past work using an organic electrolyte, such as those in Figure 1.3. In addition, the observed morphology of the discharge product, believed to be $\mathrm{Li}_{2} \mathrm{O}_{2}$, consists of stacks of hexagonal layers. This morphology agrees with theoretical predictions of the Wulff construction of $\mathrm{Li}_{2} \mathrm{O}_{2}$ being a hexagonal prism as shown in Figure 2.6.

The observation of these particularly large particles suggests an enhanced solubility of the discharge products, leading to the solution mediated precipitation of $\mathrm{Li}_{2} \mathrm{O}_{2}$. The increased solubility agrees with the large acceptor and donor number of previously studied molten salts described earlier. This enhanced solubility, in addition to the elevated temperature of the battery, would reduce the kinetic restrictions on crystal growth, allowing these $\mathrm{Li}_{2} \mathrm{O}_{2}$ crystals to grow with equilibrium shape.

Figure 2.8 displays the elemental analysis performed on a discharged carbon cathode and centered on a grown $\mathrm{Li}_{2} \mathrm{O}_{2}$ crystal. While EDS is typically unable to observe lithium directly, we do observe only the presence of oxygen, and notably the absence of carbon or potassium. The lack of carbon demonstrates that this crystal is not $\mathrm{Li}_{2} \mathrm{CO}_{3}$ or some other side product due to decomposition of the Super P carbon on the cathode, and the lack of potassium demonstrates that this crystal is not frozen salt or some side product due to decomposition of the electrolyte. The observed particle is clearly crystalline as evidenced by the well defined facets, so the diffraction of Figure 2.4 corroborates that this is in fact $\mathrm{Li}_{2} \mathrm{O}_{2}$.

SEM analysis of a Super P carbon electrode fully charged to $3.0 \mathrm{~V}$ (1st cycle) in Figure 2.9 showed no evidence of $\mathrm{Li}_{2} \mathrm{O}_{2}$, and many areas of the cathode were covered by needle-like particles of several hundred nanometers. Consistent with 

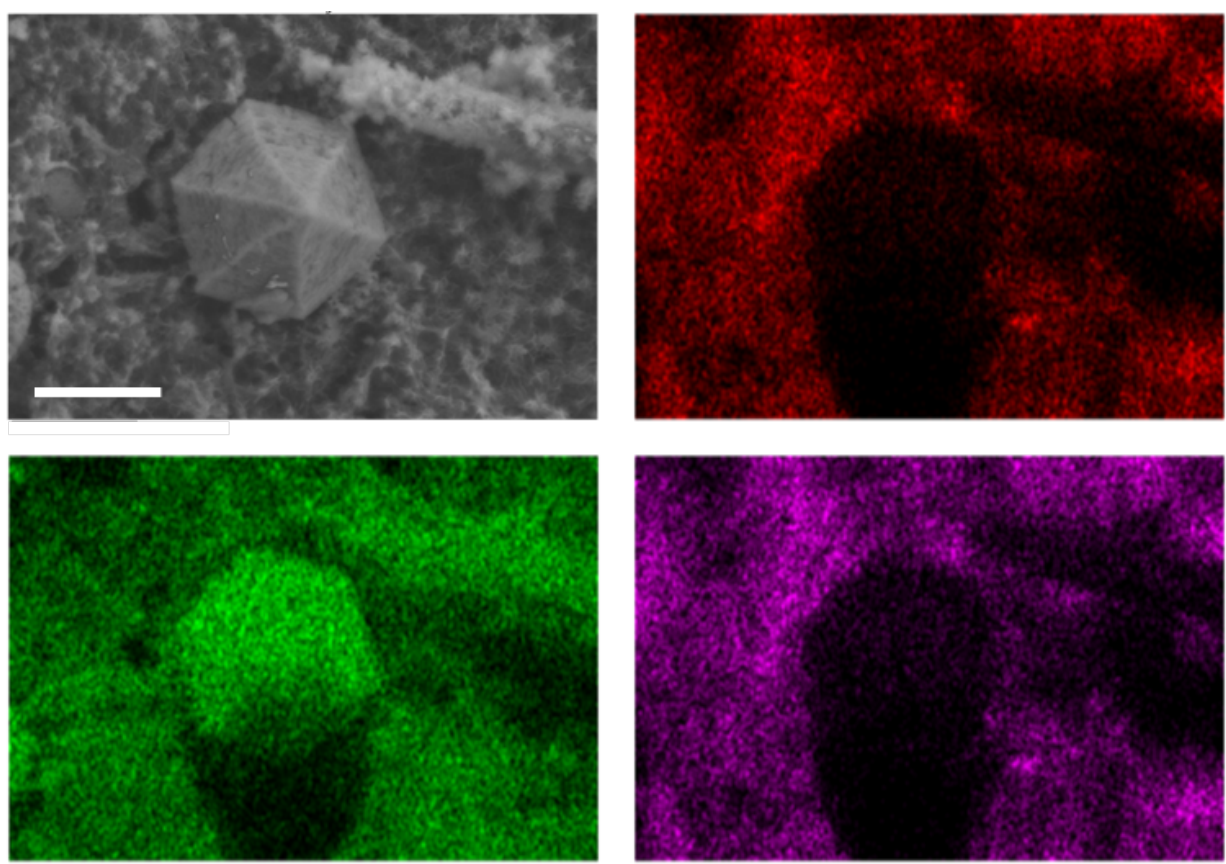

Figure 2.8: Elemental map of oxygen cathode discharge product, taken with EDS. (grayscale) Electron micrograph (scale bar: $2.5 \mu \mathrm{m}$ ) with (red) carbon, (green) oxygen, and (purple) potassium elemental maps of a Super P carbon cathode following $\sim 1400 \mathrm{mAh} / \mathrm{g}$ discharge under oxygen to $2.6 \mathrm{~V}$ cutoff.
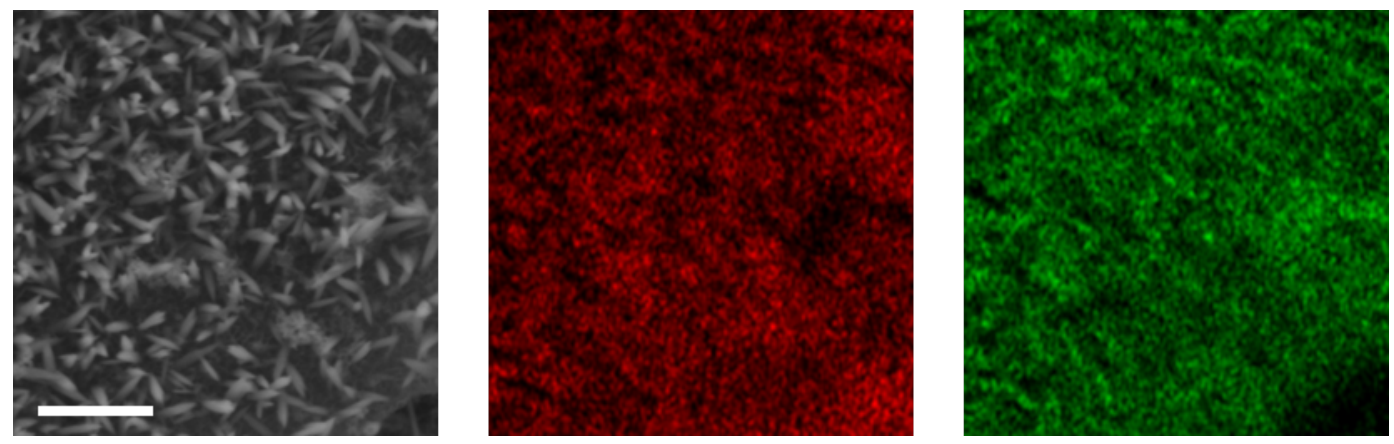

Figure 2.9: Elemental map of oxygen cathode after full cycle, taken with EDS. (grayscale) Electron micrograph (scale bar: $2 \mu \mathrm{m}$ ) with (red) carbon and (green) oxygen of a Super P carbon cathode following $\sim 1400 \mathrm{mAh} / \mathrm{g}$ discharge and charge to $3.0 \mathrm{~V}$ cutoff under oxygen.

XRD data showing $\mathrm{Li}_{2} \mathrm{CO}_{3}$ at the end of charge, elemental analysis supports the coprecipitation of $\mathrm{Li}_{2} \mathrm{CO}_{3}$ at the cathode surface. 


\section{Lithium Peroxide Solubility}

While the morphology of $\mathrm{Li}_{2} \mathrm{O}_{2}$ shown in the previous section suggests an enhanced solubility in the molten salt electrolyte, a more quantitative measure would help confirm this. $\mathrm{Li}_{2} \mathrm{O}_{2}$ solubility and diffusivity in the molten salt electrolyte were investigated by rotating disk electrode (RDE) measurements. Typically a PTFEbased electrochemical cell was used inside an argon-filled glovebox. The working electrode consisted of a platinum RDE (5.0 mm OD, 99.99\% pure, mirror polished, Pine Research), the counter electrode a platinum wire (1.0 mm OD, Sigma-Aldrich) and the reference electrode a lithium metal rod (Sigma-Aldrich). The 3-electrode cell was loaded with roughly $35 \mathrm{~mL}$ of carefully dried $\mathrm{LiNO}_{3}-\mathrm{KNO}_{3}$ eutectic and maintained at $150{ }^{\circ} \mathrm{C}$ by means of thermocouple and suitable beaker heating mantle. Once reproducible CVs were obtained in the 2.8-3.3 V range, $\mathrm{Li}_{2} \mathrm{O}_{2}$ powder (Alfa Aesar, 95\% pure) was added to the molten salt electrolyte, and using the RDE tip, the solution was vigorously stirred for several minutes until saturation. Linear sweep voltammograms (anodic scans from OCV to $3.3 \mathrm{~V}$ vs $\mathrm{Li} / \mathrm{Li}^{+}$) were then performed at $1 \mathrm{mV} / \mathrm{s}$, varying the electrode rotation rate from 100 to $2500 \mathrm{rpm}$. Levich/Cottrell analysis was used to determine bulk concentration and diffusivity of $\mathrm{Li}_{2} \mathrm{O}_{2}$ in the molten salt electrolyte. The Levich equation contains the diffusivity as well as the bulk concentration of the reacting species $\mathrm{Li}_{2} \mathrm{O}_{2}$, hence one of these quantities must be known to estimate the other. For that we used the Cottrell equation derived from transient current measurements under quiescent conditions.

Figure 2.10 shows this linear sweep voltammetry data obtained for $\mathrm{Li}_{2} \mathrm{O}_{2}$ bulk oxidation at $150{ }^{\circ} \mathrm{C}$ at a platinum RDE. Upon addition of $\mathrm{Li}_{2} \mathrm{O}_{2}$, the OCV of the battery shifted to $\sim 2.8 \mathrm{~V}$ vs $\mathrm{Li} / \mathrm{Li}^{+}$which is consistent with thermodynamic data. Slightly sloped anodic limiting currents (i.e., mass-transport limited currents) are due to interference with oxidation by impurities in the melt such as nitrite and hydroxide ions (nitrite ions form when nitrate ions get chemically reduced by the lithium reference electrode, whereas $\mathrm{LiOH}$ is a known impurity in $\mathrm{LiNO}_{3}$ ). Consistent with fast electrode kinetics, the current observed at any given potential along the voltammogram varies linearly with the square root of the rotation rate and the line intercepts the vertical axis at zero. We measured the peroxide anion concentration to be $5.2 \mathrm{e}^{-4} \mathrm{~mol} / \mathrm{L}$, which is an order of magnitude greater than values calculated in organic solvents such as DMSO or DMF at $30{ }^{\circ} \mathrm{C}$ (in the $10^{-5} \mathrm{M}$ range). For those organic solvents, lithium atomic absorption spectroscopy (AAS) was typically performed on $\mathrm{Li}_{2} \mathrm{O}_{2}$-saturated samples after dilution in water[65]. It appears that elevated temperature has an influence on $\mathrm{Li}_{2} \mathrm{O}_{2}$ solubility. Solvation 
effects between the molten salt electrolyte and the peroxide anions require further investigation.

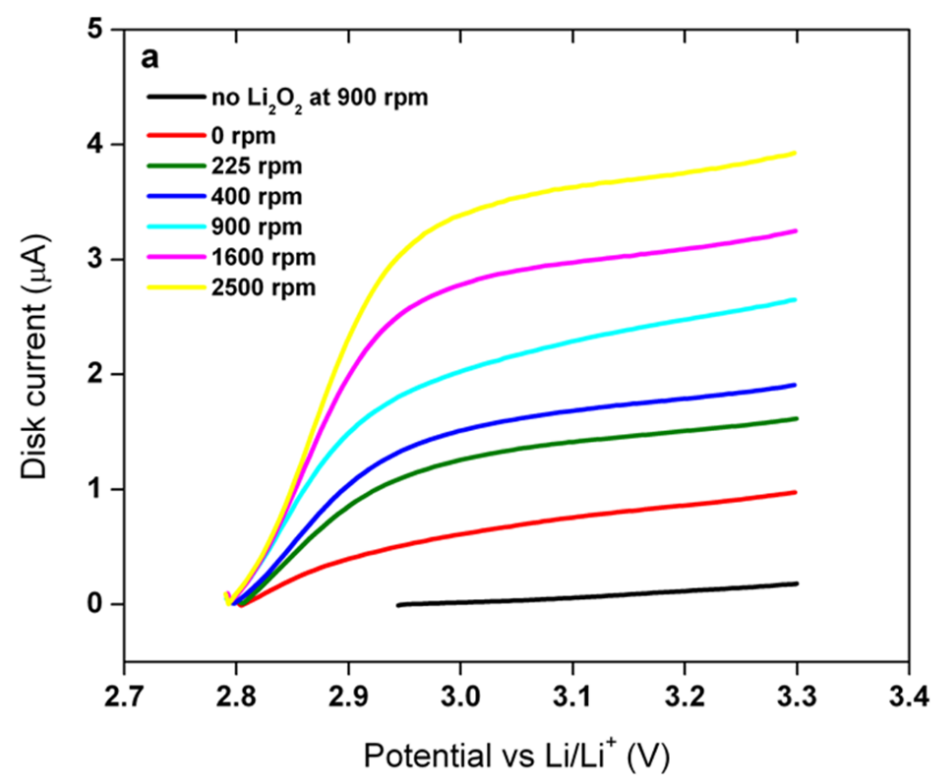

Figure 2.10: Linear sweep voltammograms of $\mathrm{Li}_{2} \mathrm{O}_{2}$ oxidation, recorded at a platinum $\mathrm{RDE}\left(\mathrm{A}=0.196 \mathrm{~cm}^{2}\right)$ in a molten salt electrolyte containing $\mathrm{Li}_{2} \mathrm{O}_{2} . \mathrm{v}=1$ $\mathrm{mV} / \mathrm{s}$, from $\mathrm{OCV}$ to $3.3 \mathrm{~V}$ vs Li/ $/ \mathrm{Li}^{+}$. RDE rotation rate increased from 0 to 2500 rpm. For comparison, a LSV scan of the molten salt electrolyte without $\mathrm{Li}_{2} \mathrm{O}_{2}$ was performed at each rotation rate to measure the background current (plotted is the $900 \mathrm{rpm}$ scan). Performed in a $\mathrm{LiNO}_{3}-\mathrm{KNO}_{3}$ electrolyte at $150{ }^{\circ} \mathrm{C}$ with platinum wire counter electrode and lithium metal rod reference electrode.

In the $\mathrm{LiNO}_{3}-\mathrm{KNO}_{3}$ eutectic molten electrolyte, the rate of the electrochemical half-reaction $\mathrm{O}_{2}^{2-} \rightarrow \mathrm{O}_{2}+2 e^{-}$at $150{ }^{\circ} \mathrm{C}$ is governed only by mass transport to the electrode surface. A diffusion coefficient of $3.1 \mathrm{e}^{-8} \mathrm{~cm}^{2} / \mathrm{s}$ was found for the $\mathrm{O}_{2}{ }^{2-}$ anion, several orders of magnitude lower than typical values for $\mathrm{O}_{2}\left(10^{-5}, 10^{-6} \mathrm{~cm}^{2} / \mathrm{s}\right.$ range), but consistent with the fact that peroxide has two negative charges and could exist as an ion pair with $\mathrm{Li}^{+}$cations. Appropriate methodology to determine the solubility and diffusivity of oxygen in molten nitrates is being developed.

The data shown throughout this section support the reversible, solution mediated growth of $\mathrm{Li}_{2} \mathrm{O}_{2}$ in a molten salt electrolyte. In particular, the solvating ability of the molten salt, paired with the elevated temperature of the battery, enables fast electrode kinetics, resulting in the extremely low discharge/charge overpotentials $(\sim 50 \mathrm{mV})$. 


\subsection{Battery Cycling Performance and Cell Death}

In order to understand the failure mechanisms of this system, the lithium-oxygen battery depicted in Figure 2.11 was galvanostatically cycled in $\mathrm{LiNO}_{3}-\mathrm{KNO}_{3}$ eutectic at $150{ }^{\circ} \mathrm{C}$ with limited depth of discharge ( $2 \mathrm{mAh}$ discharge, $\sim 45 \% \mathrm{DOD}$ ). The battery was stopped after 50 cycles $(\sim 340 \mathrm{~h}$ of cycling) when the discharge capacity had significantly dropped.
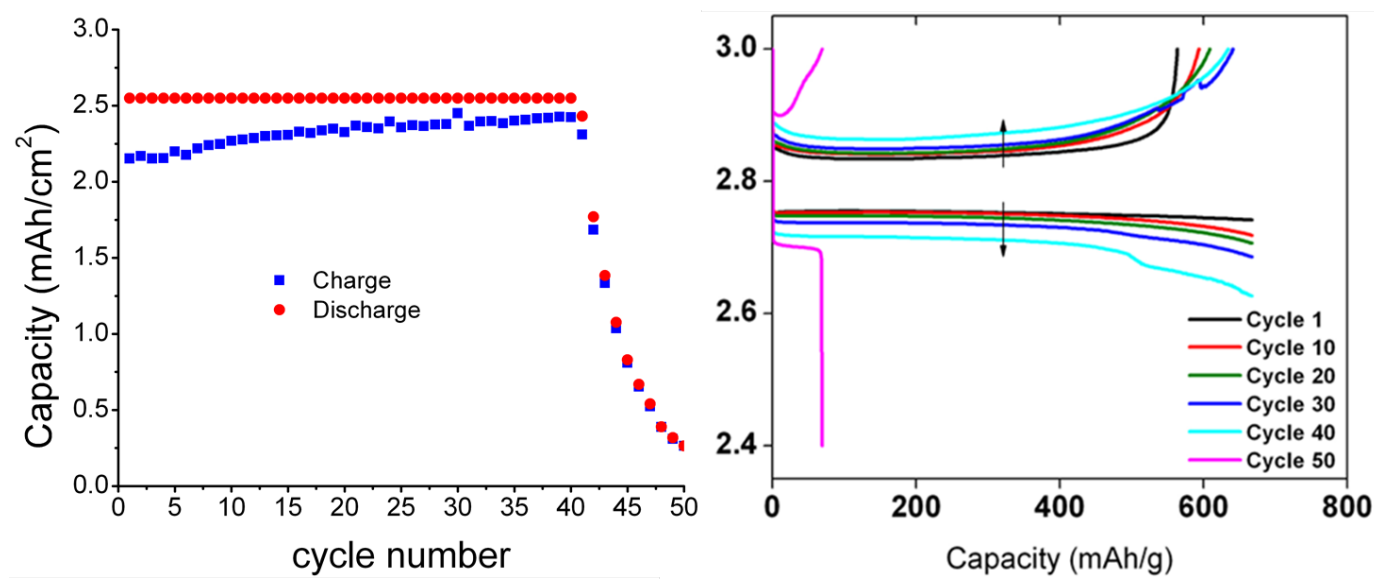

Figure 2.11: Cycling behavior of lithium-oxygen battery, including voltage profile for cycle 1, 10, 20, 30, 40, and 50. Battery cycled in $\mathrm{LiNO}_{3}-\mathrm{KNO}_{3}$ molten salt electrolyte at $150{ }^{\circ} \mathrm{C}$ using a Super $\mathrm{P}$ carbon cathode, current density of $\sim 0.64$ $\mathrm{mA} / \mathrm{cm}^{2}$ or $\sim 160 \mathrm{~mA} / \mathrm{g}$ of carbon, and carbon loading of $\sim 4 \mathrm{mg} / \mathrm{cm}^{2}$. Arrows indicate increasing voltage hysteresis with cycle number.

Interestingly, if we assume that all of the coulombic inefficiency accumulated over the life of the battery is attributed to the side reaction resulting in the formation of $\mathrm{Li}_{2} \mathrm{CO}_{3}$, it would require more carbon than is present in the cathode. To explain this apparent discrepancy, the cathode was analyzed by XRD and SEM similarly to the previous sections.

Despite ending the cycling after a complete charging half-cycle to $3.0 \mathrm{~V}$, the diffraction of Figure 2.12 reveals the presence of $\mathrm{Li}_{2} \mathrm{O}_{2}$ at the carbon surface, alongside the expected $\mathrm{Li}_{2} \mathrm{CO}_{3}$. We believe that electrically disconnected $\mathrm{Li}_{2} \mathrm{O}_{2}$ accumulates away from the electrode during cycling, accounting for the rest of the coulombic inefficiency, while $\mathrm{Li}_{2} \mathrm{CO}_{3}$ passivates carbon and is responsible for the continuous increase in battery polarization with cycle number.

SEM analysis of the cycled carbon cathode in Figure 2.13 further supports this argument. First, the surface of the cathode is clearly electrically insulating, as indicated by the charging of Figure 2.13a, with what appear to be clusters of $\mathrm{Li}_{2} \mathrm{O}_{2}$ 


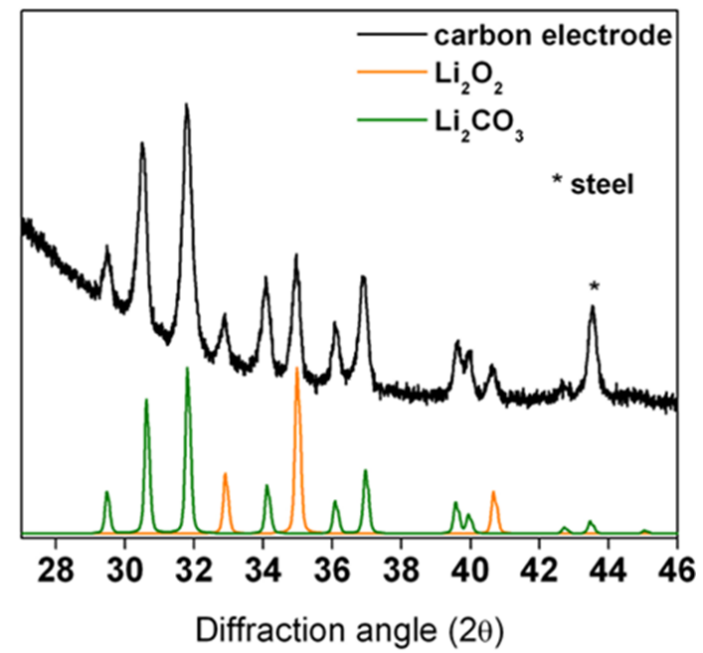

Figure 2.12: X-ray diffraction of cycled lithium-oxygen battery, from a cell similar to the one in Figure 2.11.
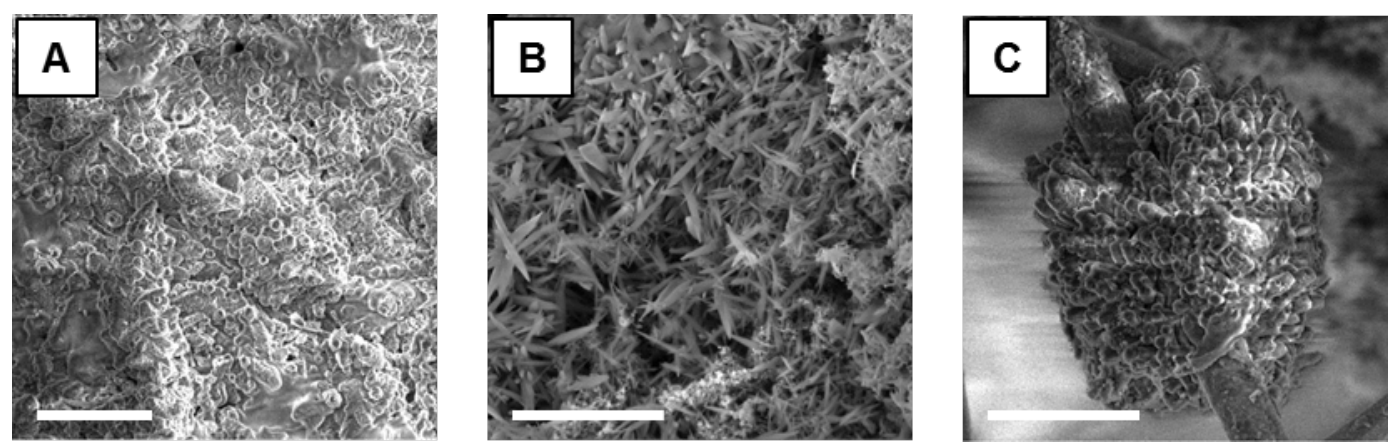

Figure 2.13: Scanning electron microscopy of cycled lithium-oxygen battery from a cell similar to the one in Figure 2.11. (A) Image charging of cathode due to electrically insulating surface (scale bar: $15 \mu \mathrm{m}$ ). (B) $\mathrm{Li}_{2} \mathrm{CO}_{3}$ particles covering carbon surface (scale bar: $5 \mu \mathrm{m}$ ). (C) $\mathrm{Li}_{2} \mathrm{O}_{2}$ particles agglomerating on a separator microfiber away from electrode surface (scale bar: $10 \mu \mathrm{m}$ ).

and $\mathrm{Li}_{2} \mathrm{CO}_{3}$ covering the carbon. A closer observation in Figure 2.13b shows large crystals of $\mathrm{Li}_{2} \mathrm{CO}_{3}$ (fuzzy "needle-like" particles) which are seen throughout the carbon surface. In addition, Figure 2.13c shows large, $>10 \mu \mathrm{m}$, clusters of $\mathrm{Li}_{2} \mathrm{O}_{2}$ hexagonal prisms growing on the residual separator glass microfibers leftover on the harvested cathode. It is noteworthy that electrochemically grown $\mathrm{Li}_{2} \mathrm{O}_{2}$ is growing on the battery separator, which is insulating by design. This serves as a direct confirmation of the solution-mediated growth process and is consistent with uncontrolled precipitation of $\mathrm{Li}_{2} \mathrm{O}_{2}$ during battery cycling.

A sustained reaction between oxygen reduction products and carbon is responsible 
for the cycle life limitation of the present batteries. Electrode passivation by $\mathrm{Li}_{2} \mathrm{CO}_{3}$, often reported as "carbon corrosion", is a known phenomenon in lithium-oxygen batteries $[42,43]$. As the number of cycles increases, the voltage hysteresis of the battery increases, consistent with the growth in electrode impedance. The origin of capacity fade in these systems is therefore 2-fold. First, one needs to better control $\mathrm{Li}_{2} \mathrm{O}_{2}$ dissolution and precipitation during discharge, and second, cathode materials stable to oxygen reduction products need to be developed in order to achieve high coulombic efficiency and maintain high energy efficiency.

\subsection{Summary}

We developed chemically stable electrolytes for the lithium-oxygen battery by replacing volatile, unstable, and air-intolerant aqueous or organic-based electrolytes with an inorganic molten salt. We used eutectic binary or ternary mixtures of alkali metal nitrate/nitrite salts and studied the oxygen electrochemistry at 120 and $150{ }^{\circ} \mathrm{C}$. Oxygen reduction was found to proceed based on a $2 \mathrm{e}^{-} / \mathrm{O}_{2}$ reaction leading to the formation of $\mathrm{Li}_{2} \mathrm{O}_{2}$. We observed the shape of deposited $\mathrm{Li}_{2} \mathrm{O}_{2}$ to be hexagonal, which agrees with equilibrium surface energy calculations of its Wulff construction. XRD

confirmed the reversible formation of crystalline $\mathrm{Li}_{2} \mathrm{O}_{2}$, and in situ gas and pressure analyses demonstrated that oxygen could be efficiently evolved during charge at a very low overpotential. A discharge/charge voltage gap of only $\sim 0.1 \mathrm{~V}$ constitutes the lowest value reported for a lithium-oxygen battery. Improved reversibility and rate capability are thought to originate from enhanced solubility of the discharge products, which alleviate the intrinsic electronic transport limitations of $\mathrm{Li}_{2} \mathrm{O}_{2}$ deposited on the lithium-oxygen battery cathode. More fundamental work needs to be done to understand solvation effects and the role of nitrate/nitrite anions in enhancing solubility of the discharge products. In the present study we used Super P carbon as the oxygen electrode material and showed that it tends to react with oxygen reduction products to form $\mathrm{Li}_{2} \mathrm{CO}_{3}$. We also demonstrated that decomposition of the amorphous carbon electrode causes battery failure, and therefore the identification of suitable non-carbonaceous oxygen electrode materials will be key to success for this chemistry. Although we found that $\mathrm{Li}_{2} \mathrm{CO}_{3}$ is sparingly soluble in the melt and can be bulk oxidized at about $3.5 \mathrm{~V}$ vs $\mathrm{Li} / \mathrm{Li}^{+}$at a platinum disk electrode, the side product passivates the carbon electrode when operating the battery in the typical voltage regime $(2.6-3.0 \mathrm{~V})$ and is responsible for increased polarization and capacity loss. XRD analysis of a cycled carbon cathode revealed substantial accumulation of electronically disconnected $\mathrm{Li}_{2} \mathrm{O}_{2}$. Large clusters, $>10 \mu \mathrm{m}$ in diameter, of $\mathrm{Li}_{2} \mathrm{O}_{2}$ 
crystals deposited on the glass fiber separator were observed by SEM. Solubility of $\mathrm{Li}_{2} \mathrm{O}_{2}$ allows growth of large particles and clusters via a solution phase mechanism which enables high areal capacity and low overpotential, but creates challenges in achieving high coulombic efficiency. Uncontrolled diffusion and precipitation of soluble $\mathrm{Li}_{2} \mathrm{O}_{2}$ is a major cause of capacity loss, and the low oxygen solubility is a challenge for achieving high rate capability. Methods to address these issues are important areas of future work. 
Chapter 3

\title{
A NITRATE REDUCTION BATTERY
}

\author{
Adapted from
}

1. Addison, D., Tozier, D., Tan, H., Uddin, J., Gallant, B. M., McCloskey, B. D., Greer, J. R., Chase, G. V. \& Giordani, V. A New Rechargeable Battery: Lithium Oxide Growth through Molten Salt Nitrate Reduction. (In Preparation).

\section{Chapter Abstract}

Next generation lithium batteries, such as the lithium-oxygen battery of the previous chapter, often employ the growth of lithium-rich phases, allowing specific capacities much higher than typical insertion cathode materials. In this chapter we introduce a battery chemistry along a similar vein. We demonstrate that a nanoparticle heterogeneous catalyst allows the reversible growth and dissolution of micron scale $\mathrm{Li}_{2} \mathrm{O}$ crystals through the effective catalysis of nitrate reduction and nitrite oxidation. This enables a new rechargeable battery system with a full cell theoretical specific energy of $1289 \mathrm{Whkg}^{-1}$ where a molten nitrate salt serves as both active material and electrolyte. 


\subsection{Nitrate Reduction Chemistry}

The Introduction Chapter discussed the potential benefits of moving beyond the typical intercalation cathode materials of lithium-ion batteries, looking at chemistries that employ the growth and dissolution of new phases such as oxygen and sulfur cathodes, both widely studied systems. The Second Chapter proposed a novel approach to the lithium-oxygen battery, replacing the traditional organic electrolyte with a molten salt one in hopes of overcoming some of practical challenges involved in that system. This molten salt electrolyte also led to interesting growth mechanisms of that systems lithium-rich phase, $\mathrm{Li}_{2} \mathrm{O}_{2}$.

This chapter considers a similar phase-forming conversion chemistry, whereby a molten nitrate salt serves as both an active material and the electrolyte. Molten nitrate salts have been previously studied as an active material in a primary lithium battery where $\mathrm{Li}_{2} \mathrm{O}$ irreversibly forms as nitrate reduces to nitrite[50, 51, 66, 67]. The reaction and thermodynamic potential at $150{ }^{\circ} \mathrm{C}$ are given in Equation 3.1.

$$
2 \mathrm{Li}+\mathrm{LiNO}_{3} \rightarrow \mathrm{Li}_{2} \mathrm{O}+\mathrm{LiNO}_{2} \quad E^{0}=2.44 \mathrm{~V}
$$

When using a eutectic composition $\mathrm{LiNO}_{3}-\mathrm{KNO}_{3}$ electrolyte (the same one as in Chapter Two), Equation 3.1 has a theoretical capacity of $612 \mathrm{mAhg}^{-1}$, and paired with a lithium metal anode at the thermodynamic potential of $2.44 \mathrm{~V}$, has a full cell theoretical specific energy of $1289 \mathrm{Whkg}^{-1}$. This is an encouraging value when looking at Table 1.1, especially when considering the electrolyte serves as the active material. If only a fraction of this theoretical specific energy were available, it would still be competitive with state of the art battery chemistries.

Previous work on this chemistry as a primary battery used a high surface area carbon current collector, resulting in a large overpotential on discharge[67]. When attempting to reverse the chemistry after discharge as in Figure 3.1, there is significant overpotential accompanied by gas evolution, suggesting the irreversibility of the reaction. However, by using a cathodic current collector which catalyzes Equation 3.1, in particular the reverse reaction of nitrite oxidation, this chemistry could be implemented as a secondary battery. Such a catalyst for nitrite oxidation is important because $\mathrm{Li}_{2} \mathrm{O}$ will directly oxidize to oxygen above $2.8 \mathrm{~V}$ in a similar way to $\mathrm{Li}_{2} \mathrm{O}_{2}$ in a lithium-oxygen battery, and this reaction contributes to the pressure rise of Figure 3.1.

If such a catalyst were found, a secondary nitrate reduction battery could be operated as schematically described in Figure 3.2. Just as in the lithium-oxygen system, a 


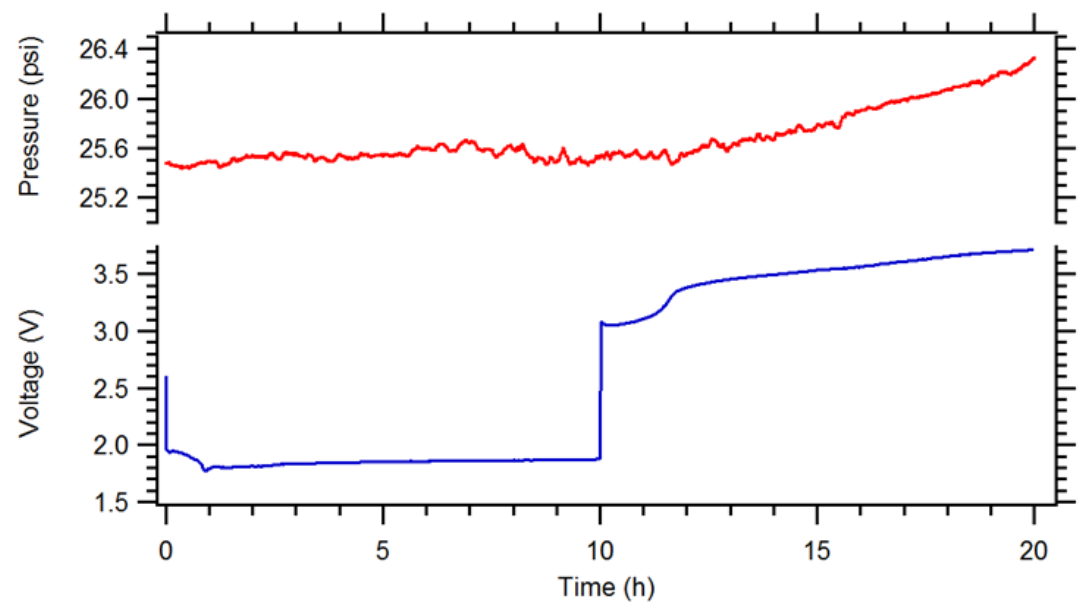

Figure 3.1: Nitrate reduction first cycle on a Super $\mathrm{P}$ carbon cathode, with pressure monitoring of the cell. $\mathrm{LiNO}_{3}-\mathrm{KNO}_{3}$ electrolyte at $150{ }^{\circ} \mathrm{C}$ with carbon loading of $\sim 4 \mathrm{mg} / \mathrm{cm}^{2}$.

lithium-rich phase would grow on the surface of the catalytic porous cathode support on discharge, and it would be removed on charge. In addition, note the presence of $\mathrm{Li}_{2} \mathrm{O}$ on the surface of the lithium anode. Interestingly, this natural SEI, which was previously reported for lithium in molten nitrate salts[67, 68], is the same reaction as the one occurring at the cathode, Equation 3.1, except that it occurs chemically. While a lithium anode directly exposed to the electrolyte is not practical for extended cycling, it is stable enough here to enable the study of this cathode chemistry.
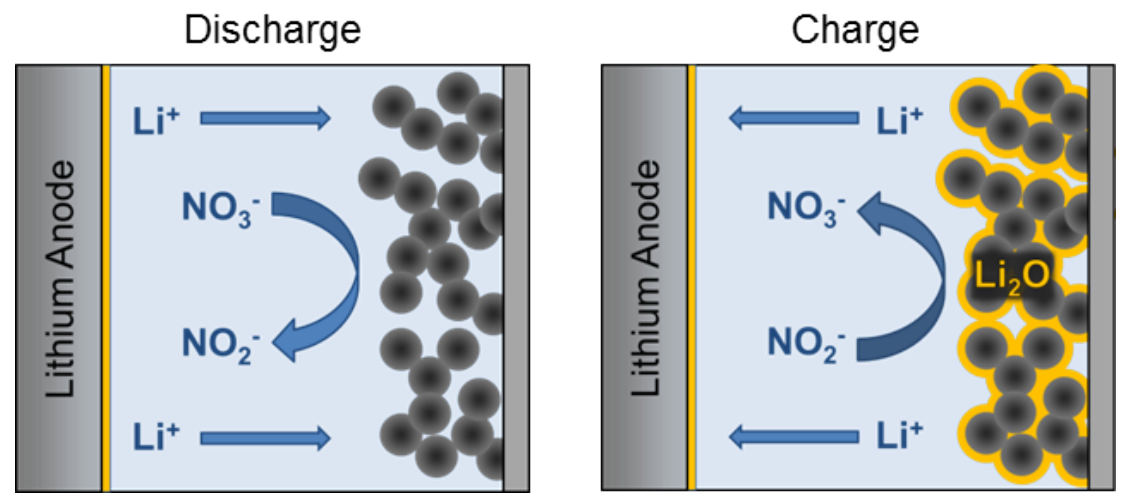

Figure 3.2: Nitrate reduction schematic, with depictions of the beginning of the discharge and charge processes. Molten nitrate electrolyte in blue and $\mathrm{Li}_{2} \mathrm{O}$ in yellow on both the lithium metal anode and conductive catalyst cathode support. 


\subsection{Catalysis of Nitrite Oxidation}

A combination of galvanostatic cycling and galvanostatic intermittent titration technique (GITT) are used to compare the electrochemical behavior of various catalyst candidates and electrochemically confirm the reversibility of any promising material. These experiments were performed in the same Swagelok cells used in Chapter Two. Cathodes consisted of about $10-20 \mathrm{mg} / \mathrm{cm}^{2}$ of metal nanoparticles (or microparticles) pressed onto a stainless steel or aluminum mesh without the use of binder. A glass microfiber separator was impregnated with about $200 \mathrm{mg}$ of molten salt electrolyte, $\mathrm{LiNO}_{3}-\mathrm{KNO}_{3}$ unless otherwise noted, and vacuum dried overnight at $200{ }^{\circ} \mathrm{C}$. Anodes were a simple lithium foil. All assembly took place in a glovebox, then the cells were filled with argon after a leak test, and finally placed in an oven to be held at the $150{ }^{\circ} \mathrm{C}$. A detailed description of the cell design and assembly is given in the appendix.

\section{Searching for a Catalyst}

A single galvanostatic cycle for various metal nanoparticles (all around 30-50 nm), including many typically used as catalysts for OER and ORR in other systems, is shown in Figure 3.3.

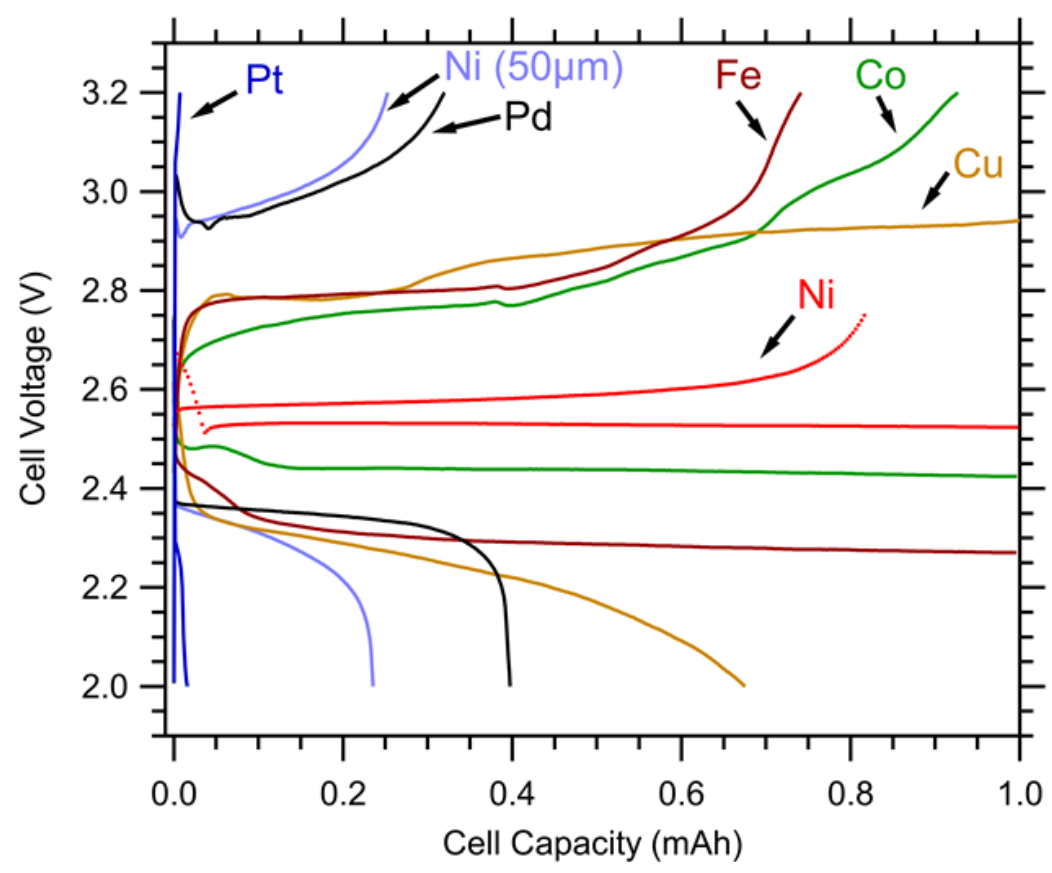

Figure 3.3: Catalysis comparison for nitrate reduction reversibility. First cycle of nitrate reduction using various nanoparticle (except where indicated) cathodes, at $0.1 \mathrm{~mA} \mathrm{~cm}{ }^{-2}$. 
A comparison of discharge and charge overpotentials between the different metals serves as a good metric for catalytic activity toward either nitrate reduction or nitrite oxidation. The overpotential for nickel is clearly the smallest $(\sim 100 \mathrm{mV})$, demonstrating that nickel nanoparticles can effectively catalyze both the reduction of nitrate and the oxidation of nitrite. In addition, micron-sized nickel particles exhibit a large overpotential and low capacity, demonstrating the importance of using a high surface area catalyst. While these nickel nanoparticles do have a large surface area $\left(\sim 10 \mathrm{~m}^{2} / \mathrm{g}\right)$, Super $\mathrm{P}$ carbon has a surface area an order of magnitude larger, suggesting that the nickel surface does in fact serve a catalytic role.

To confirm electrochemical reversibility and determine the OCV when using nickel nanoparticles as a cathode catalyst, we employ GITT in Figure 3.4with two different electrolyte compositions: one all nitrate, the other a nitrate/nitrite mixture. In the case of a $\mathrm{LiNO}_{3}-\mathrm{KNO}_{2}$ electrolyte, the measured $\mathrm{OCV}$ is $\sim 2.47 \mathrm{~V}$, in agreement with the calculated potential of $2.44 \mathrm{~V}$ in Equation 3.1. In addition, the OCV is the same on discharge and charge which suggests that the forward and backward reactions have the same standard potential, a good indication that the chemistry of Equation 3.1 is happening reversibly.

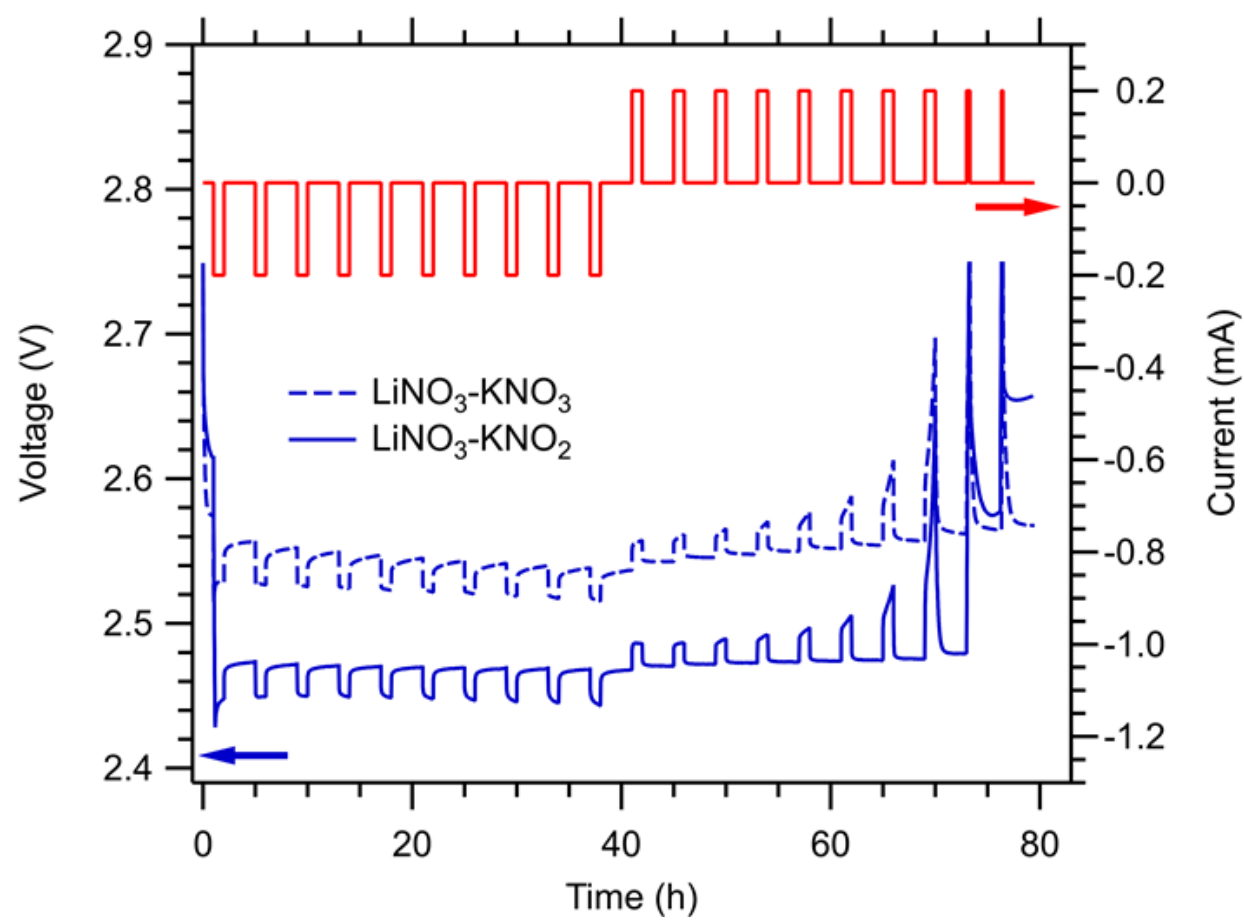

Figure 3.4: Galvanostatic intermittent titration technique of nitrate reduction, with a nickel nanoparticle cathode in both an all nitrate and nitrate/nitrite electrolyte. 
In the case of a $\mathrm{LiNO}_{3}-\mathrm{KNO}_{3}$ electrolyte, the measured $\mathrm{OCV}$ is $\sim 2.55 \mathrm{~V}$ initially, while gradually decreasing on discharge and then increasing on charge. This process agrees with what we would expect from the Nernst equation[69], reproduced in Equation 3.2.

$$
E=E^{0}-\frac{R T}{z F} \ln \left(\frac{\alpha_{R e d}}{\alpha_{O x}}\right)
$$

The concentration of nitrite, the reduced species, is initially negligible, while that of nitrate, the oxidized species, is well above standard conditions. Then the reaction quotient is less than one and the Nernstian contribution is positive, causing the observed OCV to be above the standard potential. As the concentration of nitrite increases throughout discharge, its activity approaches that of nitrate and thus the OCV approaches the calculated standard potential.

\section{Catalytic Properties of Nickel}

With a good understanding of the role that nickel nanoparticles can play in the catalysis of nitrate reduction and nitrite oxidation, a combination of X-ray photoelectron spectroscopy (XPS) and transmission electron microscopy (TEM) are used to identify the surface state of the nickel and a potential explanation for its catalytic activity, and samples were cleaned as described previously. XPS was performed with a Surface Science Instruments M-Probe XPS system under monochromatic Al $\mathrm{K} \alpha \mathrm{X}$-ray (1486.6 eV) illumination[70], and samples were briefly exposed to air as they were put into the transfer chamber.
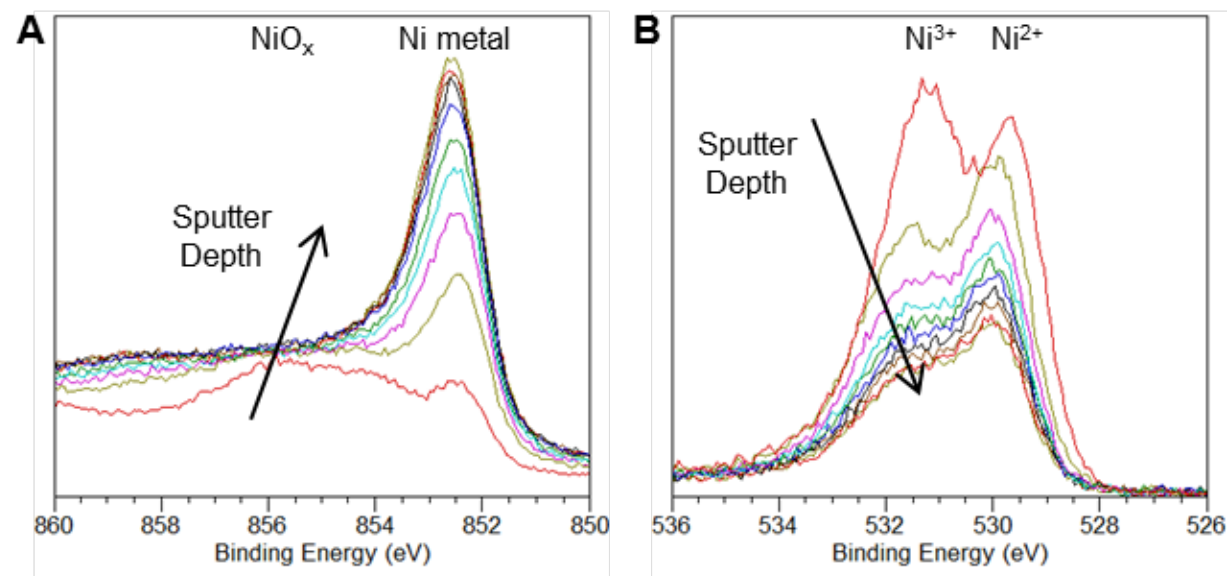

Figure 3.5: X-ray photoelectron spectroscopy of nickel nanoparticles, with depth profiling and performed after exposure to molten nitrate. (A) $\mathrm{Ni} 2 \mathrm{p}$ and (B) $\mathrm{O} 1 \mathrm{~s}$ binding energies. 
Figure 3.5 contains an XPS depth profile of nickel nanoparticles after exposure to molten nitrate. The surface state of the nickel is a nickel oxide with both $\mathrm{Ni}^{2+}$ and $\mathrm{Ni}^{3+}$ states. As the depth profile proceeds, the spectrum progresses from a nickel oxide state to a metallic nickel one. This suggests that there is a nickel oxide surface layer, but that the metallic nickel is retained in the center of the nanoparticles. In addition, the existence of a mixed nickel oxidation state indicates that the surface nickel oxide is nickel deficient. While a native oxide layer with a small nickel vacancy concentration does form on nickel surfaces exposed to air[71], we believe that the exposure to a molten nitrate salt enhances the nickel deficiency by an in situ introduction of lithium substitutions at nickel sites.

TEM is used to observe and better understand these nickel nanoparticles and their nickel oxide surface. To prepare samples, cathode material was scraped from the mesh current collector, ground between glass slides, and put onto a copper TEM grid with holey carbon film. TEM was performed using a FEI Tecnai F30ST (300 $\mathrm{kV}$ ), and the TEM grid was briefly exposed to air upon inserting the TEM holder.
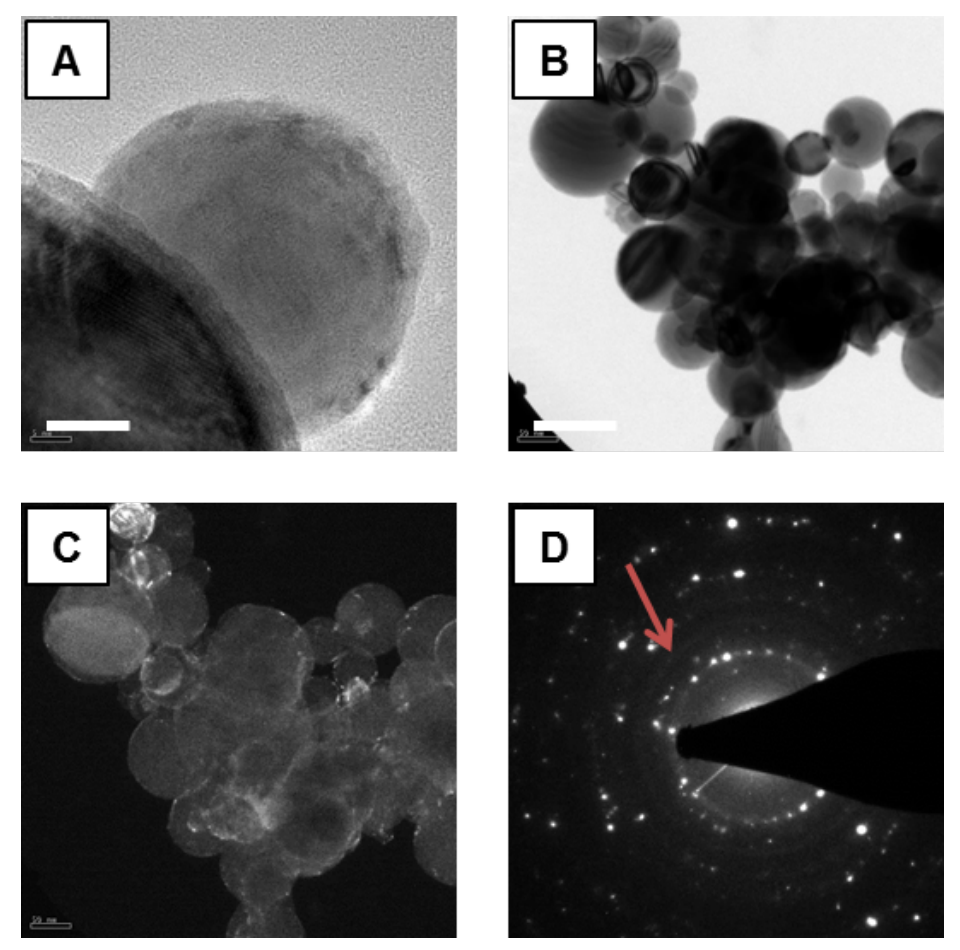

Figure 3.6: Transmission electron microscopy of nickel nanoparticles, performed after exposure to molten nitrate. (A) High resolution of two nickel particles (scale bar: $10 \mathrm{~nm}$ ). (B) Bright field and (C) dark field of a collection of particles (scale bar: $100 \mathrm{~nm}$ ). (D) Diffraction pattern of area in panels B,C. Dark field taken at location of red arrow on faint diffraction ring. 
TEM analysis of nickel nanoparticles is shown in Figure 3.6. The high resolution micrograph of Figure 3.6a demonstrates the surface layer present on these nickel nanoparticles. In order to understand what this surface layer is, diffraction is performed on the collection of particles in Figure 3.6b. The resulting pattern of Figure 3.6d has all the expected rings of nickel, in addition to two faint extra ones. The most clear of these is pointed at by a red arrow, and a bright field image at this spot is shown in Figure 3.6c. Interestingly, these extra rings correspond to those of nickel oxide with a rock salt structure. Note that the bright field consists of a diffuse contrast across all the particles, consistent with the fact that the surface layer is nickel oxide.

We propose that it is this cation deficient nickel oxide surface, and not metallic nickel, which serves as the catalyst for reversible nitrate reduction. In particular, these point defect sites, whether in the form of a nickel vacancy or lithium substitution, serve as an oxide ion transfer catalyst enabled by the neighboring nickel atom's ability to cycle between $2^{+}$and $3^{+}$oxidation states.

In order to confirm this, we synthesize lithium-doped nickel oxide (L-NiO) particles for use as a cathode catalyst. $2.0 \mathrm{~mL}$ of water:iso-propanol (2:1) was added to a mixture of $\mathrm{Ni}(\mathrm{OH})_{2}(1.0 \mathrm{~g}, 10.79 \mathrm{mmol})$ and $\mathrm{LiOH}(12.93 \mathrm{mg}, 0.54 \mathrm{mmol})$ in a vial. The suspension was sonicated at room temperature for 2 hours to make it a homogeneous mixture. Water and iso-propanol were then removed using a rotary evaporator under vacuum. The resulting wet slurry was dried in an oven at $50{ }^{\circ} \mathrm{C}$ overnight. The $\mathrm{Ni}(\mathrm{OH})_{2}-\mathrm{LiOH}$ solid mix was then heated to $300{ }^{\circ} \mathrm{C}$ in a furnace for 3 hours to give nanoparticles of L-NiO. BET surface area measurements were performed using a Micromeritics TriStar II Plus surface area analyzer. A BET surface area of $120 \mathrm{~m}^{2} / \mathrm{g}$ was measured, following a 17 hour degassing at $120{ }^{\circ} \mathrm{C}$ under nitrogen flow. Note that such a doped nickel oxide displays p-type conductivity, allowing its use without a conductive additive[72-74].

Figure 3.7 compares the first cycle of nitrate reduction and nitrite oxidation on this $\mathrm{L}-\mathrm{NiO}$ to the nickel nanoparticles used previously. The performance on both charge and discharge is nearly identical to that of the nickel nanoparticles, confirming that it is in fact this doped nickel oxide which serves as the catalyst for this reaction.

\subsection{Lithium Oxide as a Discharge Product}

With a catalyst allowing the reversible reduction of nitrate based on the electrochemical data, a combination of XRD, SEM, EDS, and TEM are used to characterize 


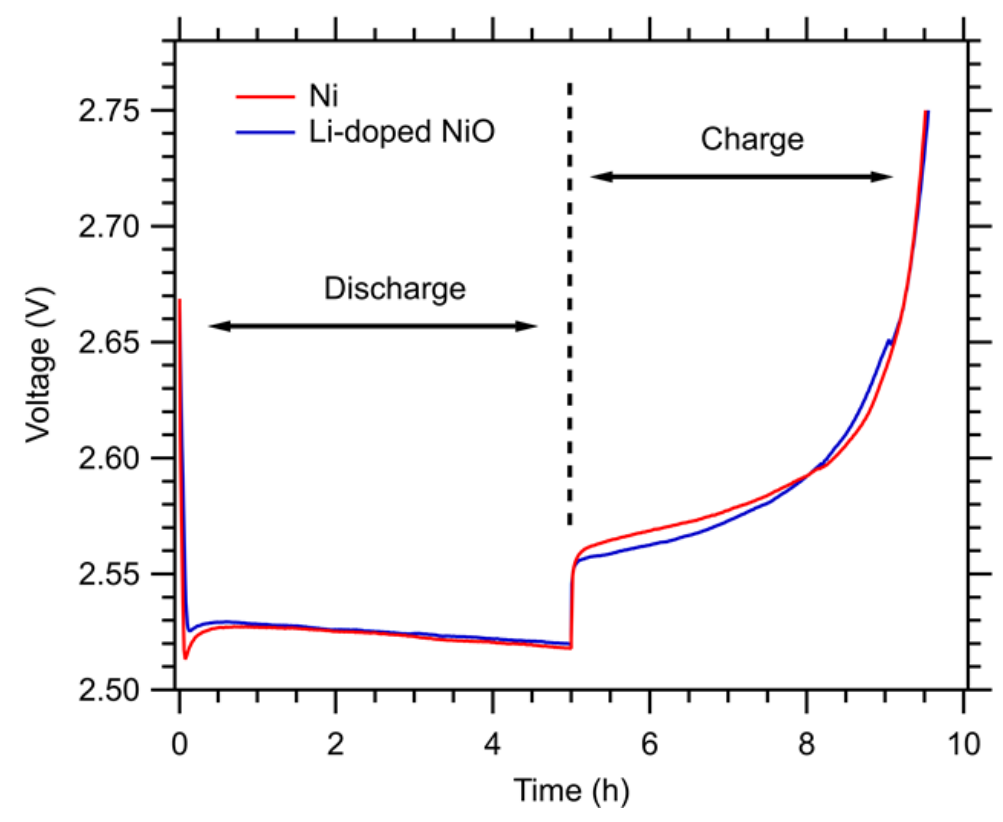

Figure 3.7: Lithium-doped nickel oxide as a catalyst.

the discharge product grown on the cathode. As before, the cathode was extracted from heated batteries inside an argon-filled glovebox and rinsed with NMA solvent to remove residual nitrate and nitrite salts.

\section{X-ray and Electron Diffraction}

After extraction from the battery following the procedure used previously, nickel electrodes were then sealed in Kapton tape for protection against air contamination. Diffraction was again performed on a PANalytical X'Pert Pro X-ray powder diffractometer with $\mathrm{Cu} \mathrm{K} \alpha 1$ radiation.

XRD patterns of the nickel electrode before discharge, following a discharge to 2.3 $\mathrm{V}$ cathodic cutoff, and after a completed cycle (electrode fully recharged to 2.75 V) are depicted in Figure 3.8. The XRD results clearly demonstrate that crystalline $\mathrm{Li}_{2} \mathrm{O}$ forms on the nickel surface during discharge and can subsequently be oxidized upon battery charge. Unlike the case with the lithium-oxygen battery from before, there is no carbon present in this system (lithium metal anode, ceramic separator, molten salt electrolyte, nickel cathode, no binder). As a result, there is no means of forming carbonaceous side products, and the only crystalline discharge product observed is the desired $\mathrm{Li}_{2} \mathrm{O}$.

Because structural confirmation of electrochemically grown $\mathrm{Li}_{2} \mathrm{O}$ is not (to our knowledge) reported in literature, TEM was used to further confirm its existence. 


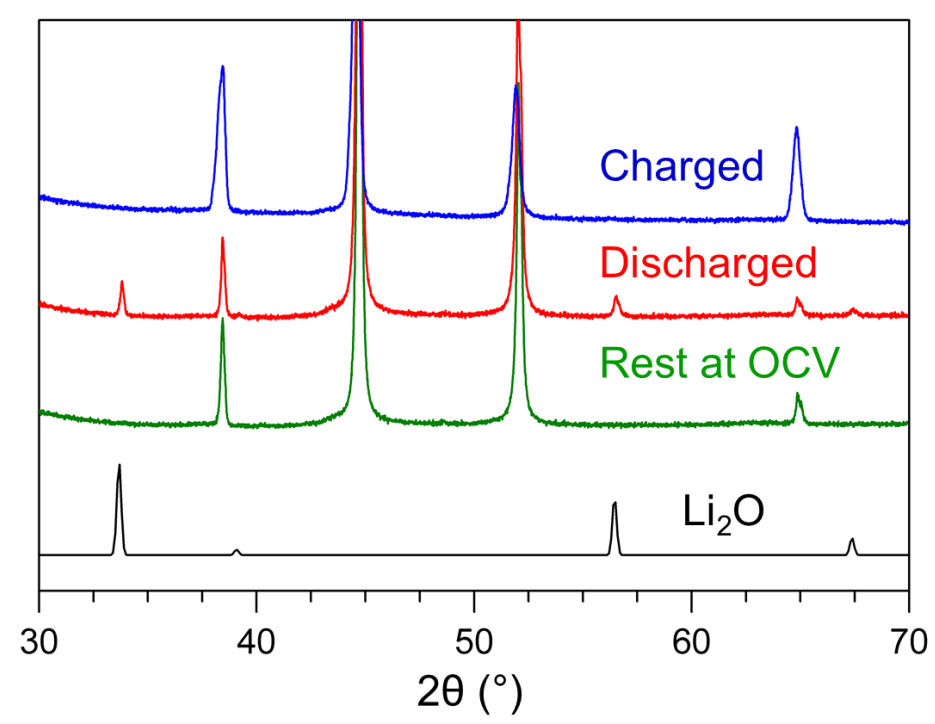

Figure 3.8: X-ray diffraction of nitrate reduction cathode across one cycle. Scans taken following an OCV period (before discharge), a single discharge to $2.3 \mathrm{~V}$, and a discharge/charge cycle between 2.3 and $2.75 \mathrm{~V}$, in $\mathrm{LiNO}_{3}-\mathrm{KNO}_{3}$ molten salt electrolyte at $150{ }^{\circ} \mathrm{C}$ with nickel nanoparticle cathode. Peaks not attributed to $\mathrm{Li}_{2} \mathrm{O}$ are from the nickel nanoparticles and aluminum grid they are pressed onto.

As before, cathode material was cleaned as described above, scraped from the mesh current collector, ground between glass slides, and put onto a copper TEM grid with holey carbon film. TEM was performed using a FEI Tecnai F30ST (300 kV), and the TEM grid was briefly exposed to air upon inserting the TEM holder.
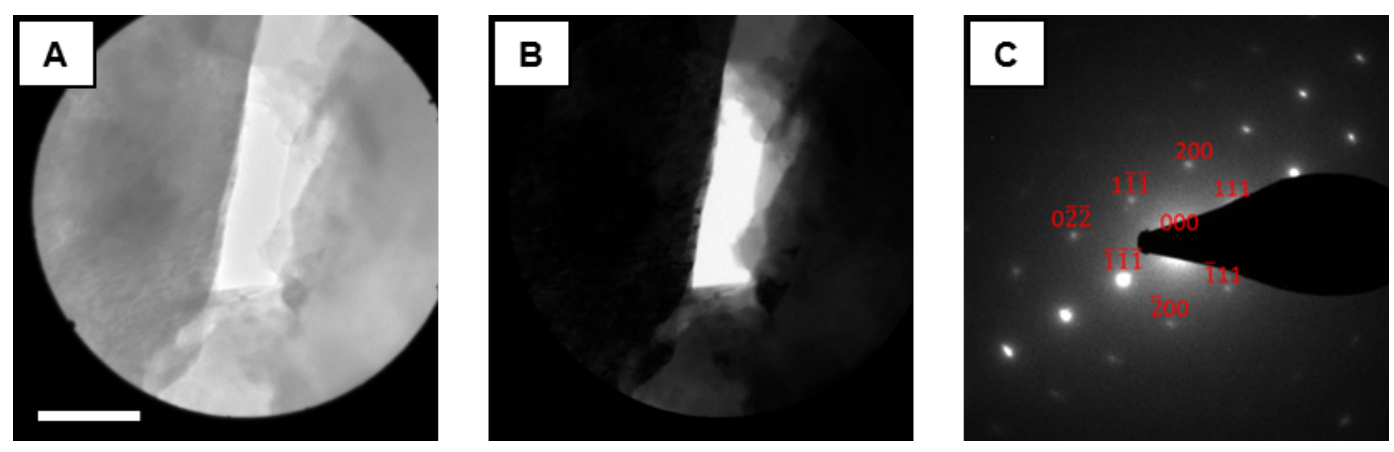

Figure 3.9: Transmission electron microscopy of nitrate reduction cathode. (A) Standard and (B) bright field images of discharge product (scale bar: $200 \mathrm{~nm}$ ), with selected area indicated for $(\mathrm{C})$ diffraction pattern, indexed to [01 $\overline{1}]$ orientation of Antifluorite structure $\mathrm{Li}_{2} \mathrm{O}$. Sample taken from cathode discharged to $2.3 \mathrm{~V}$ at 150 ${ }^{\circ} \mathrm{C}$ in $\mathrm{LiNO}_{3}-\mathrm{KNO}_{3}$ electrolyte. 
While $\mathrm{Li}_{2} \mathrm{O}_{2}$ is extremely beam sensitive, requiring the use of cryo-TEM to effectively image it[75], $\mathrm{Li}_{2} \mathrm{O}$ appears to be only relatively beam sensitive, allowing one to obtain a single diffraction pattern at ambient temperature by working quickly. Interestingly, $\mathrm{Li}_{2} \mathrm{O}_{2}$ first decomposes to $\mathrm{Li}_{2} \mathrm{O}$ under the electron beam, painstakingly shown with detailed cryo-TEM experiments[21]. Figure 3.9 shows both the micrograph and diffraction pattern of discharge product from a cathode discharged to $2.3 \mathrm{~V}$. Indexing the diffraction confirms that this is the Antifluorite crystal structure of $\mathrm{Li}_{2} \mathrm{O}$. While a full analysis would involve tilting of the sample and obtaining diffraction patterns along different zone axes, the instability of $\mathrm{Li}_{2} \mathrm{O}$ under the beam allowed only the single pattern (without tilting, purely luck) at ambient temperature before the crystal decomposed under the electron beam.

\section{Microscopy and Elemental Analysis}

As done previously, after extraction from the battery following the procedure described above, nickel electrodes were briefly exposed to air ( 30 seconds) as they were loaded into an SEM vacuum chamber. SEM analysis was performed in a Versa 3D DualBeam focused ion beam (FIB) microscope (FEI), and the elemental analysis with a ZEISS 1550VP FESEM microscope equipped with an Oxford X-Max SDD $\mathrm{X}$-ray energy dispersive spectrometer.
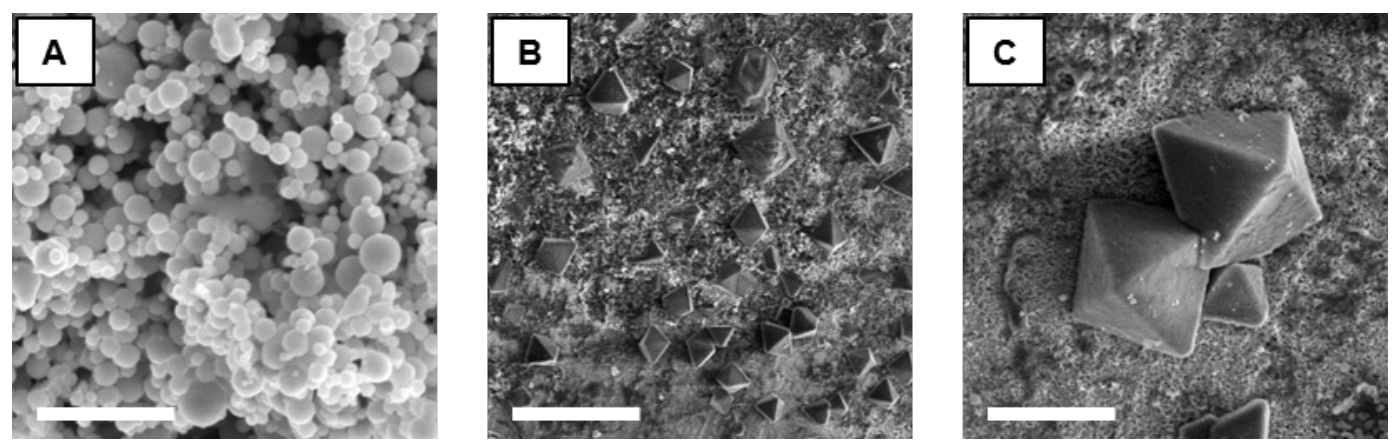

Figure 3.10: Morphology of nitrate reduction cathode discharge product. (A) Nickel nanoparticles before discharge (scale bar: $500 \mathrm{~nm}$ ). (B,C) Cathode following discharge to $2.3 \mathrm{~V}$ cutoff (scale bar: $20 \mu \mathrm{m}$ and $5 \mu \mathrm{m}$, respectively.)

Figure 3.10 shows SEM images of the nickel cathode surface before and after discharge to $2.3 \mathrm{~V}$ in a $\mathrm{LiNO}_{3}-\mathrm{KNO}_{3}$ molten salt. Typically, large particles several microns in size and a thin film are observed growing over the bed of nickel nanoparticles, and the cyrstallinity of this discharge product is evident. In particular, note the octahedral morphology of large crystals. In a similar vein to the $\mathrm{Li}_{2} \mathrm{O}_{2}$ of the 
previous chapter, this morphology agrees with theoretical predictions of the Wulff construction of $\mathrm{Li}_{2} \mathrm{O}$ being an octahedron[76].

While there is no formal proposal of growth mechanisms of electrochemically grown $\mathrm{Li}_{2} \mathrm{O}$ as there is for $\mathrm{Li}_{2} \mathrm{O}_{2}$, the growth of these large particles which should be insulating suggests that a similar thing is happening here as the case of the solutionmediated $\mathrm{Li}_{2} \mathrm{O}_{2}$ growth mechanisms described previously. There is evidence of oxide solubility in molten nitrates[52,77], and based on the size of these crystals, such a solution growth mechanism makes sense. As before with $\mathrm{Li}_{2} \mathrm{O}_{2}$, the high solubility of discharge products, in addition to the elevated temperature of the battery, would reduce the kinetic restrictions on crystal growth and encourage the growth of the equilibrium Wulff shape.
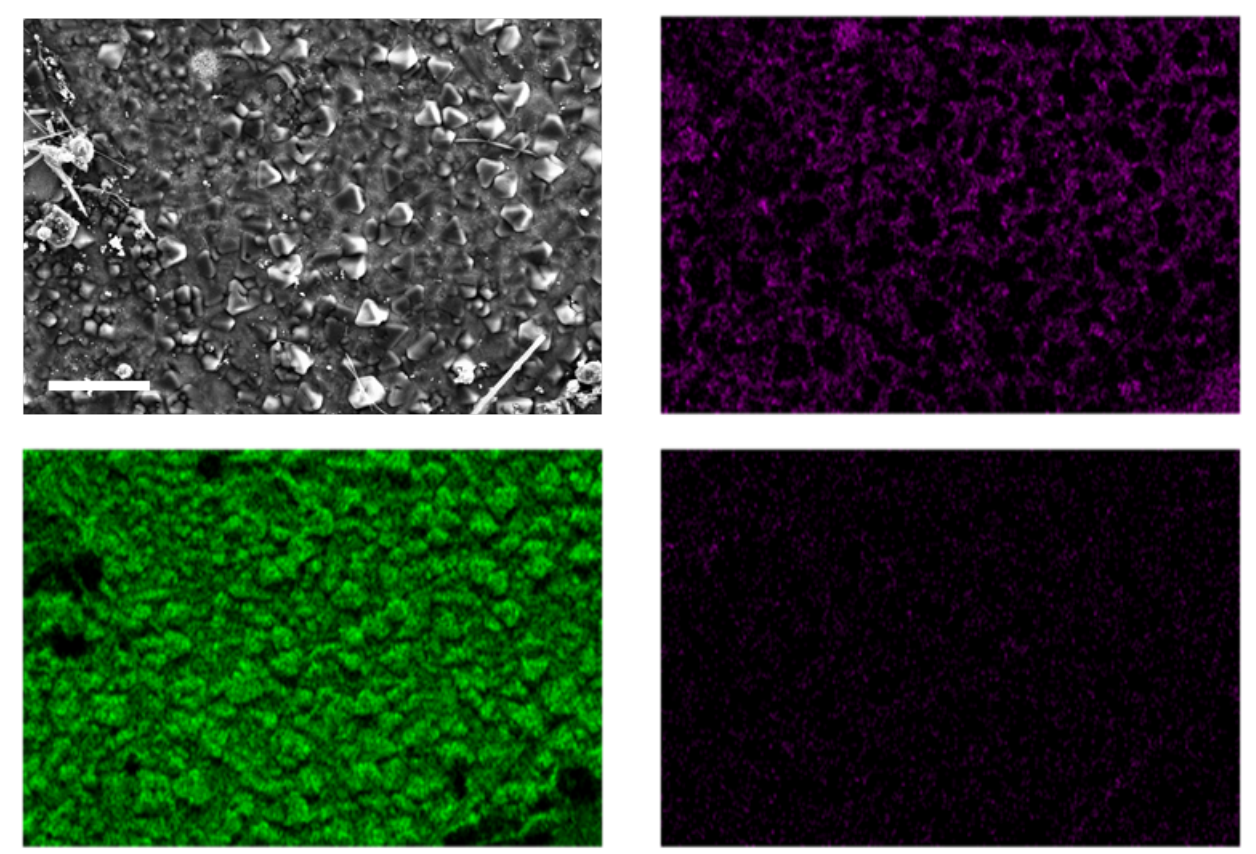

Figure 3.11: Elemental map of nitrate reduction cathode discharge product, taken with EDS. (grayscale) Electron micrograph (scale bar: $40 \mu \mathrm{m}$ ) with (purple) nickel, (green) oxygen, and (pink, bottom right) potassium elemental maps of a nickel nanoparticle cathode following discharge to $2.3 \mathrm{~V}$ cutoff.

Figure 3.11 displays the elemental analysis performed on a discharged nickel cathode, performed with a wide field of view capturing many $\mathrm{Li}_{2} \mathrm{O}$ crystals. While EDS is typically unable to observe lithium directly, we do observe only the presence of oxygen, and notably the absence of nickel or potassium. As discussed previously, there is no carbon in this system. The observed particles are clearly crystalline, so the diffraction of Figure 3.8 corroborates that this is in fact $\mathrm{Li}_{2} \mathrm{O}$. 


\subsection{Nitrate to Nitrite and Back Again}

By contrast to the lithium-oxygen system, this nitrate reduction chemistry has two reaction products which must be verified. Having confirmed the growth and dissolution of $\mathrm{Li}_{2} \mathrm{O}$ on discharge and charge, it is time to address the other reaction product, nitrite. A combination of Raman spectroscopy, clever electrochemistry, and ion exchange chromatography are used to characterize the electrolyte constituents. Electrolytes were extracted from batteries inside an argon-filled glovebox by disassembling the entire Swagelok fixture without remelting the frozen salt.

\section{Raman Spectroscopy}

After extraction from the battery, frozen electrolytes were taken for Raman spectroscopy in air as the species of interest are not air sensitive. Raman spectroscopy was performed on a Renishaw M1000 Mirco Raman Spectrometer System with an argon ion laser at $514.5 \mathrm{~nm}$.

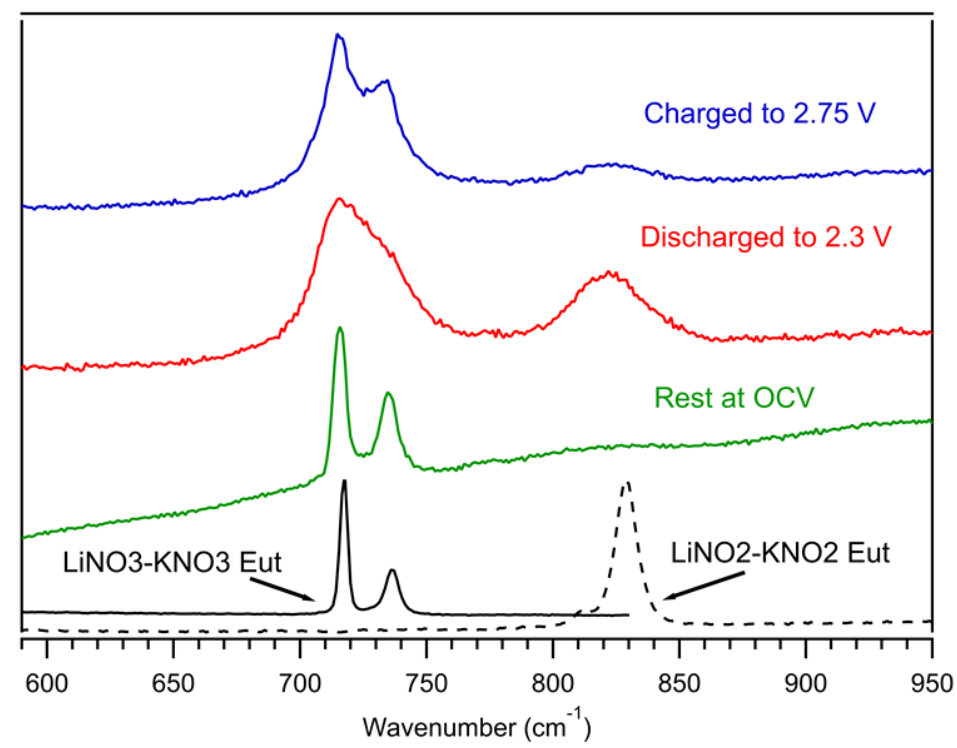

Figure 3.12: Raman spectroscopy of nitrate reduction electrolyte across one cycle. Spectra taken following an OCV period (before discharge), a single discharge to 2.3 $\mathrm{V}$, and a discharge/charge cycle between 2.3 and $2.75 \mathrm{~V}$, in $\mathrm{LiNO}_{3}-\mathrm{KNO}_{3}$ molten salt electrolyte at $150^{\circ} \mathrm{C}$ with nickel nanoparticle cathode.

Raman spectra of the initially $\mathrm{LiNO}_{3}-\mathrm{KNO}_{3}$ frozen electrolyte before discharge, following a discharge to $2.3 \mathrm{~V}$ cathodic cutoff, and after a completed cycle (electrode fully recharged to $2.75 \mathrm{~V}$ ) are depicted in Figure 3.12. The spectra clearly demonstrate the presence of a nitrite peak upon discharge and most of the peak going away upon charge. The peak does not fully go away for two reasons. The coulombic 
efficiency of the first cycle is not $100 \%$, and the lithium anode SEI growth forms nitrite as described previously.

\section{Ion Exchange Chromatography}

Batteries of varying electrolyte compositions were assembled as described previously and discharged to a $2.3 \mathrm{~V}$ cutoff. The cells were taken to the glovebox and disassembled, separating the electrolyte and cathode. For some cells, the cathode was cleaned using the procedure above and then put into another cell with new lithium anode and electrolyte. Several electrolyte compositions were tested, and these cells with discharged cathodes (preloaded with $\mathrm{Li}_{2} \mathrm{O}$ ) were then charged a fixed amount, $2 \mathrm{mAh}$.

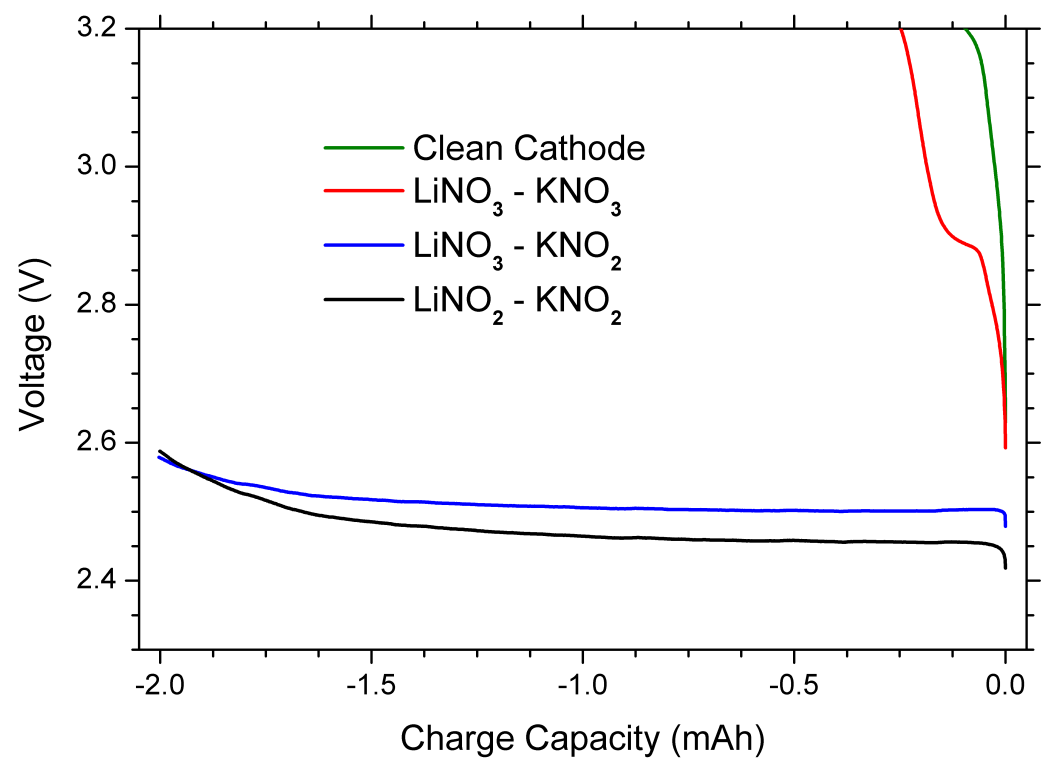

Figure 3.13: Charging profile of newly constructed cells preloaded with $\mathrm{Li}_{2} \mathrm{O}$, with various electrolyte compositions. Clean cathode contains no pre-grown $\mathrm{Li}_{2} \mathrm{O}$, and the other three cells contain a nickel nanoparticle cathode harvested from a discharged cell and put into a new cell containing the labeled electrolyte composition.

Figure 3.13 demonstrates the effect of attempting this charging process in newly constructed cells. When using an all nitrite electrolyte and clean cathode, the cell polarizes as expected due to the absence of $\mathrm{Li}_{2} \mathrm{O}$. Now consider the other three cells which contain a cathode harvested from another cell that was discharged to $2.3 \mathrm{~V}$, preloading the cells with $\mathrm{Li}_{2} \mathrm{O}$. Note that the cell with a purely nitrate electrolyte also polarizes, because the absence of nitrite disallows the charging reaction. By contrast, the cells with partial or entire nitrite electrolyte and a discharged cathode are able to charge, showing that both $\mathrm{Li}_{2} \mathrm{O}$ and nitrite must be present to allow the 
charging reaction. In addition, note that the charging potential of the all nitrite electrolyte is lower than that of the part nitrate, part nitrite one, in agreement with the discussion of the Nernst potential in this system.

While we have used several techniques to qualitatively confirm the formation of both nitrite and $\mathrm{Li}_{2} \mathrm{O}$ on discharge, a quantitative technique that can be corroborated with electrochemical data would make an even stronger argument that the chemistry described herein is in fact happening. In a similar vein, differential electrochemical mass spectrometry (DEMS) found use in the lithium-oxygen battery field to directly quantify the amount of oxygen consumed and produced, whereas before a simple qualitative confirmation of $\mathrm{Li}_{2} \mathrm{O}_{2}$ was seen as sufficient $[39,43]$. To this end, we use ion exchange chromatography to measure the ratio of nitrate to nitrite anions in the electrolyte. This allows a direct comparison between the electrochemical data and the amount of nitrate and nitrite present in the electrolyte.

Once the process of Figure 3.13 was complete, the battery was again disassembled using the same procedure. All electrolytes of interest were collected and dissolved in $\mathrm{mQ}$ water (very pure water) of known volume. Following a dilution procedure, the ion concentration was in the $10-500 \mu \mathrm{M}$ range which is appropriate for ion exchange chromatography. A Dionex ICS-2000 Ion Chromatography System was used for all experiments, and a calibration procedure for both nitrite and nitrate was performed before each set of samples. See the appendix for a detailed calibration procedure.

Some typical ion exchange chromatography data is shown in Figure 3.14, demonstrating the peak separation for nitrate and nitrite, in addition to the inevitable carbonate impurity due to carbon dioxide in the air. This peak separation is important as the concentration of species in solution is proportional to the area under the curve.

All three of the electrolyte compositions in Figure 3.13 were put through ion exchange chromatography, but the purely nitrite electrolyte is the most revealing. A detailed reasoning for focusing on the all nitrite system is given in the appendix. A ratio of nitrate to nitrite anions was calculated from the measurements, and using the initial mass of electrolyte in the cell, the number of moles of each could be calculated. After accounting for the small impurity amounts found in nitrite, all of the nitrate can be attributed to the charging reaction. Considering this reaction transfers $2 \mathrm{e}^{-} / \mathrm{mol}$ nitrite, we can convert the number of moles of produced nitrate to the equivalent amount of charge passed due to this reaction. From the electro- 


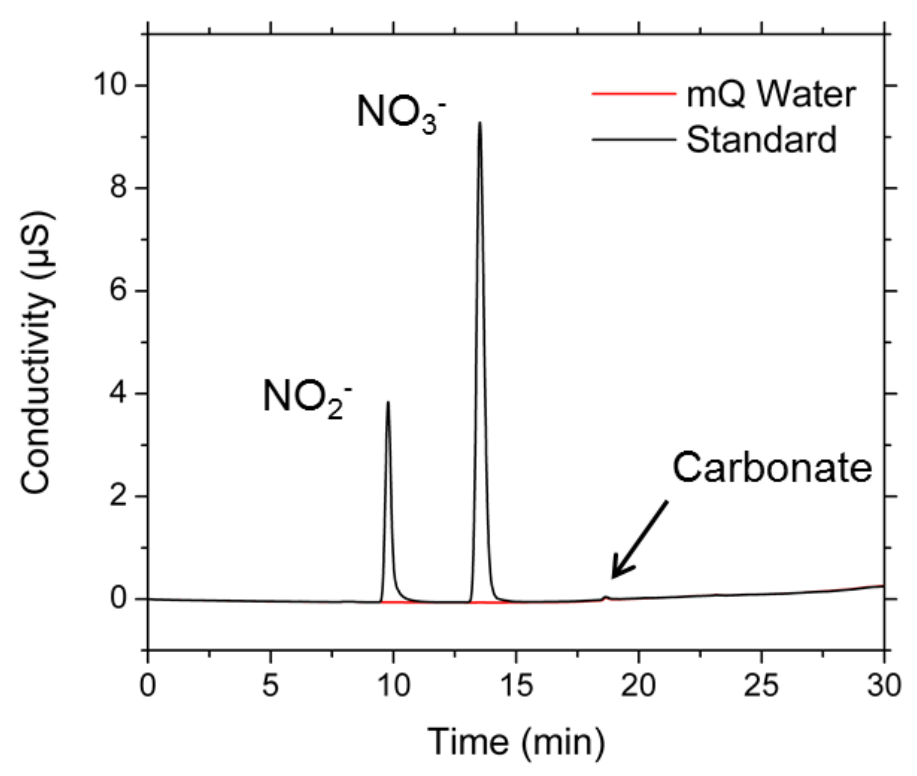

Figure 3.14: Ion exchange chromatography of nitrate/nitrite solution, prepared as a standard for calibration procedures.

chemical data in Figure 3.13, we expect $2 \mathrm{mAh}$ of charge to have been passed, and the ion exchange chromatography data suggest that $2.09 \mathrm{mAh}$ equivalent of nitrate is present in the electrolyte. This suggests that the charge process is in fact the electrochemical reaction described in Equation 3.1.

\subsection{Battery Cycling Performance}

With a good understanding the the chemistry of Equation 3.1 can serve as a secondary battery chemistry, both in the reversibility of nitrite and $\mathrm{Li}_{2} \mathrm{O}$ formation and the role of catalysis afforded by the surface $\mathrm{L}-\mathrm{NiO}$, we can now probe the cycling behavior of the system. In order to study the reversibility of the chemistry and not the ability of the cathode structure to accommodate $\mathrm{Li}_{2} \mathrm{O}$ growth (a subject for Chapter Four), we cycle with a capacity limitation of $1.27 \mathrm{mAh} \mathrm{cm}^{-2}$ on discharge, and to avoid oxygen evolution at higher potentials, we cycle with a potential limitation of $2.75 \mathrm{~V}$ on charge.

Note that the pressure in the head-space of the cell in Figure 3.15 remains constant over the course of 1000 hours of cycling, suggesting that we are not engaging any side reactions with gaseous evolution. In addition, the cycling profile remains unchanged over 100 cycles except for the gradual drop in potential due to accumulating nitrite and the increase in coulombic efficiency as the electrolyte and cathode saturate with nitrite and $\mathrm{Li}_{2} \mathrm{O}$. This is again in agreement with what we would expect 

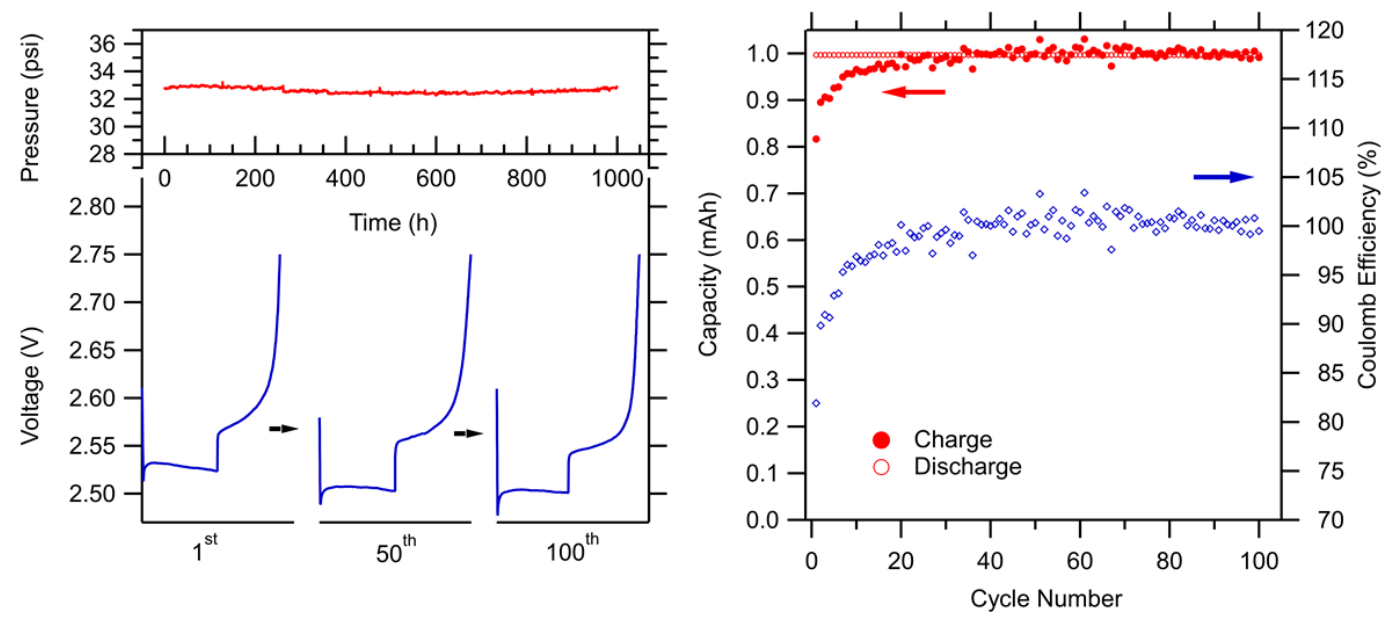

Figure 3.15: Cycling behavior of nitrate reduction battery. Pressure of cell headspace with evolution of cycling profile and discharge/charge capacity with coulombic efficiency for a cell using a nickel nanoparticle cathode $\left(0.26 \mathrm{~mA} \mathrm{~cm}^{-2}, 1.27 \mathrm{mAh}\right.$ $\mathrm{cm}^{-2}$ capacity limitation). Nickel loading of $15 \mathrm{mg} \mathrm{cm}^{-2}$ and nitrate loading of 200 $\mathrm{mg} \mathrm{cm}{ }^{-2}$.

from the Nernstian contribution to the potential. The initially poor coulombic efficiency can be attributed to the diffusion of nitrite away from the cathode and the sparing solubility of $\mathrm{Li}_{2} \mathrm{O}$ in molten nitrate, allowing the discharge product to become electrically disconnected[68]. Although the current design allows only $\sim 10 \%$ nitrate utilization (over $6 \mathrm{mAh} \mathrm{cm}^{-2}$ ), this is a cell engineering problem related to the cathode structure which is addressed in Chapter Four, and not any limitation of the chemistry. While prolonged cycling of this chemistry is hindered by the long term stability of a lithium anode (an issue in most "beyond lithium-ion" chemistries), the cycling stability of the cathodic reaction stands in contrast to similar systems such as the lithium-oxygen battery which is plagued by degrading side reactions[42].

\subsection{Summary}

Through careful characterization of the nitrate reduction reaction described in Equation 3.1, we have demonstrated the ability of a nickel nanoparticle catalyst to enable the reversibility of a previously irreversible system. In doing so, we have created a new, high capacity secondary battery chemistry in which the electrolyte also serves as the active material. In addition, we have shown that it is the surface oxide layer, $\mathrm{L}-\mathrm{NiO}$, which is responsible for the catalytic activity. Having described the catalytic behavior of nickel nanoparticles, we explicitly confirmed the reversible growth and dissolution of crystalline $\mathrm{Li}_{2} \mathrm{O}$, and we observed that this $\mathrm{Li}_{2} \mathrm{O}$ grows according to 
its equilibrium Wulff construction. We also quantitatively confirmed the reversible formation of nitrite in the electrolyte. Finally, we validated this reversibility by cycling the battery over the course of 1000 hours, achieving a steady coulombic efficiency fluctuating around $100 \%$. The lack of an obvious degradation mechanism on the cathode side suggests that this chemistry should be able to cycle for far longer, but the limitation of uncontrolled SEI growth on the lithium anode makes such an experiment untenable. The development of a protected lithium anode is key to enabling this and many other "beyond lithium-ion" systems. While the utilization of active material was quite low, Chapter Four will address the capacity limitations of this system and possible means of alleviating them. 
Chapter 4

\title{
ROLE OF CATHODE ARCHITECTURE IN CONVERSION REACTION CHEMISTRIES
}

\author{
Adapted from \\ 1. Tozier, D., Giordani, V., Chase, G. V., Addison, D. \& Greer, J. R. The Role of \\ Battery Cathode Architecture in Conversion Reaction Chemistries. (In Prepa- \\ ration).
}

\section{Chapter Abstract}

The previous two chapters have investigated the use of cathodes which employ the growth of lithium-rich phases. Using the growth of $\mathrm{Li}_{2} \mathrm{O}$ through nitrate reduction as a model system, we address the effect of cathode geometry on the electrochemical performance of such a battery chemistry. In particular, we note that the growth of such large, solid phase species on the surface of the catalyst support imposes new design restrictions when optimizing a cathode for energy density. For instance, it is not just the surface area of the catalyst support that determines the discharge capacity, but also the amount of usable pore volume which can accommodate this solid phase discharge product. As a proof of concept, we design and implement an architected electrode with large pore volume and relatively small surface area, comparing it with the more typical electrode geometries of thin films and nanoparticles. Finally, we directly vary the pore volume of an electrode, noting the implications these structural changes will have on a battery's energy density. 


\subsection{Capacity Limitations}

Chapters Two and Three discussed the reversibility of battery chemistries which employ growth and dissolution of a new phase that serves as the lithium host in a battery's cathode. In addition, the growth mechanism of these phases, $\mathrm{Li}_{2} \mathrm{O}_{2}$ and $\mathrm{Li}_{2} \mathrm{O}$, were explored, and both of these molten salt systems saw the growth of large, several micron crystals which must be formed each battery cycle. These types of chemistries attracted the attention of researchers due to their potentially large discharge capacities.

\section{Defining Capacity in Phase Forming Chemistries}

In the case of an intercalation cathode such as the ones described in the Introduction Chapter, it is easy to define the capacity of the cathode in terms of the mass of active material. For example, the stoichiometric ratio of lithium in $\mathrm{LiCO}_{2}$ along with the fraction of lithium which can be reversibly removed from the crystal structure gives a well defined theoretical capacity of $164 \mathrm{mAh} \mathrm{g}^{-1}$ as shown in Table 1.1. Then for a given mass loading of active material, a well controlled value when assembling a battery, the expected capacity is easily calculated, and the actual capacity can be normalized to this known weight of active material, giving a clear comparison between ideal and real capacity.

This procedure is far less straightforward in a system which does not use an intercalation mechanism for lithium storage. For instance, consider the lithium-oxygen system. As is often imagined for such a battery (quite impractically, but it makes for a good thought experiment), the active material, oxygen, is taken from the atmosphere. This means that a lithium-oxygen battery has an infinite reservoir of active material as its cathode. Clearly one cannot normalize the capacity of such a battery by an infinite amount of oxygen. This raises the question of what value is a reasonable one to normalize by so that battery capacities can be readily compared and still have meaning.

As a result of this issue, the typical approach for normalizing battery capacity in lithium-oxygen cells is to use the mass of the cathode catalyst support material. In the case of the molten salt lithium-oxygen battery of Chapter Two, this corresponded to the mass of Super $\mathrm{P}$ carbon that was then pressed onto the mesh current collector. However, such an approach can lead to confusion and misleading reported capacities. For instance, if a very small amount of cathode catalyst material, say on the order of $\mu \mathrm{g}$, is used in conjunction with a relatively large surface area current collector, one 
can achieve outrageous normalized capacity values which begin to lose meaning[78]. When replacing this mass normalization with a geometric footprint normalization, the true cell level capacity is revealed and often insignificant compared to realistic values found in traditional lithium-ion cells. But normalizing by the footprint area gives little information about the material performance of the system, a metric which we are after.

The real question then is what is it that determines the capacity of such a battery. Why were the lithium-oxygen batteries of Chapter Two generally limited to 1400 mAh

$\mathrm{g}_{\text {carbon }}{ }^{-1}$ for $\sim 4 \mathrm{mg} \mathrm{cm}^{-2}$ carbon loading? In addition, why were the nitrate reduction batteries of Chapter Three limited to 5-10\% utilization of active material (nitrate in the electrolyte)? When normalizing similarly to the lithium-oxygen system, this utilization corresponded to $\sim 800 \mathrm{mAh} \mathrm{gnickel}^{-1}$ for $\sim 5 \mathrm{mg} \mathrm{cm}^{-2}$ nickel loading. To further complicate things, these normalized capacities are not constant for varying mass loadings of the cathode catalyst material, suggesting some property other than mass is responsible for determining the observed capacity.

Consider the mechanism of charge storage in these types of batteries. A solid phase which is electronically insulating is growing on the surface of this cathode catalyst support material. Then having more surface to accommodate this growth should result in a larger capacity, and one would expect the capacity to scale with the "true" or electrochemical surface area of the electrode. The electrochemical surface area corresponds to the total surface area of the electrode able to make contact with the electrolyte and participate electrochemically. This surface area has been used as a normalization scheme in some reports in literature[26], and it seems to get at the material performance of the cathode despite being a difficult value to compare with other types of battery chemistries.

\section{Cathode Structure and Capacity}

While the electrochemical surface area appears to be a clean way to anticipate the capacity for such a battery chemistry, the system is not quite that simple. To demonstrate this, consider the case of nitrate reduction where the cathode catalyst is a bed of pressed nickel nanoparticles, just as in Chapter Three. By assuming a packing density of nickel nanoparticles (here taken to be 60\%, the packing factor for randomly dispersed, pressed spheres[79]), we can calculate an upper bound on the expected capacity for nitrate reduction by taking all of the pore space between the nickel nanoparticles were filled with $\mathrm{Li}_{2} \mathrm{O}$. Equation 4.1 gives the simple series 
of unit conversions needed to arrive at this capacity, as normalized by the mass of nickel.

$$
\begin{aligned}
& \left(\frac{1 \mathrm{~cm}^{3} \mathrm{Ni}}{8.91 \mathrm{~g} \mathrm{Ni}}\right)\left(\frac{0.40 \mathrm{~cm}^{3} \text { void }}{0.60 \mathrm{~cm}^{3} \mathrm{Ni}}\right)\left(\frac{1 \mathrm{~cm}^{3} \mathrm{Li}_{2} \mathrm{O}}{1 \mathrm{~cm}^{3} \text { void }}\right)\left(\frac{2.01 \mathrm{~g} \mathrm{Li}{ }_{2} \mathrm{O}}{1 \mathrm{~cm}^{3} \mathrm{Li}_{2} \mathrm{O}}\right) \\
& \cdot\left(\frac{1 \mathrm{~mol} \mathrm{Li}{ }_{2} \mathrm{O}}{29.9 \mathrm{~g} \mathrm{Li} \mathrm{i}_{2} \mathrm{O}}\right)\left(\frac{2 \mathrm{~mol} \mathrm{e}^{-}}{1 \mathrm{~mol} \mathrm{Li} \mathrm{i}_{2} \mathrm{O}}\right)\left(\frac{96485 \mathrm{C}}{1 \mathrm{~mol} \mathrm{e}^{-}}\right)\left(\frac{1 \mathrm{mAh}}{3.6 \mathrm{C}}\right)=270 \frac{\mathrm{mAh}}{\mathrm{g}_{\mathrm{Ni}}}
\end{aligned}
$$

This simple calculation gives an upper bound on capacity significantly lower than what is measured experimentally, even when accounting for the sparing solubility of $\mathrm{Li}_{2} \mathrm{O}$ in solution. A similar analysis can be performed for the lithium-oxygen system with similar results. In order to address this apparent paradox, it is worthwhile to consider the state of a fully discharged cathode. Figure 4.1 contains SEM images of fully discharged cathodes from both the lithium-oxygen and nitrate reduction systems of Chapters Two and Three.
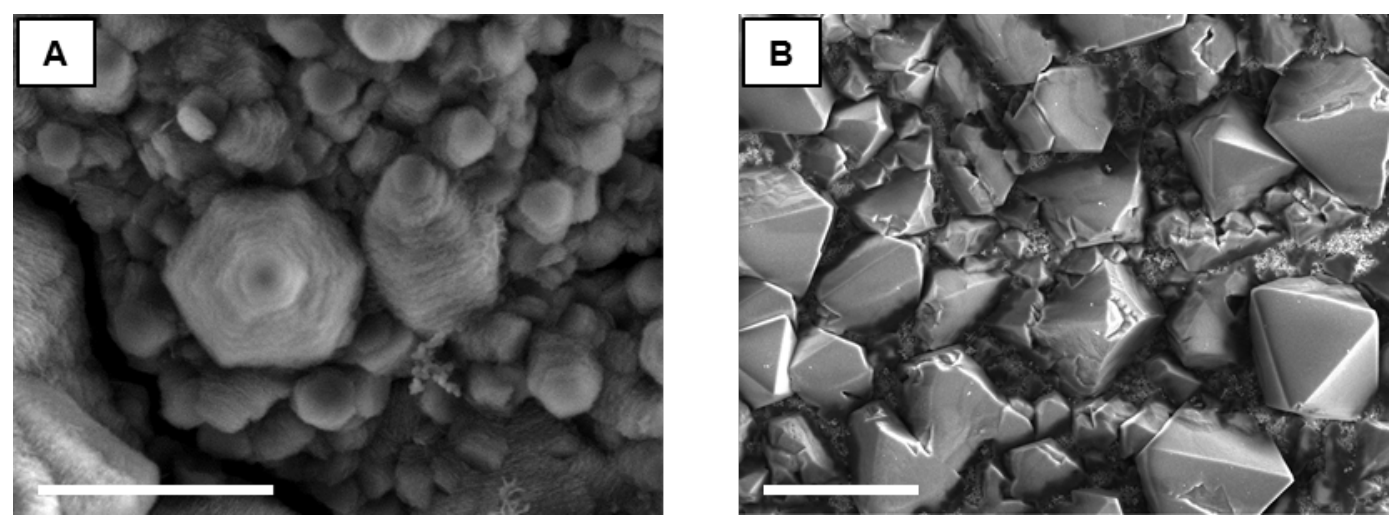

Figure 4.1: Surface of fully discharge cathodes. (A) $\mathrm{Li}_{2} \mathrm{O}_{2}$ and (B) $\mathrm{Li}_{2} \mathrm{O}$ fully covering the surface of the cathode after a full discharge (scale bar: 2 and $10 \mu \mathrm{m}$, respectively).

Note that the surfaces of these cathodes are fully covered with the discharge product of their respective systems. In particular, these particles which are several microns in size are growing on top of the bed of pressed nanoparticles, not within it. Based on a similar calculation as the one in Equation 4.1, the majority of the capacity of these cathodes is a result of this discharge product growing out of the bed of nanoparticles, and not the product growing within the pore space. As a result, all the surface area of the cathode catalyst nanoparticles within the pressed bed is essentially wasted, and the capacity of the battery cathode will not scale with its electrochemical surface area. 
This makes for a system vastly different than a traditional battery chemistry. Whereas in the typical intercalation system the capacity is directly proportional to the mass of active material, in these phase forming chemistries the capacity is determined by the ability of the "useful" electrochemical surface area to accommodate the growth of the discharge product. This means that not only will the cathode's surface area play a role in determining capacity, but its structure will too, and this is a much harder thing to quantify.

While there is no cleanly defined material property which can be used to predict the capacity of such a battery, the previous discussion is useful in elucidating which attributes a cathode should have to enable a large capacity. The cathode should have a large amount of surface that is exposed to open pore volume which can accommodate the growth of discharge product. Figure 4.2 gives two examples of structured electrodes with relatively large pore structures, and inverse opals have been used in the past to study battery electrode properties[80].
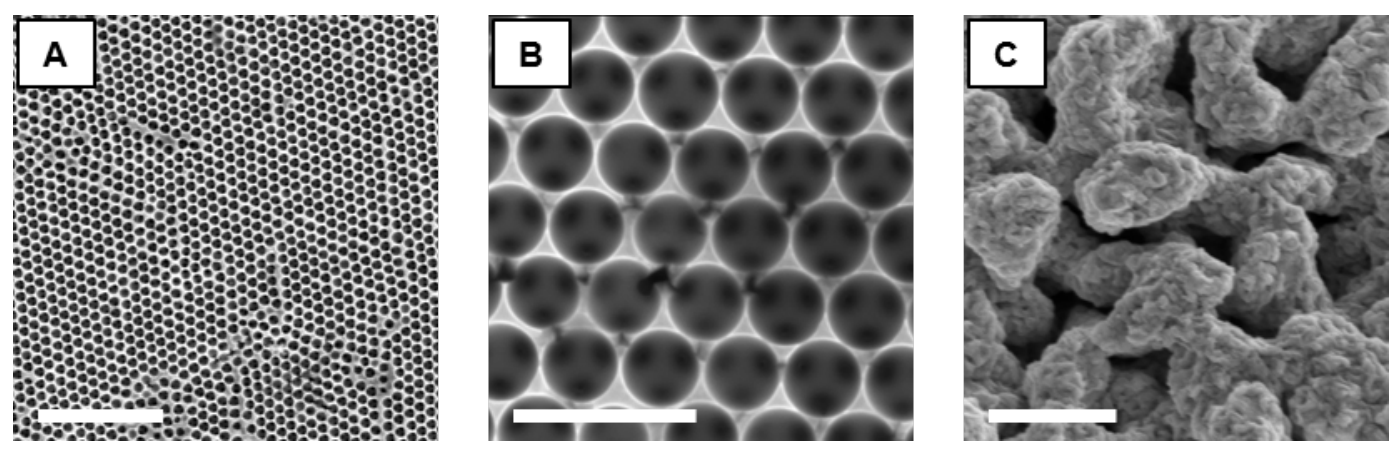

Figure 4.2: Example structured nickel electrodes. (A,B) Nickel inverse opal, fabricated by electroplating nickel into the pores of settled $500 \mathrm{~nm}$ polymer particles, which were then etched away (scale bar: 5 and $1 \mu \mathrm{m}$, respectively). (C) Nickel nanoparticles sintered in a hydrogen environment at $500{ }^{\circ} \mathrm{C}$ (scale bar: $1 \mu \mathrm{m}$ ).

However, for the case of nitrate reduction, which we will use as a model system in this chapter, the discharge product morphology of $\mathrm{Li}_{2} \mathrm{O}$ is often on the order of $10 \mu \mathrm{m}$ in size, far too large for these two structures to accommodate. The pore size of these structures are limited by their fabrication methodology, making them inappropriate to study this system. The following section will discuss the fabrication of an electrode with explicit control over pore structure in the size regime we care about.

This chapter will study the interplay between electrochemical surface area and pore structure, and their effect on the discharge capacity of a nitrate reduction cathode. 
In particular, we will approach this problem from two directions: first we will design and fabricate an architected electrode with large pore volume and small electrochemical surface area and see the effect on capacity, comparing against thin film and nanoparticle morphologies; second we will compare two electrodes with identical surface area but different pore volume, noting the effects on capacity and the implications for battery energy density. Many of the conclusions drawn throughout this chapter can be applied to other similar chemistries such as lithium-oxygen or lithium-sulfur batteries.

\subsection{Fabrication of Architected Electrodes}

The previous section discussed the possible interplay of electrochemical surface area and pore structure on the capacity of a nitrate reduction cathode (and by extension other phase forming conversion chemistries such as lithium-oxygen and lithiumsulfur). In order to study this relation, it would be instructive to design an electrode where all of the electrochemical surface area is "useful," in that the pore structure cannot become clogged and render parts of the electrode inactive. The electrode designs of Figure 4.2 point in the right direction, but better control and larger pore sizes are desired. In particular, being able to accommodate the growth of crystals $10 \mu \mathrm{m}$ in size would be required.

Lattice trusses are a class of structures which have been in use for centuries due to their superior mechanical properties. Recent work in small scale fabrication has allowed the miniaturization of these structures and led to remarkable mechanical phenomena at the micro- and nano-scale[81-83]. This class of structures, if made on the appropriate length scale, fulfill the requirements of an open pore cathode described above, namely explicit control over structure and pore geometry. In addition, lattice trusses display impressive mechanical properties which should lead to a more mechanically resilient electrode. Due to the complexities of assembly described later, this is beneficial for this molten salt system compared to other potential structured electrodes.

Based on the criteria described above, a lattice with openings larger than $20 \mu \mathrm{m}$ is desired so that a film thickness of $10 \mu \mathrm{m}$ would not close off the pore network. When taking into account the beam thickness such a structure would have, but still wanting to keep the structure as small as possible to allow a reasonable electrode thickness, a unit cell of $30 \mu \mathrm{m}$ is used. Figure 4.3 shows a computer rendered model of such a lattice, with beam dimensions shown that are a result of the fabrication process 


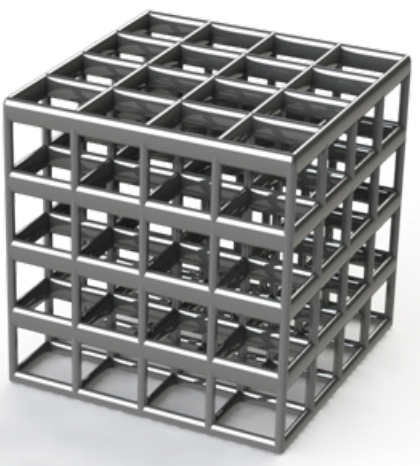

Figure 4.3: Model of lattice electrode unit, made using SOLIDWORKS. Unit cell: $30 \mu \mathrm{m}$; vertical beams: $4 \mu \mathrm{m}$ diameter; horizontal beams: $4 \times 10 \mu \mathrm{m}$ ellipse.

described shortly. A simple cubic lattice is chosen for its open pore structure and ease of fabrication. The result is a $120 \mu$ m thick electrode made of $4 \times 4 \times 4$ unit cell components which can be tiled in a plane to make a macroscopic electrode.

\section{Nanoscribe Fabrication of Polymer Scaffold}

In order to create such a lattice truss structure, we employ an instrument called Nanoscribe which allows the fabrication of a polymer scaffold. This instrument has been used to make many small scale structures for a variety of uses[83-86], and a brief overview of its operation is provided here.

Nanoscribe employs a process called two-photon direct laser write lithography to perform additive manufacturing of polymers on a small scale. Two-photon lithography is a lithography process in which a photoresist is polymerized by a laser of photons with half the energy needed for the polymerization reaction to occur (i.e. twice the wavelength of light that would be used in a normal lithography process). This laser is focused to a small volume, or voxel, such that the probability of two photons interacting with the same molecule is high enough that the polymerization process takes place. This voxel is then rastered in space, allowing the direct writing of polymer throughout the photoresist. In the case of the Nanoscribe system, this corresponds to a $780 \mathrm{~nm}$ femtosecond pulsed laser, and the resist of choice is the proprietary IP-S due to its large interaction volume, giving a faster write time at the sacrifice of resolution. A detailed description of the writing procedure and its optimization for the model of Figure 4.3 is given in the appendix.

Once this structure has been written in the photoresist, it is developed in propylene 
glycol methyl ether acetate (PGMEA) to remove the remaining photoresist, cleaned in isopropyl alcohol (IPA), and then dried with a critical point dryer to prevent surface tension from destroying the structure.
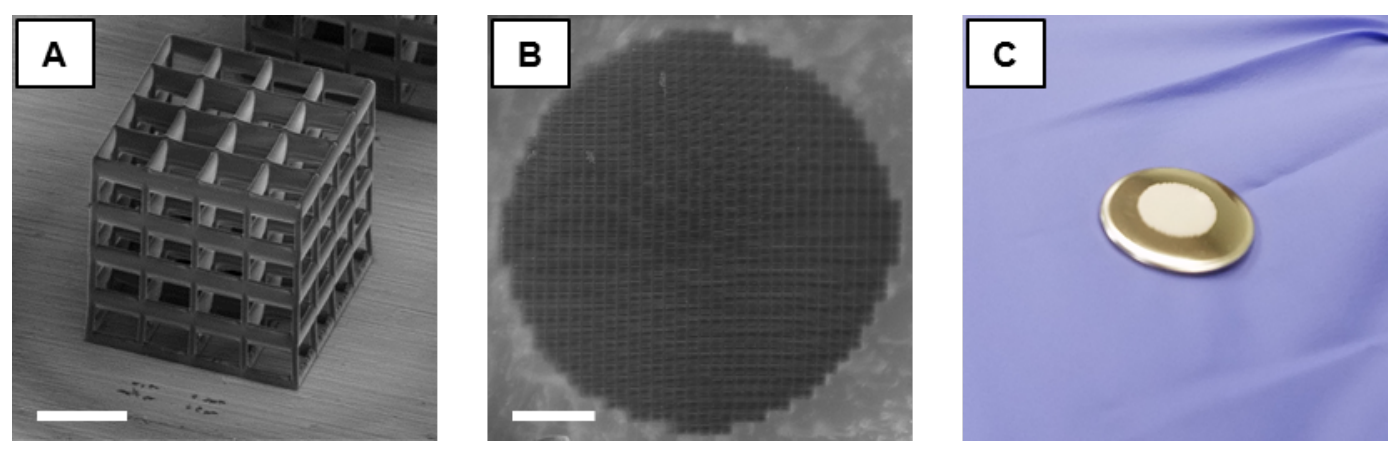

Figure 4.4: Fabrication of polymer lattice, as made with Nanoscribe. (A) Individual lattice unit (scale bar: $50 \mu \mathrm{m}$ ). (B) Tiling of 880 of the lattice units from 'A' (scale bar: $1 \mathrm{~mm}$ ). (C) Phone camera picture of tiled polymer lattices in 'B' (scale: metal disc is $1 \mathrm{~cm}$ in diameter).

The result of this Nanoscribe fabrication is the replication of the model of Figure 4.3 as a polymer scaffold in Figure 4.4a. This unit, a $120 \mu \mathrm{m}$ cube, can then be tiled across a substrate to form a macroscopic electrode $5 \mathrm{~mm}$ in diameter as in Figure $4.4 \mathrm{~b}$, a process which takes 20 hours of write time (see appendix for write time optimization of what would have originally taken 1-2 weeks). The picture in Figure $4.4 \mathrm{c}$ demonstrates the macroscopic nature of the electrode, as well as showing the 1 $\mathrm{cm}$ polished stainless steel disc that is used as a substrate.

\section{Sputtering a Nickel Coating}

With a polymer scaffold of the desired geometry in hand, we now must coat it with a conductive material so that it may serve as an electrode. Before coating the electrode though, the substrate must be cleaned. Note the splotchy film surrounding the lattice array in Figure 4.4b. This remnant photoresist will cause any deposited film to easily peel off, as is happening to the nickel film of Figure 4.5a. This residue seems to be a result of writing the structure on a polished metal substrate (to serve as a current collector) as opposed to the traditional glass or silicon substrate used in most Nanoscribe fabrications. In order to clean the stainless steel substrate, many techniques were attempted (such as oxygen plasma cleaning among many others) with little success. In the end, simplicity prevailed, and a sharpened wooden dowel dipped in acetone and IPA was used to manually clean the area around the lattice array, with the aid of an optical microscope. This method, while tedious, proved 
surprisingly effective while maintaining the integrity of the polymer scaffold.

With the polymer scaffold made and the substrate clean enough to have a film adhere, a sputtered film was used to coat the lattice and substrate. Sputtering has been used in the past to coat smaller lattices $[85,86]$, and as long as the structure is open enough, the film can effectively cover the polymer and function as an electrode. In the case of nitrate reduction, this is best served by a nickel coating as detailed in Chapter Three. Sputtering was performed with a magnetron sputter deposition system from ATC Orion sputtering system, AJA International, Inc. with base pressure below $10^{-6}$ Torr. First, a thin $(5-10 \mathrm{~nm})$ chromium layer was deposited to encourage adhesion, using a DC power supply at $100 \mathrm{~W}$ under 3 mTorr argon for five minutes. Following this, a roughly $500 \mathrm{~nm}$ (as measured on the substrate) nickel layer was deposited, using a DC power supply at $100 \mathrm{~W}$ under 5 mTorr argon for 1.5 hours.
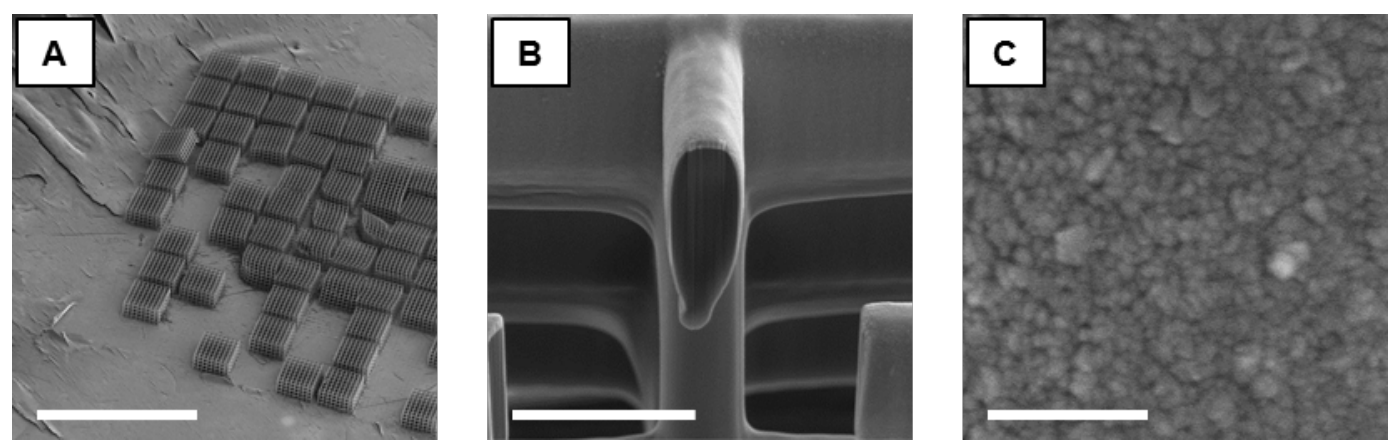

Figure 4.5: Sputtered nickel film coating a polymer lattice. (A) Nickel film peeling off substrate holding remains of an old lattice design iteration (scale bar: $1 \mathrm{~mm}$ ). (B) FIB cross-section of internal lattice beam with sputtered nickel film coating (scale bar: $10 \mu \mathrm{m}$ ). (C) High resolution SEM micrograph showing the roughness of the sputtered nickel surface (scale bar: $200 \mathrm{~nm}$ ).

A FIB cross-section of an internal beam of the nickel coated lattice is shown in Figure 4.5b. Note that while the nickel film is not as thick as it is when deposited on the substrate, the beam is still fully covered with nickel, at an average thickness of $\sim 250 \mathrm{~nm}$. A high resolution SEM micrograph of the nickel film is shown in Figure $4.5 \mathrm{c}$, demonstrating its surface roughness. This surface roughness will play a role in determining the observed reaction kinetics, and its magnitude will be explored in the next section.

Through this series of fabrication steps, we have made a macroscopic nickel electrode with explicitly controlled geometry, and the final electrode is shown in Figure 4.6. An identical stainless steel disc without a polymer scaffold was put in the sputtering 

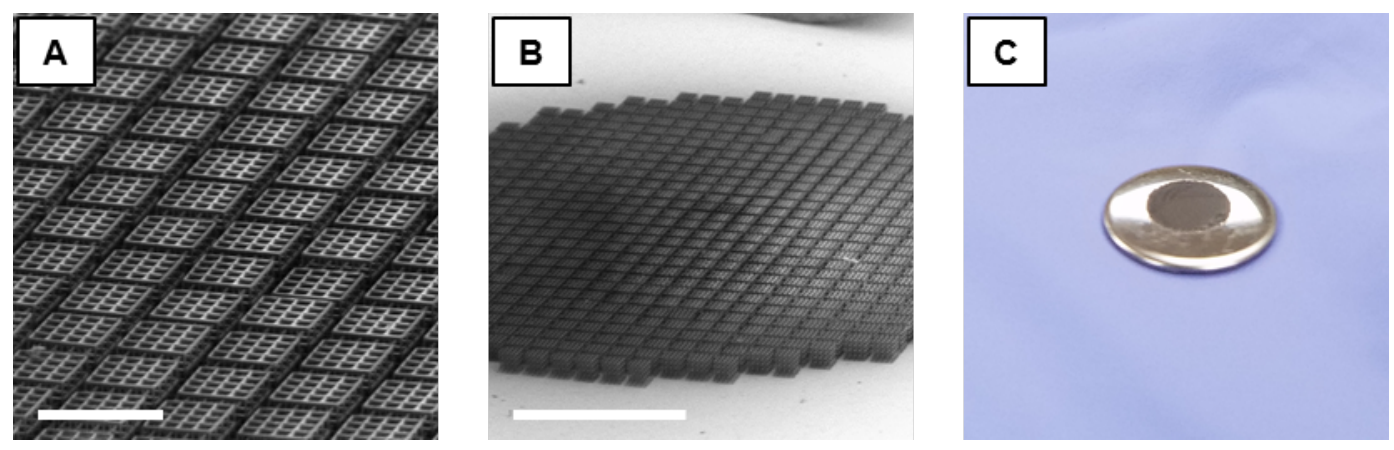

Figure 4.6: Nickel lattice electrode. (A,B) SEM micrographs of final iteration of tiled nickel-coated lattices (scale bar: $200 \mu \mathrm{m}$ and $1 \mathrm{~mm}$, respectively). (C) Phone camera picture of similar lattice electrode as those in 'A' and 'B' (scale: metal disc is $1 \mathrm{~cm}$ in diameter).

chamber at the same time as the lattice array, providing a thin film electrode with the same nickel surface morphology to serve as a control, such that the effect of electrode geometry could be easily observed.

\subsection{Electrochemical Surface Area of Nickel Electrodes}

Before using this lattice truss array as a nitrate reduction cathode, it is important to know its electrochemical surface area so that we can easily compare normalized capacities across electrode geometries. There are two aspects of this cathode which will affect the surface area: the micron-scale structural features imposed by design, and the nano-scale features imposed by the roughness of the sputtered nickel film. Brunauer-Emmett-Teller (BET) analysis is a common technique to measure the surface area of nano-scale materials, but the pores in this lattice structure are too large and the surface area too small for that method to be used here. Instead, we turn to a recently developed electrochemical method which takes advantage of the surface states of nickel.

\section{Surface Chemistry of Nickel}

The behavior of a polished nickel electrode in an alkaline solution over a wide potential range is shown by CV in Figure 4.7, as performed in [87]. The electrode was polished just before performing electrochemistry in order to remove as much of the native oxide layer as possible. During the beginning of the scan at $-1.2 \mathrm{~V}$, the hydrogen evolution reaction (HER) is taking place. As the potential increases, the first oxidation peak around $-0.7 \mathrm{~V}$ indicates the formation of nickel hydroxide $\left(\mathrm{Ni}(\mathrm{OH})_{2}\right)$. Moving higher in potential, a further oxidation occurs as nickel hy- 


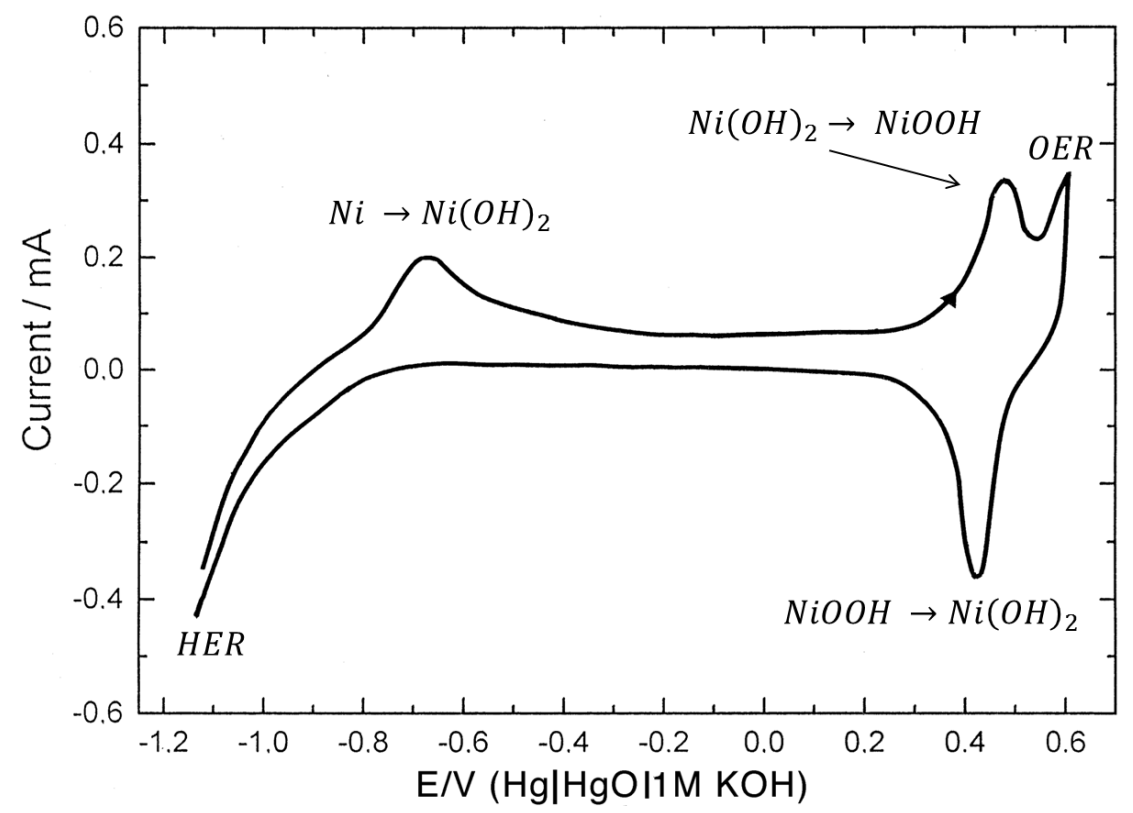

Figure 4.7: Surface electrochemistry of nickel, in an alkaline solution. Adapted from [87].

droxide becomes nickel oxyhydroxide $(\mathrm{NiOOH})$ around $0.5 \mathrm{~V}$, and finally OER. Reversing the scan, $\mathrm{NiOOH}$ reduces to $\mathrm{Ni}(\mathrm{OH})_{2}$. Interestingly, this reversible redox process drives the reaction at the positive electrode in both the nickel-cadmium and nickel metal hydride batteries. Moving further down in potential gets back to HER, notably not fully reversing the formation of $\mathrm{Ni}(\mathrm{OH})_{2}$.

In recent years, several groups have developed techniques to measure the surface area of nickel using electrochemical methods. In particular, there are two approaches using the redox process described above which involve integrating the peak for either the oxidation of nickel to $\mathrm{Ni}(\mathrm{OH})_{2}[88,89]$ or the reduction of $\mathrm{NiOOH}$ to $\mathrm{Ni}(\mathrm{OH})_{2}[90$, 91]. In this work, we will use the latter hydroxide/oxyhydroxide redox process method, described in detail shortly. Both of these techniques require removing any native oxide layer before doing any electrochemistry, and many different approaches have been used. For planar electrodes, polishing is the preferred method, but this would not work for structured electrodes for obvious reasons. For structured electrodes, the two common approaches involve holding at the potential for HER in hopes that the hydrogen will reduce the nickel surface or quickly etching the nickel surface with an acid. We will use the latter method as we found that holding at the potential for HER did not sufficiently clean the nickel surface.

In order to use the reduction of $\mathrm{NiOOH}$ to measure the surface area of a nickel 
electrode, we need to know a few things. First, we must know the ratio of charge passed to electrode surface area. This has been calculated by considering the crystal structure of the preferred orientation of $\mathrm{Ni}(\mathrm{OH})_{2}$, giving a value of $195 \mu \mathrm{C}$ $\mathrm{cm}^{-2}[90]$. Second, we must be confident that the redox processes are limited to a single monolayer of nickel. It has been shown that using an adsorbed oxalate anion $\left(\mathrm{C}_{2} \mathrm{O}_{4}{ }^{2-}\right)$ will limit the $\mathrm{Ni}(\mathrm{OH})_{2}$ layer to a single monolayer during the first scan when performed at a high scan rate[90, 91]. Finally, as already discussed the initial surface must be cleaned of a native oxide layer, which can be achieved through an acid bath.

\section{Surface Area of Film and Lattice Electrodes}

The process described in this section was first tested on commercial nickel foams, and the values were in agreement with what was expected from literature. In order to clean the nickel electrode before measuring its surface area, we briefly etch it with an acid bath. The composition of the acid bath is shown in Table 4.1, and it was found to be the best acid solution of several tested ones based on its etching rate and selectivity for nickel[88].

\begin{tabular}{ll}
\hline $\begin{array}{l}\text { Acid bath } \\
\text { component }\end{array}$ & $\begin{array}{l}\text { Solution } \\
\text { composition } \\
\text { (vol \%) }\end{array}$ \\
\hline $\begin{array}{l}\text { Acetic Acid } \\
\left(\mathrm{CH}_{3} \mathrm{COOH}\right)\end{array}$ & 50 \\
$\begin{array}{l}\text { Nitric Acid } \\
\left(\mathrm{HNO}_{3}\right)\end{array}$ & 30 \\
$\begin{array}{l}\mathrm{Phosphoric} \mathrm{Acid}_{\left(\mathrm{H}_{3} \mathrm{PO}_{4}\right)} \\
\begin{array}{l}\mathrm{Sulfuric} \text { Acid } \\
\left(\mathrm{H}_{2} \mathrm{SO}_{4}\right)\end{array}\end{array}$ & 10 \\
\hline
\end{tabular}

Table 4.1: Acid bath for nickel surface cleaning.

It is important that the acid bath be prepared before each etching session as the bath ages fairly quickly. The nickel electrode was held in the bath for 120 seconds before being quickly neutralized in a large bath of deionized (DI) water and finally put into to the electrolyte for a CV similar to Figure 4.7.

All CVs were performed in a stirred aqueous electrolyte with $0.3 \mathrm{M}$ potassium hydroxide $(\mathrm{KOH})$ and $0.1 \mathrm{M}$ oxalic acid $\left(\mathrm{H}_{2} \mathrm{C}_{2} \mathrm{O}_{4}\right)$. Due to reaction of these species, the resulting electrolyte was $0.1 \mathrm{M} \mathrm{KOH}$ with $0.1 \mathrm{M}$ potassium oxalate $\left(\mathrm{K}_{2} \mathrm{C}_{2} \mathrm{O}_{4}\right)$. 
The counter electrode was a platinum coated mesh and the reference electrode $\mathrm{Hg} / \mathrm{HgO}$.

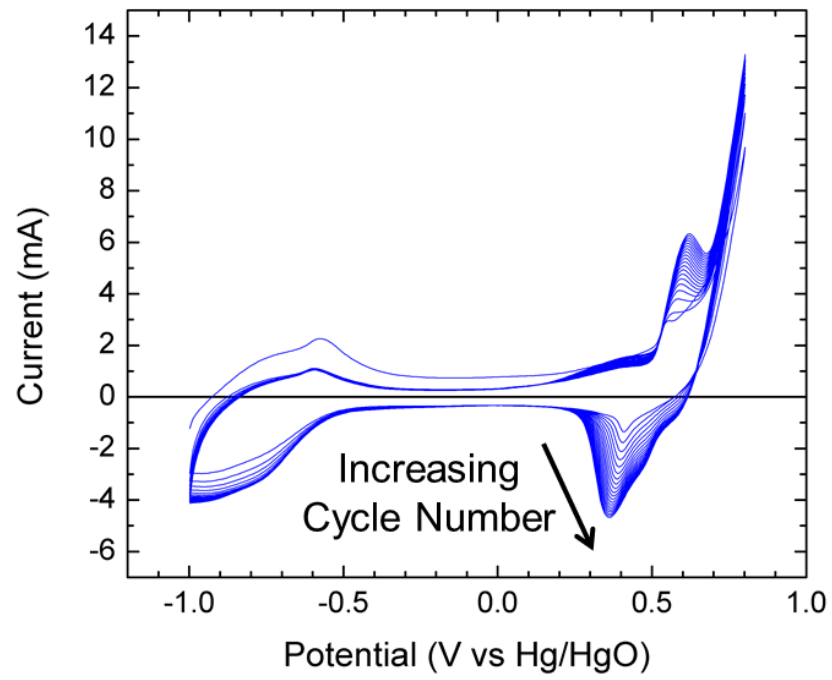

Figure 4.8: Electrochemical surface area of sputtered nickel, by CV in a $0.1 \mathrm{M} \mathrm{KOH}$ and $0.1 \mathrm{M} \mathrm{K}_{2} \mathrm{C}_{2} \mathrm{O}_{4}$ electrolyte with a platinum counter electrode. Scan rate: 150 $\mathrm{mV} \mathrm{s}^{-1}$.

Figure 4.8 shows CVs of a sputtered nickel thin film working electrode which was etched with the acid bath previously discussed. First, note that the peaks for both $\mathrm{Ni}(\mathrm{OH})_{2}$ oxidation and $\mathrm{NiOOH}$ reduction grow with each cycle, suggesting that the cycles following the first one engage more that just a monolayer. By integrating the first scan's $\mathrm{NiOOH}$ reduction peak and then calculating the electrochemical surface area of nickel, we find a surface area of $1.6 \mathrm{~cm}^{2}$. When integrating the peak, a CV from a stainless steel disc was used as a background which was subtracted from the integration, leaving just the peak area. To get a sense of the surface roughness of the film, normalizing the electrochemical surface area value by the geometric area of the electrode (a $1 \mathrm{~cm}$ disc), we find a surface area enhancement factor of 2.0.

Now that we have an understanding of the roughness of the sputtered nickel film, we can look at the lattice electrode of Figure 4.6. In order to use this lattice electrode, it is necessary to make sure that it can be wet. This is surprisingly non-trivial, and a thorough discussion of lattice wetting is given in the appendix. In short, lattices are kept in DI water overnight, and before use are checked for bubbles in an optical microscope.

Confident that the nickel lattice can be fully wet, we put it through the same procedure used on the nickel thin film. Unfortunately, the lattice electrodes did not survive 
the acid bath used for cleaning the nickel surface, so a slightly different approach was used. Instead of explicitly calculating the surface area of the electrode by first removing the surface oxide layer, the $\mathrm{CVs}$ were performed on the untreated sputtered nickel. By comparing a lattice electrode and thin film electrode, the ratio of their surface areas can be calculated since the nickel surface states are the same.

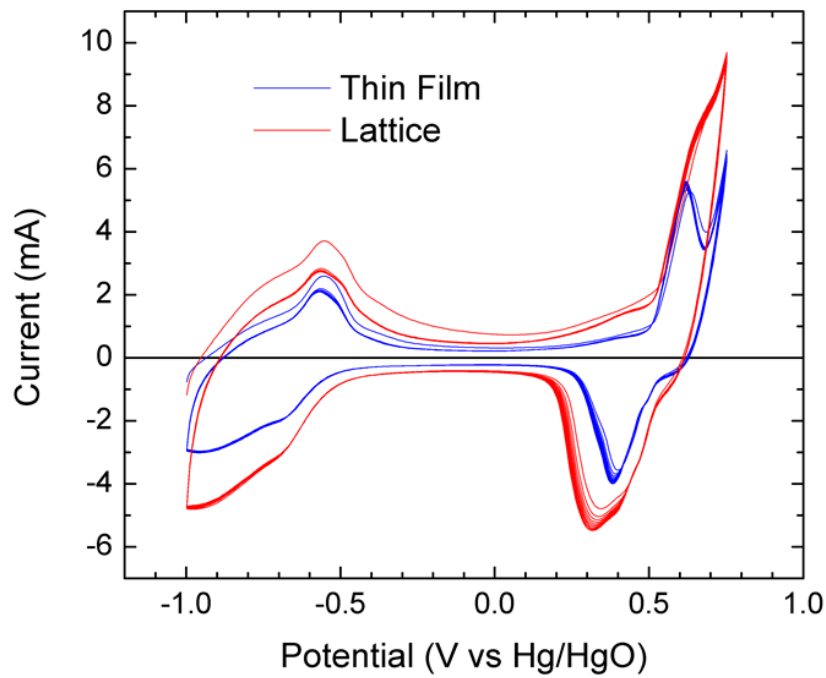

Figure 4.9: Electrochemical surface area of lattice electrode, by $\mathrm{CV}$ in a $0.1 \mathrm{M} \mathrm{KOH}$ and $0.1 \mathrm{M} \mathrm{K}_{2} \mathrm{C}_{2} \mathrm{O}_{4}$ electrolyte with a platinum counter electrode. Scan rate: 150 $\mathrm{mV} \mathrm{s}^{-1}$.

CVs of both the nickel thin film and lattice electrodes are shown in Figure 4.9. Note that since the surface is untreated, the difference in peak size across each scan is significantly smaller. While the actual value of the surface area can not be calculated here, the ratio of $\mathrm{NiOOH}$ reduction peak areas gives a value of 2.1. The calculated value from the SOLIDWORKS model of Figure 4.3 gives an expected ratio of 2.5. When taking into account the presence of a small amount of bubbles in the lattice electrode after performing CVs (likely due to HER and OER processes), the discrepancy makes sense. Then we can be confident in the surface area ratio of 2.5 from the model, and using the surface area enhancement factor of the sputtered nickel thin film, we know the electrochemical surface area of both the nickel thin film and lattice electrodes. When attempting this process on nickel nanoparticles, the surface area is far too large, and a meaningful value can not be calculated. Instead, when normalizing by surface area the BET measurements mentioned in Chapter Three are used. 


\subsection{Performance of Architected Electrodes}

Now that the nickel thin film and lattice electrodes are well characterized, we can use them as cathodes for nitrate reduction, comparing them to the nickel nanoparticle electrode. A combination of $\mathrm{CV}$ and galvanostatic discharge are used to this end. As before, these experiments were performed in the same Swagelok cells used in Chapter Two. Nanoparticle cathodes consisted of $\sim 6 \mathrm{mg} \mathrm{cm}^{-2}$ of nickel nanoparticles pressed onto a stainless steel mesh without the use of binder. Lattice cathodes were first wet with a $100 \mathrm{~g} \mathrm{~L}^{-1} \mathrm{LiNO}_{3}-\mathrm{KNO}_{3}$ in water solution by being immersed and then briefly put in a vacuum chamber until all bubbles left the electrode. It was then dried on a hotplate and finally overnight in a vacuum oven, impregnating the electrode with salt so that it more easily wets when coming in contact with the electrolyte. A detailed description of lattice wetting is given in the appendix. A glass microfiber separator was impregnated with about $200 \mathrm{mg}$ of $\mathrm{LiNO}_{3}-\mathrm{KNO}_{3}$ molten salt electrolyte, and vacuum dried overnight at $200^{\circ} \mathrm{C}$. Anodes were a simple lithium foil. All assembly took place in a glovebox, then the cells were filled with argon after a leak test, and finally placed in an oven to be held at the $150{ }^{\circ} \mathrm{C}$. A detailed description of the cell design and assembly is given in the appendix

\section{Cyclic Voltammetry}

In order to compare the nickel thin film, lattice, and nanoparticle cathodes, CVs around the nitrate reduction/nitrite oxidation redox potential are performed to understand the achievable current densities and reversibility of the redox couple.

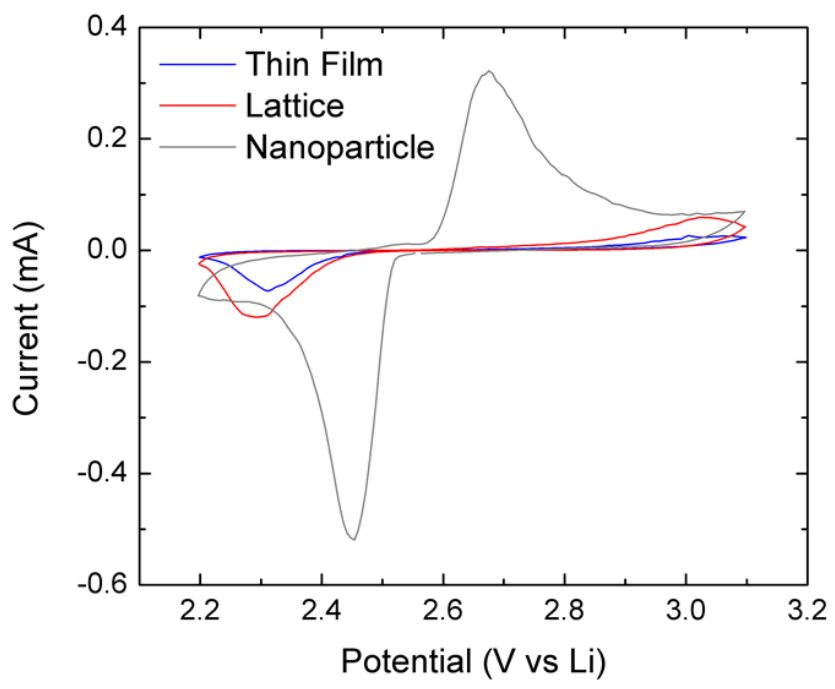

Figure 4.10: Cyclic voltammetry of nitrate reduction on different cathodes, all of which are $1 \mathrm{~cm}$ in diameter. Scan rate: $0.01 \mathrm{mV} \mathrm{s}^{-1}$. 
Figure 4.10 shows these $\mathrm{CV}$ s performed at a slow scan rate of $0.01 \mathrm{mV} \mathrm{s}^{-1}$. The large peak to peak separation suggests that this redox couple is not truly reversible, but quasi-reversible in a similar vein as the CVs of Figure 2.1. As this is a fairly complex redox process involving the growth and dissolution of solid species, one would expect a quasi-reversible $\mathrm{CV}$. For the case of nickel nanoparticles, the peak separation is $200 \mathrm{mV}$ and centered around the potential observed in the GITT of Figure 3.4 for an all nitrate electrolyte. When considering the thorough characterization of nitrate reduction with a nickel nanoparticle cathode in Chapter Three, we can be confident that this quasi-reversible couple can be attributed to the reversible growth and dissolution of $\mathrm{Li}_{2} \mathrm{O}$ through nitrate reduction.

The peak to peak separation is much larger in the thin film and lattice cases, consistent with the expectation for a much smaller surface area electrode in a quasi-reversible system (the nanoparticle electrode has a surface area 2-3 orders of magnitude larger than the thin film and lattice ones).In particular, the cathodic scan for nitrite oxidation has a much larger overpotential than the anodic scan for nitrate reduction, but there is a slowly increasing current across the cathodic scan. This wide peak separation and small peak current suggests that the thin film and lattice electrodes will not be able to achieve a large current on discharge. In addition, if the discharge capacity in such a system were proportional to the cathode surface area, then we would expect a negligible absolute capacity. This all points to these low surface area electrodes being poor candidates for a cathode in this system.

\section{Galvanostatic Discharge}

Having an understanding of the rate capability of the low surface area electrodes, we attempt a galvanostatic discharge. The CVs of Figure 4.10 give a sense of the achievable currents for each cathode, and after testing a range of values, a current of $25 \mu \mathrm{A}$ was selected for the lattice cathode. In order to fairly compare across electrode structures, the nanoparticle cathode was discharged at the same rate of 25 $\mu \mathrm{A}$, and the thin film cathode was discharged at $10 \mu \mathrm{A}$ so that the current normalized by electrochemical surface area would be the same. These discharges are shown in Figure 4.11.

Considering the $\mathrm{CV}$ behavior of the lattice and thin film electrodes, one might have expected their discharge performance to be significantly worse than expected. However, the discharge capacity of the lattice and nickel cathodes is quite similar at the same current, clearly pointing to the role of structure in discharge capacity 


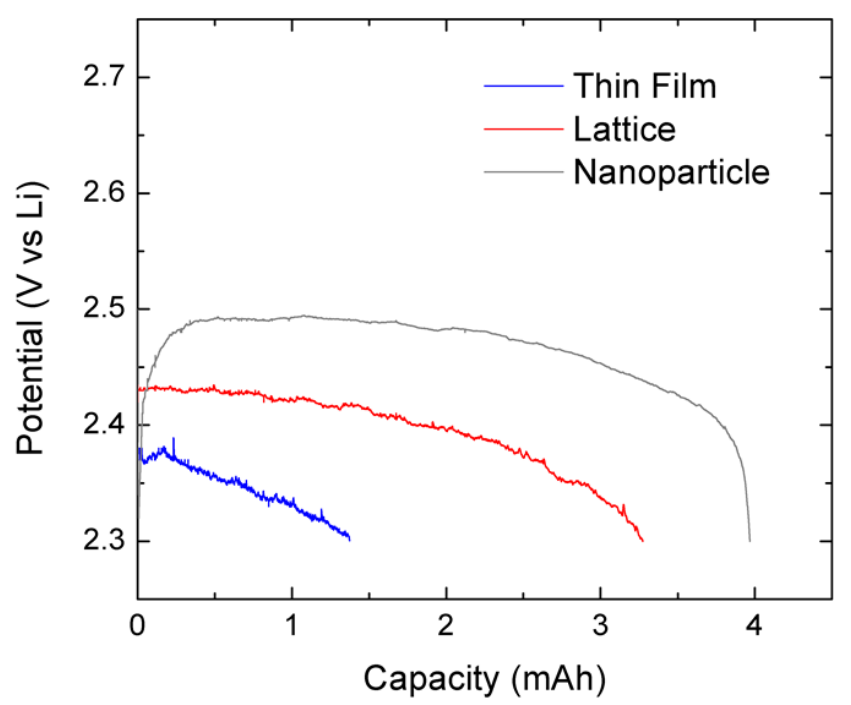

Figure 4.11: First discharge of nitrate reduction on different cathodes, all of which are $1 \mathrm{~cm}$ in diameter. Discharged at $25 \mu \mathrm{A}$ for the lattice and nanoparticle cathodes, and $10 \mu \mathrm{A}$ for the thin film cathode.

for a chemistry such as nitrate reduction. Before more thoroughly discussing the different normalization schemes available to compare these discharge capacities, we first want to see if any $\mathrm{Li}_{2} \mathrm{O}$ is actually growing within the lattice structure. As before, the cathode was extracted from heated batteries inside an argon-filled glovebox and rinsed with NMA. This process was extremely delicate for the lattice electrodes, and few survived, disallowing a thorough discharge product characterization. However, enough were salvaged to allow Figure 4.12, SEM micrographs of a discharged lattice.
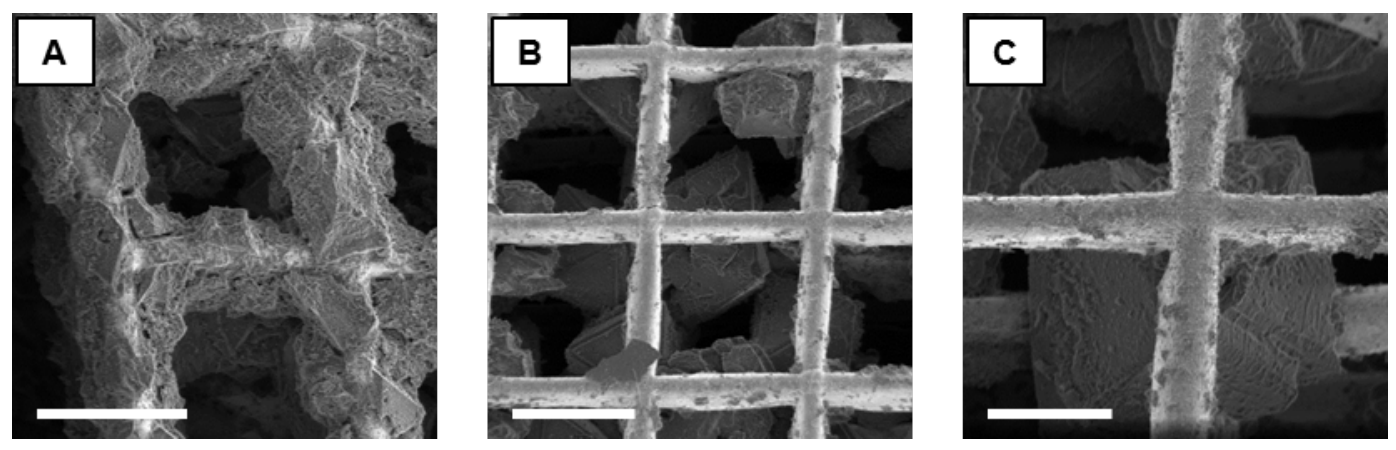

Figure 4.12: Nitrate reduction discharge product on lattice electrode, by SEM. Discharge conditions similar to those of Figure 4.11 (scale bar: (A) $15 \mu \mathrm{m}$, (B) 20 $\mu \mathrm{m}$, and (C) $10 \mu \mathrm{m})$.

Note two observations from the discharge product. First, it is growing within 
the lattice structure, confirming that the pre-wetting of the electrode successfully allowed the infiltration of electrolyte. Second, the morphology of the discharge product is octahedral, suggesting that this is in fact $\mathrm{Li}_{2} \mathrm{O}$ growing according to its Wulff construction as observed for the nanoparticle cathodes in Figure 3.10. While this is not an exhaustive confirmation of the nitrate reduction chemistry, it does seem to confirm the growth of $\mathrm{Li}_{2} \mathrm{O}$.

Having established that the lattice electrode performed as desired and accommodated the growth of $\mathrm{Li}_{2} \mathrm{O}$, we can turn back to the discharges of Figure 4.11. There are several questions of interest, and the best way to address them is to normalize the capacity in a few different ways: by projected electrode area to get a sense of cell level capacity, by mass of nickel in a similar vein to the lithium-oxygen system, and by the true surface area of nickel to see its interplay with electrode structure. The projected electrode area is simply the area of the $1 \mathrm{~cm}$ diameter electrodes, 0.785 $\mathrm{cm}^{2}$. The mass of nickel was simply measured for the nanoparticles, and for the thin film and lattice it was estimated from the film thickness, and in the case of the lattice, the calculated volumes in SOLIDWORKS. These masses were too small (on the order of $100 \mu \mathrm{g}$ ) to measure accurately on a balance, but the substrate was too heavy to use a micro-balance. The surface areas of nickel for the thin film and lattice were taken from the $\mathrm{CV}$ measurements earlier in this chapter, and for the nanoparticles, the BET value mentioned in Chapter Three was used.

\begin{tabular}{|c|c|c|c|}
\hline & $\begin{array}{l}\text { Thin film } \\
\text { electrode } \\
(10 \mu \mathrm{A})\end{array}$ & $\begin{array}{l}\text { Lattice } \\
\text { electrode } \\
(25 \mu \mathrm{A})\end{array}$ & $\begin{array}{l}\text { Nanoparticle } \\
\text { electrode } \\
(25 \mu \mathrm{A})\end{array}$ \\
\hline $\begin{array}{l}\text { Areal capacity } \\
\left(\mathrm{mAh} \mathrm{cm}^{-2} \text { projected }\right)\end{array}$ & 1.7 & 4.1 & 5.1 \\
\hline $\begin{array}{l}\text { Gravimetric capacity } \\
\left(\mathrm{mAh} \mathrm{g}^{-1}{ }_{\text {nickel }}\right)\end{array}$ & 3400 & 8200 & 790 \\
\hline $\begin{array}{l}\text { Surface capacity } \\
\left(\mathrm{mAh} \mathrm{m}^{-2}{ }_{\text {nickel }}\right)\end{array}$ & 8700 & 8300 & 79 \\
\hline
\end{tabular}

Table 4.2: Normalized discharge capacity of nitrate reduction on different cathodes, all of which are $1 \mathrm{~cm}$ in diameter.

These normalized capacities are displayed in Table 4.2, and they indicate a few things. First, the lattice electrode has an areal capacity comparable to the nanoparticle one, and both of these values are similar to those found in commercial lithium-ion batteries. This clearly demonstrates the role that "useful" surface area plays in de- 
termining the capacity in these types of systems. Second, the thin film and lattice electrodes have gravimetric values so large that they lose meaning. By architecting an electrode comprised of a thin film wrapped around a polymer scaffold, one can design an electrode with an arbitrarily small amount of nickel and achieve an inflated capacity value, a problem in the lithium-oxygen community which has thankfully started to be addressed in recent years. Finally, the surface capacities of the thin film and lattice electrodes are not only much larger than that of the nickel nanoparticles as discussed earlier, but they are also remarkably similar in value. This suggests that if one designs a sufficiently open pore structure, the capacity will in fact scale with surface area.

\subsection{Commercial Foam Electrode Comparison}

In the previous section, we addressed the role of cathode structure in a nitrate reduction battery by designing a proof of concept electrode to demonstrate among other things that capacity will scale with surface area given the appropriate pore structure. Now we take the inverse approach by using two identical electrodes and changing the pore structure of one of them, seeing the effect on performance as a nitrate reduction cathode. To do so, we use commercially available nickel foams (MTI Corporation), one of which is as synthesized and $1.6 \mathrm{~mm}$ tall, the other which was the same but then densified by putting it through rollers to make it $80 \mu \mathrm{m}$ tall. These foams will be referred to as "open" and "dense" henceforth. This rolling process allows the significant removal of pore volume while keeping the nickel mass and surface area relatively unchanged.

The structure of these foams is shown in Figure 4.13. The open foam has pores ranging from $200-500 \mu \mathrm{m}$ in size, and based on the bulk foam density, a porosity of $97.4 \%$. Interestingly, because of the way the dense foam was densified, its pores are no longer isotropic. The out of plane direction saw a $95 \%$ strain, and the pores collapsed accordingly. This resulted in pores that were still a few hundred microns for the in plane direction, but only a few microns for the out of plane direction. This densification process resulted in a porosity of $48.2 \%$, again as calculated from the bulk foam density.

With a good sense of the structure of these electrodes, we can proceed with a similar set of electrochemical measurements as the ones taken in the previous section with thin film, lattice, and nanoparticle electrodes. Again, because the foam is not trivial to wet (though much easier than the lattice), we pre-wet it with the same $100 \mathrm{~g} \mathrm{~L}^{-1}$ 
$1.6 \mathrm{~mm}$ Tall Foam
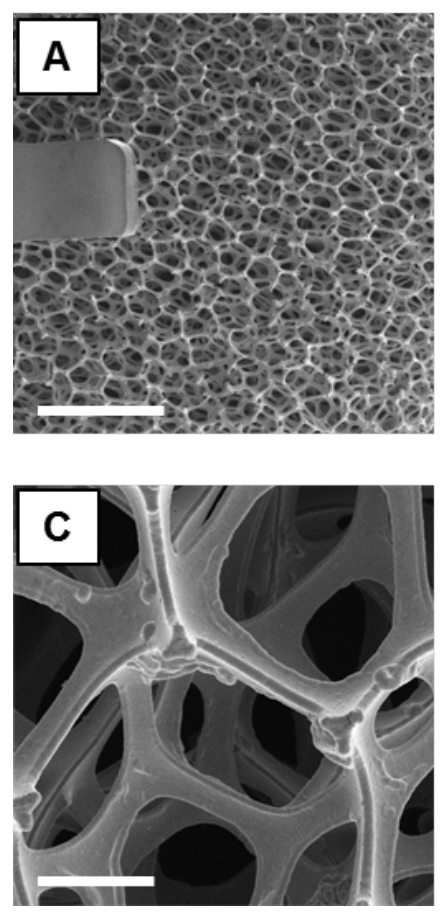

$80 \mu \mathrm{m}$ Tall Foam
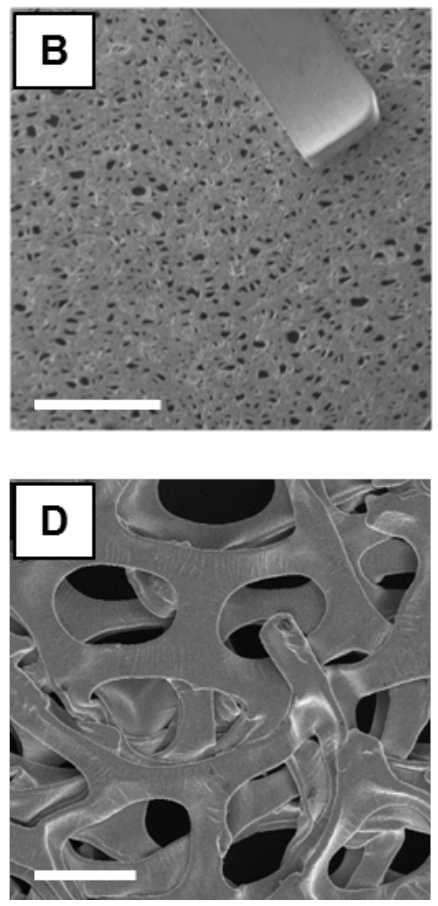

Figure 4.13: Foam electrode morphologies. (A,C) Open and (B,D) dense nickel foam structures (scale bar: (A,B) $2 \mathrm{~mm}$ and (C,D) $200 \mu \mathrm{m}$ ).

$\mathrm{LiNO}_{3}-\mathrm{KNO}_{3}$ aqueous solution. This time, due to the easy handling of the nickel foam, we can simply sonicate it in solution, dry it on the hotplate, infiltrate with more electrolyte, and finally dry overnight in the vacuum oven. Due to the thickness of the open foam, a total of $450 \mathrm{mg}$ of electrolyte was used instead of the typical $200 \mathrm{mg}$. Otherwise, the cell assembly procedure was the same as in the previous section.

\section{Cyclic Voltammetry}

As in the previous section, CVs around the nitrate reduction/nitrite oxidation redox potential are performed to understand the achievable current densities and reversibility of the redox couple. Because the surface area of a nickel foam is $\sim 500 \mathrm{~cm}^{2} \mathrm{~g}^{-1}$, this gives an electrode surface area about a factor of four larger than the lattice electrode of the previous section and an order of magnitude larger than the thin film case. As a result, we perform these $\mathrm{CVs}$ at a faster scan rate of $0.02 \mathrm{mV} \mathrm{s}^{-1}$, twice that of the previous section.

These Cvs are shown in Figure 4.14. Interestingly, the nitrate reduction peak current of the open foam is more than twice that of the nanoparticle one in Figure 4.10, 


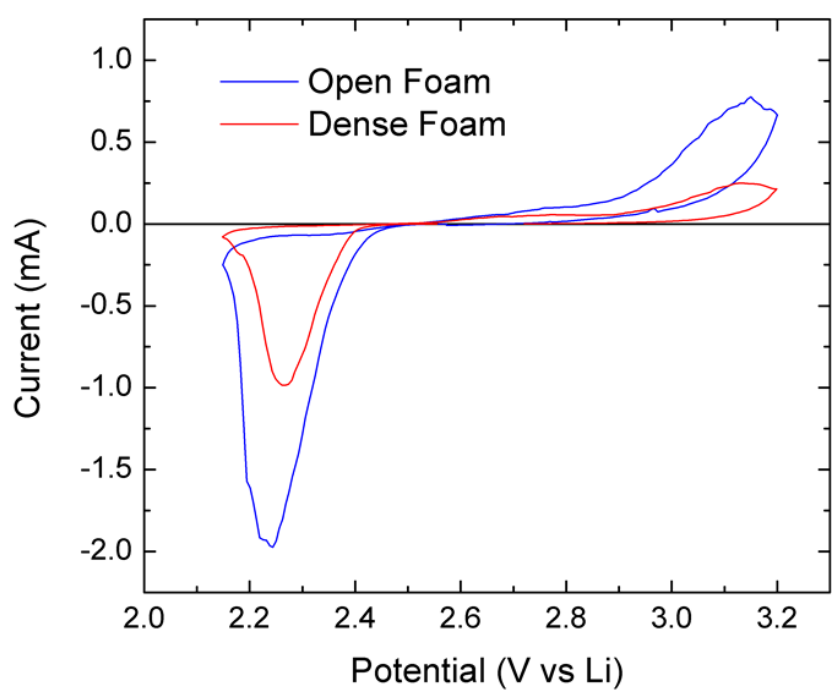

Figure 4.14: Cyclic voltammetry of nitrate reduction on foam cathodes, both of which are $1 \mathrm{~cm}$ in diameter. Scan rate: $0.02 \mathrm{mV} \mathrm{s}^{-1}$

but it is also shifted $200 \mathrm{mV}$ lower in potential than the nanoparticle case. This is interesting, as one would expect the lower surface area electrode to have both a lower peak current and an increased overpotential. However, this could make sense when considering the quasi-reversible nature of this redox couple. Due to the large porosity of the open foam, it would not be subject to pore blocking, potentially allowing the the electrode to reach lower potentials before it becomes passivated. In addition, note that the peak currents of the dense foam are significantly lower than those of the open one, further supporting the argument of pore blocking playing a role here.

\section{Galvanostatic Discharge}

Comparing the electrochemical surface areas of the foam and lattice electrodes, in addition to considering the CVs of Figure 4.14, gives a sense of the achievable current for the open and dense foam electrodes. After testing a range of discharge currents, we then attempt a deep galvanostatic discharge with a current of $50 \mu \mathrm{A}$, twice that of the lattice electrode. Figure 4.15 shows this discharge profile for both the open and dense foams.

Unlike when comparing the $\mathrm{CV}$ and discharge capacity for the lattice and nanoparticle cathodes, there is no apparent discrepancy in the case of the foam cathodes. The open foam displayed larger peak currents in its $\mathrm{CV}$ and a larger discharge capacity on its galvanostatic half-cycle. Interestingly, both the open and dense foams display 


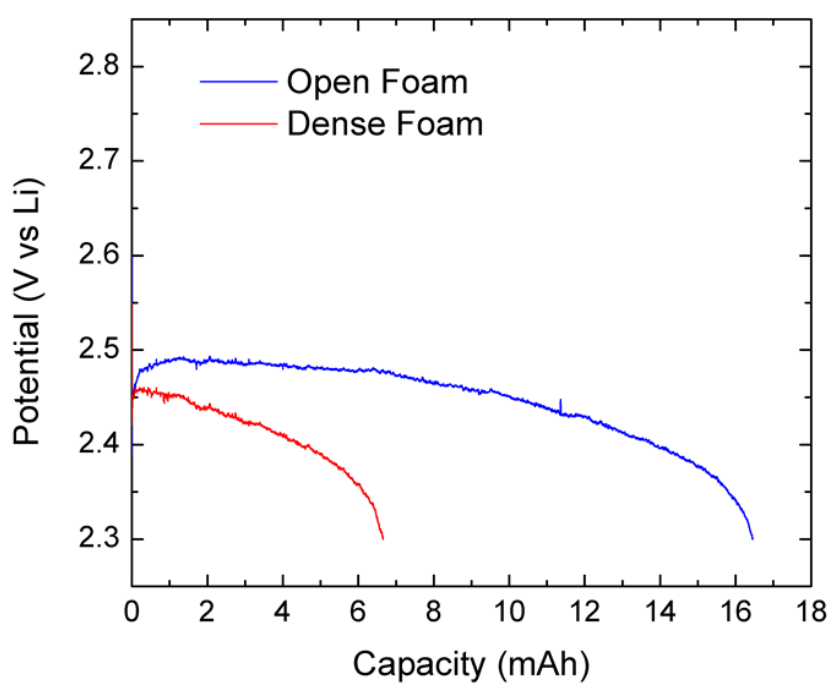

Figure 4.15: Galvanostatic discharge of nitrate reduction on foam cathodes, both of which are $1 \mathrm{~cm}$ in diameter. Discharged at $50 \mu \mathrm{A}$

a larger discharge capacity than the nanoparticle electrode (at twice the discharge rate too) despite having a significantly smaller electrochemical surface area.

\begin{tabular}{lll}
\hline & Open foam & Dense foam \\
\hline $\begin{array}{l}\text { Thickness } \\
(\mathrm{mm})\end{array}$ & 1.6 & 0.08 \\
$\begin{array}{l}\text { Porosity } \\
(\%)\end{array}$ & 97.4 & 48.2 \\
$\begin{array}{l}\text { Discharge capacity } \\
\left(\mathrm{mAh} \mathrm{cm} \text { crojected }^{-2}\right)\end{array}$ & 21.0 & 8.5 \\
$\begin{array}{l}\mathrm{Li}_{2} \mathrm{O} \text { fraction } \\
(\%)\end{array}$ & 3.6 & 29.4 \\
$\begin{array}{l}\text { Filled pore space } \\
(\%)\end{array}$ & 3.7 & 61.0 \\
\hline
\end{tabular}

Table 4.3: Structure of discharged foam cathodes, where $\mathrm{Li}_{2} \mathrm{O}$ fraction corresponds to the thickness of $\mathrm{Li}_{2} \mathrm{O}$ grown relative to the electrode thickness, and filled pore space corresponds to the percent of porosity filled with $\mathrm{Li}_{2} \mathrm{O}$ assuming it all grows within the electrode.

The normalized capacities and some structural information of the two foam electrodes are shown in Table 4.3. Before beginning a detailed discussion of the role of porosity in these foam electrodes, it is worth pointing out the absurdly large areal capacity of the open foam cathode: $21.0 \mathrm{mAh} \mathrm{cm}^{-2}$. This is about six to seven times larger than what one can expect for a lithium-ion battery, and it corresponds 
to stripping $\sim 100 \mu \mathrm{m}$ of lithium metal from the anode.

When considering the structural information of Table 4.3, there are two ways to interpret the data. First, we can make a similar argument to the one we have made throughout this chapter: the discharge capacity of a nitrate reduction battery, and by extension any other phase forming conversion chemistry, is largely dependent on the architecture of the cathode and not just its available surface area. This is clear as we note that two cathodes with similar surface area have a significant difference in discharge capacity which is accounted for by the larger porosity of the open foam. This issue of pore blocking becomes clear when considering the fraction of pore space that must be filled by $\mathrm{Li}_{2} \mathrm{O}$ in order to accommodate the measured discharge capacity. The open foam is only filling $3.7 \%$ of its pore space with $\mathrm{Li}_{2} \mathrm{O}$, while the dense foam is filling $61 \%$. This all suggests that the open foam is the preferable cathode structure of the two.

However, we can look at these numbers in a different way. When considering the utilization of pore space, the dense foam performed far better than the open foam. It may seem strange to consider the utilization of pore space, but in a phase forming conversion chemistry such a metric is analogous to the packing factor of active material in a lithium-ion cathode. If the packing factor of active material in a lithium-ion battery is low, now matter how great the loading is, it will always have a poor cell level energy density. In the case of these foam electrodes, the same thing is true of pore space utilization. If only a small fraction of the pore space is used, then a significant amount of mass and volume will become attributed to the electrolyte filling that unused pore space, resulting in a poor cell level energy density. This concept is not often used in the lithium-oxygen field. However, it has been explored in the lithium-sulfur one[92, 93], and simple calculations have shown that unless a much smaller amount of electrolyte is used than what is typical in research, lithium-sulfur batteries will never be able to compete with lithium-ion ones[94].

When considering both of these interpretations of Table 4.3, it would appear that the ideal foam electrode lies somewhere between the open and dense foams studied in this section. By varying the foam thickness between these two edge cases and performing some simple cell level energy density calculations, one could find this ideal foam porosity for maximizing the energy density of this nitrate reduction system. 


\subsection{Summary}

We began this chapter by motivating the need to find an appropriate metric to normalize the capacity of phase forming conversion reaction batteries, eventually determining that one needs to understand the relationship between electrochemical surface area and pore structure to be able to predict a cathodes discharge capacity. We then designed and fabricated a proof of concept nickel coated lattice electrode and determined its electrochemical surface area. Using this proof of concept electrode, we partially decoupled the cathodes discharge capacity from its electrochemical surface area, only seeing a direct scaling when the pore structure was explicitly designed such that the electrode behaved as a thin film. Finally, we inverted the notion of varying an electrodes "useful" electrochemical surface area by instead varying an electrodes porosity with a fixed surface area. This allowed us to reinforce the conclusions drawn with the lattice electrode, while also demonstrating the intricacies of cell design. While we were able to attain very large discharge capacities by using structured electrodes, they were still lacking in their achievable current densities, rendering them inappropriate for most battery applications. However, these findings provide guidelines for how one would design the ideal electrode: a hierarchical electrode which combines large scale porosity at the micro-scale to accommodate discharge product growth with a large surface area at the nano-scale to accommodate a high current density. 
Chapter 5

\section{SUMMARY AND OUTLOOK}

Throughout this thesis, we have studied battery cathodes which employ a phase forming conversion reaction chemistry, as opposed to the more common intercalation chemistry of lithium-ion batteries. In particular, we have stressed the difference in how these two classes of batteries store charge and the resulting distinction in their reaction mechanisms.

For the lithium-oxygen battery, this has meant a discussion of how an insulating species can grow electrochemically on the cathode catalyst support. As the solution mediated growth process for $\mathrm{Li}_{2} \mathrm{O}_{2}$ was developed in literature, it became clear that it is these intermediate species which facilitate a large capacity but are also the ones that enable unwanted side reactions. We determined that through the use of a molten salt electrolyte, the issue of organic solvent decomposition can be obviated. In addition, through thorough characterization we demonstrated the reversible growth and dissolution of $\mathrm{Li}_{2} \mathrm{O}_{2}$ which grew according to its Wulff construction. Furthermore, this molten salt electrolyte resulted in a lithium-oxygen battery with enhanced intermediate solubility and reaction kinetics, leading to a large discharge capacity at a remarkably low overpotential. However, due to degradation of the amorphous carbon cathode catalyst support, the battery still failed due to $\mathrm{Li}_{2} \mathrm{CO}_{3}$ accumulation and passivation. While this work has served as a promising step towards realizing a truly reversible lithium-oxygen battery, there are still many issues left unresolved, notably the lack of a stable cathode catalyst which works in this electrolyte and the lack of an effective protected lithium anode.

Continuing work in this molten nitrate electrolyte, we introduced a new take on an old primary battery chemistry. Through the use of a nickel nanoparticle catalyst, we have enabled the reversible nitrate reduction/nitrite oxidation redox couple, carefully characterizing the growth and dissolution of $\mathrm{Li}_{2} \mathrm{O}$. Interestingly, this $\mathrm{Li}_{2} \mathrm{O}$ also grew according to its Wulff construction. In addition, we have developed a quantitative ex situ chemical confirmation of this chemistry in a similar vein to using mass spectrometry in the lithium-oxygen field. Confident in the reversibility of this chemistry, we cycled a battery for over 1000 hours, and with no obvious cathodic degradation mechanisms, it should have been able to cycle for far longer 
given a more stable anode. However, as with the lithium-oxygen system, the lack of a protected lithium anode stands as a crucial impediment to further development of this chemistry.

Having examined these two phase forming conversion reaction chemistries, we turned to the question of how to best define capacity in such a battery, using nitrate reduction as a model system. By explicitly designing a proof of concept architected electrode with controllable surface area and pore size, we were able to study the interplay of these two properties and their effect on discharge capacity. In addition, we used commercially available foam electrodes to similarly examine the role pore structure plays in determining discharge capacity. It became clear that discharge capacity only scales with electrochemical surface area when that surface area is able to behave as a thin film, allowing the unobstructed growth of discharge product. This suggests that for any real electrode, there is no simple normalization scheme one can employ to easily define the system like there is in the lithium-ion battery. It also lends a simple design principle if one wants to make a large capacity phase forming chemistry: incorporate an open pore structure to accommodate discharge product growth.

Putting all of this together, we have a good idea of what is necessary for any similar phase forming chemistry to be realized as a practical battery. First, if a chemistry involves the dissolution of species into the electrolyte, then it must be paired with a protected anode to avoid crossover and the dissolved species needs to be stable to every component in the battery. Second, if discharge product is to be grown on the surface of some catalytic support, this structure needs to be designed to accommodate the growth to enable a useful areal capacity. Finally, it is important to remember that inactive components, such as a large current collector supporting the catalyst or a large electrolyte volume enabling the product solubility, begin to play a large role when calculating the cell level energy density. Solving all of these problems may seem a daunting task, but it was not so long ago when the same was said of lithium-ion batteries. 


\section{BIBLIOGRAPHY}

1. International Energy Agency (IEA), Clean Energy Ministerial, and Electric Vehicles Initiative (EVI). Global EV Outlook 2016: Beyond one million electric cars. IEA Publications (2016).

2. Nykvist, B. \& Nilsson, M. Rapidly falling costs of battery packs for electric vehicles. Nature Climate Change 5, 329-332. Issn: 17586798 (2015).

3. Routledge, R. A popular history of science (G. Routledge and sons, 1880).

4. Dell, R. M. \& Rand, D. A. J. Understanding batteries (Royal Society of Chemistry, 2001).

5. Whittingham, M. S. Electrical Energy Storage and Intercalation Chemistry. Science 192, 1126-1127. ISSN: 09476539 (1976).

6. Whittingham, M. S. Chemistry of intercalation compounds: Metal guests in chalcogenide hosts. Progress in Solid State Chemistry 12, 41-99. ISSN: 00796786 (1978).

7. Mizushima, K., Jones, P. C., Wiseman, P. J. \& Goodenough, J. B. LixCoO2 $(0<x a \hat{a} \%$ a1): A new cathode material for batteries of high energy density. Solid State Ionics 3-4, 171-174. ISSN: 01672738 (1981).

8. Yazami, R. \& Touzain, P. A reversible graphite-lithium negative electrode for electrochemical generators. Journal of Power Sources 9, 365-371. ISSN: 03787753 (1983).

9. Padhi, A. K., Nanjundaswamy, K. \& Goodenough, J. B. Phospho-olivines as Positive-Electrode Materials for Rechargeable Lithium Batteries. Journal of The Electrochemical Society 144, 1188-1194. IssN: 00134651 (1997).

10. Tarascon, J. M. \& Armand, M. Issues and challenges facing rechargeable lithium batteries. Nature 414, 359-367. IsSN: 00280836 (2001).

11. Schmuch, R., Wagner, R., Hörpel, G., Placke, T. \& Winter, M. Performance and cost of materials for lithium-based rechargeable automotive batteries. Nature Energy 3, 267-278. ISSN: 2058-7546 (2018).

12. Blomgren, G. E. The Development and Future of Lithium Ion Batteries. Journal of The Electrochemical Society 164, A5019-A5025. IssN: 0013-4651 (2017).

13. Graetz, J., Ahn, C. C., Yazami, R. \& Fultz, B. Highly Reversible Lithium Storage in Nanostructured Silicon. Electrochemical and Solid-State Letters 6 , A194. ISSN: 10990062 (2003).

14. Kraytsberg, A., Ein-Eli, Y., Kraytsberg, A. \& Ein-Eli, Y. Higher, stronger, better ... A review of 5 volt cathode materials for advanced lithium-ion batteries. Advanced Energy Materials 2, 922-939. Issn: 16146832 (2012). 
15. Manthiram, A., Knight, J. C., Myung, S. T., Oh, S. M. \& Sun, Y. K. Nickel-Rich and Lithium-Rich Layered Oxide Cathodes: Progress and Perspectives. Advanced Energy Materials 6. IssN: 16146840. doi:10 . 1002/aenm. 201501010 (2016).

16. McCloskey, B. D., Burke, C. M., Nichols, J. E. \& Renfrew, S. E. Mechanistic insights for the development of $\mathrm{Li}-\mathrm{O}<\mathrm{sub}>2</$ sub $>$ battery materials: addressing $\mathrm{Li}<\mathrm{sub}>2</$ sub $>\mathrm{O}<\mathrm{sub}>2</$ sub $>$ conductivity limitations and electrolyte and cathode instabilities. Chem. Commun. 51, 12701-12715. ISSN: 1359-7345 (2015).

17. Abraham, K. M. \& Jiang, Z. A Polymer Electrolyte - Based Rechargeable Lithium / Oxygen Battery. Journal of the Electrochemical Society 143, 1-5. ISSN: 00134651 (1996).

18. Bruce, P. G., Freunberger, S. A., Hardwick, L. J. \& Tarascon, J.-M. Li-O2 and Li-S batteries with high energy storage. Nature Materials 11, 19-29. ISSN: 1476-1122 (2012).

19. Luntz, A. C. \& McCloskey, B. D. Nonaqueous Li-air batteries: A status report. Chemical Reviews 114, 11721-11750. ISSN: 15206890 (2014).

20. Rahman, M. A., Wang, X. \& Wen, C. A review of high energy density lithiumair battery technology. Journal of Applied Electrochemistry 44, 5-22. ISSN: 0021891X (2014).

21. Mitchell, R. R., Gallant, B. M., Shao-Horn, Y. \& Thompson, C. V. Mechanisms of Morphological Evolution of $\mathrm{Li}<\mathrm{sub}>2</$ sub $>\mathrm{O}<\mathrm{sub}>2</$ sub $>$ Particles during Electrochemical Growth. The Journal of Physical Chemistry Letters 4, 1060-1064. ISSN: 1948-7185 (2013).

22. Horstmann, B. et al. Rate-Dependent Morphology of Li $2 \mathrm{O} 2$ Growth in Li-O 2 Batteries. The Journal of Physical Chemistry Letters 4, 4217-4222. ISSN: 1948-7185 (2013).

23. Xu, J. J., Wang, Z. L., Xu, D., Zhang, L. L. \& Zhang, X. B. Tailoring deposition and morphology of discharge products towards high-rate and long-life lithiumoxygen batteries. Nature Communications 4, 1-10. ISSN: 20411723 (2013).

24. Hou, J., Yang, M., Ellis, M. W., Moore, R. B. \& Yi, B. Lithium oxides precipitation in nonaqueous Li-air batteries. Physical Chemistry Chemical Physics 14, 13487. ISSN: 1463-9076 (2012).

25. Aetukuri, N. B. et al. Solvating additives drive solution-mediated electrochemistry and enhance toroid growth in non-aqueous Li-O2batteries. Nature Chemistry 7, 50-56. ISSN: 17554349 (2015).

26. Xu, C., Gallant, B. M., Wunderlich, P. U., Lohmann, T. \& Greer, J. R. ThreeDimensional $\mathrm{Au}$ Microlattices as Positive Electrodes for Li-O<inf $>2<$ inf $>$ Batteries. ACS Nano 9, 5876-5883. ISSN: 1936086X (2015). 
27. Johnson, L. et al. The role of $\mathrm{LiO} 2$ solubility in $\mathrm{O} 2$ reduction in aprotic solvents and its consequences for Li-O 2 batteries. Nature Chemistry 6, 10911099. ISSN: 17554349 (2014).

28. Luntz, A. C. et al. Tunneling and polaron charge transport through $\mathrm{Li} 2 \mathrm{O} 2$ in Li-O2 batteries. Journal of Physical Chemistry Letters 4, 3494-3499. ISSN: 19487185 (2013).

29. Gutmann, V. Empirical parameters for donor and acceptor properties of solvents. Electrochimica Acta 21, 661-670. ISSN: 00134686 (1976).

30. Cho, M. H. et al. The effects of moisture contamination in the Li-O2battery. Journal of Power Sources 268, 565-574. ISSN: 03787753 (2014).

31. Meini, S., Piana, M., Tsiouvaras, N., Garsuch, A. \& Gasteiger, H. A. The Effect of Water on the Discharge Capacity of a Non-Catalyzed Carbon Cathode for LiO2 Batteries. Electrochemical and Solid-State Letters 15, A45. ISSN: 10990062 (2012).

32. Chen, Y., Freunberger, S. A., Peng, Z., Fontaine, O. \& Bruce, P. G. Charging a $\mathrm{Li}-\mathrm{O}<\mathrm{sub}>2</$ sub $>$ battery using a redox mediator. Nature Chemistry $\mathbf{5}$, 489-494. ISSN: 1755-4330 (2013).

33. Chase, G. V. et al. Soluble Oxygen Evolving Catalysts for Rechargeable MetalAir Batteries. US patent 1, US 20120028137A1 (2012).

34. Fong, R., von Sacken, U. \& Dahn, J. R. Studies of Lithium Intercalation into Carbons Using Nonaqueous Electrochemical Cells. Journal of The Electrochemical Society 137, 2009. IssN: 00134651 (1990).

35. Freunberger, S. A. et al. Reactions in the Rechargable Lithium-O2 Battery with Alkyl Carbonate Electrolytes. Journal of the American Chemical Society 133, 8040-8047 (2011).

36. Kwabi, D. G. et al. Chemical instability of dimethyl sulfoxide in lithium-air batteries. Journal of Physical Chemistry Letters 5, 2850-2856. ISSN: 19487185 (2014).

37. Sharon, D. et al. Reactivity of amide based solutions in lithium-oxygen cells. Journal of Physical Chemistry C 118, 15207-15213. ISSN: 19327455 (2014).

38. Bryantsev, V. S. et al. Predicting solvent stability in aprotic electrolyte Liair batteries: Nucleophilic substitution by the superoxide anion radical (O2-). Journal of Physical Chemistry A 115, 12399-12409. ISSN: 10895639 (2011).

39. McCloskey, B. D., Bethune, D. S., Shelby, R. M., Girishkumar, G. \& Luntz, A. C. Solvents' Critical Role in Nonaqueous Lithium-Oxygen Battery Electrochemistry. The Journal of Physical Chemistry Letters 2, 1161-1166. ISSN: 1948-7185 (2011). 
40. Black, R. et al. Screening for superoxide reactivity in $\mathrm{Li}-\mathrm{O}<<\mathrm{sub}>2</$ sub $>$ batteries: effect on $\mathrm{Li}<\mathrm{sub}>2</ \mathrm{sub}>\mathrm{O}<\mathrm{sub}>2</ \mathrm{sub}>/ \mathrm{LiOH}$ crystallization. Journal of the American Chemical Society 134, 2902-2905. ISSN: 1520-5126 (2012).

41. McCloskey, B. D. et al. Combining Accurate O2 and Li2O2 Assays to Separate Discharge and Charge Stability Limitations in Nonaqueous Li-O $<\mathrm{sub}>2</$ sub $>$ Batteries. J. Phys. Chem. Lett. 4, 2989-2993 (2013).

42. Gallant, B. M. et al. Chemical and Morphological Changes of Li-O2 Battery Electrodes upon Cycling. The Journal of Physical Chemistry C 116, 2080020805. ISSN: 1932-7447 (2012).

43. McCloskey, B. D. et al. Twin problems of interfacial carbonate formation in nonaqueous $\mathrm{Li}-\mathrm{O}<\mathrm{sub}>2</ \mathrm{sub}>$ batteries. Journal of Physical Chemistry Letters 3, 997-1001. ISSN: 19487185 (2012).

44. Peng, Z., Freunberger, S. A., Chen, Y. \& Bruce, P. G. A reversible and higherrate $\mathrm{Li}-\mathrm{O}<\mathrm{sub}>2</$ sub > battery. Science 337, 563-566. ISSN: 10959203 (2012).

45. Riaz, A. et al. Carbon-free cobalt oxide cathodes with tunable nanoarchitectures for rechargeable lithium-oxygen batteries. Chemical Communications 49, 5984. ISSN: 1359-7345 (2013).

46. Liu, X., Wang, D. \& Shi, S. Exploration on the possibility of Ni foam as current collector in rechargeable lithium-air batteries. Electrochimica Acta 87, 865-871. ISSN: 00134686 (2013).

47. Aurbach, D., McCloskey, B. D., Nazar, L. F. \& Bruce, P. G. Advances in understanding mechanisms underpinning lithium-air batteries. Nature Energy 1, 1-11. ISSN: 20587546 (2016).

48. Lu, Y.-C. et al. Lithium-oxygen batteries: bridging mechanistic understanding and battery performance. Energy \& Environmental Science 6, 750. ISSN: 17545692 (2013).

49. Uddin, J., Addison, D., Giordani, V., Chase, G. V. \& Walker, W. Alkali Metal/Oxygen Batteries Employing Molten Nitrate Electrolytes 2014.

50. Raistrick, I. D., Poris, J. \& Huggins, R. A. Nitrate Molten Salt Electrolytes for Use in Intermediate Temperature Lithium Cells 1981.

51. Miles, M. H. Cation Effects on the Electrode Reduction of Molten Nitrates. Journal of The Electrochemical Society 127, 1761. ISSN: 00134651 (1980).

52. Zambonin, P. G. \& Jordan, J. Redox chemistry of the system O2-O2-O22-O2in fused salts. Journal of the American Chemical Society 91, 2225-2228. ISSN: 0002-7863 (Apr. 1969).

53. Zambonin, P. G. Reversible oxygen electrode systems in molten salts. Journal of Electroanalytical Chemistry 33, 243-251. IssN: 00220728 (1971). 
54. Zawodzinski, T. A. \& Osteryoung, R. A. Donor-Acceptor Properties of AmbientTemperature Chloroaluminate Melts. Inorganic Chemistry 28, 1710-1715. ISSN: 1520510X (1989).

55. Evans, J., Vincent, C. A. \& Bruce, P. G. Electrochemical measurement of transference numbers in polymer electrolytes. Polymer 28, 2324-2328. ISSN: 00323861 (1987).

56. Walker, W. et al. A Rechargeable Li-O $<$ sub $>2</$ sub $>$ Battery Using a Lithium Nitrate/N,N-Dimethylacetamide Electrolyte. Journal of the American Chemical Society 135, 2076-2079. ISSN: 1520-5126 (2013).

57. Burke, C. M., Pande, V., Khetan, A., Viswanathan, V. \& McCloskey, B. D. Enhancing electrochemical intermediate solvation through electrolyte anion selection to increase nonaqueous $\mathrm{Li}-\mathrm{O}<\mathrm{sub}>2</ \mathrm{sub}>$ battery capacity. Proceedings of the National Academy of Sciences 112, 9293-9298. ISSN: 00278424 (2015).

58. Sharon, D. et al. Oxidation of Dimethly Sulfoxide Solutions by Electrochemical Reduction of Oxygen. The Journal of Physical Chemistry Letters 4, 31153119. ISSN: 1948-7185 (2013).

59. Strickland-Constable, R. F. Kinetics and Mechanism of Crystallization from the Fluid Phase and of the Condensation and Evaporation of Liquids (1968).

60. Gibbs, J. W. The collected works of J. Willard Gibbs, volume I: thermodynamics (Yale University Press, 1928).

61. Wulff, G. On the question of speed of growth and dissolution of crystal surfaces. Z. Kristallogr 34, 449-530 (1901).

62. Herring, C. The use of classical macroscopic concepts in surface energy problems in Structure and properties of solid surfaces (1953), 5.

63. Radin, M. D., Rodriguez, J. F., Tian, F. \& Siegel, D. J. Lithium peroxide surfaces are metallic, while lithium oxide surfaces are not. Journal of the American Chemical Society 134, 1093-1103. Issn: 00027863 (2012).

64. Mo, Y., Ong, S. P. \& Ceder, G. First-principles study of the oxygen evolution reaction of lithium peroxide in the lithium-air battery. Physical Review B Condensed Matter and Materials Physics 84, 1-9. ISSN: 10980121 (2011).

65. Lopez, N. et al. Reversible reduction of oxygen to peroxide facilitated by molecular recognition. Science 335, 450-453. ISSN: 10959203 (2012).

66. Desimoni, E., Palmisano, F. \& Zambonin, P. G. Catalytic currents in fused salts: Discharge mechanism of nitrite in molten alkali nitrates. Journal of Electroanalytical Chemistry 84, 315-322. ISSN: 00220728 (1977).

67. Huggins, R. Advanced batteries: materials science aspects (Springer Science \& Business Media, 2008). 
68. Giordani, V. et al. A Molten Salt Lithium-Oxygen Battery. Journal of the American Chemical Society 138, 2656-2663. IssN: 15205126 (2016).

69. Bard, A. J. \& Faulkner, L. R. Electrochemical methods: fundamentals and applications (wiley New York).

70. Bansal, A., Li, X., Yi, S. I., Weinberg, W. H. \& Lewis, N. S. Spectroscopic studies of the modification of crystalline si(111) surfaces with covalently-attached alkyl chains using a chlorination/alkylation method. Journal of Physical Chemistry B 105, 10266-10277. ISSN: 10895647 (2001).

71. Chiang, Y.-M., Birnie, D. P., Kingery, W. D. \& Newcomb, S. Physical ceramics: principles for ceramic science and engineering (Wiley New York, 1997).

72. Tietz, F., Dias, F. J., Simwonis, D. \& Stöver, D. Evaluation of commercial nickel oxide powders for components in solid oxide fuel cells. Journal of the European Ceramic Society 20, 1023-1034. IssN: 09552219 (2000).

73. Chia-Ching, W. \& Cheng-Fu, Y. Investigation of the properties of nanostructured Li-doped $\mathrm{NiO}$ films using the modified spray pyrolysis method. Nanoscale Research Letters 8, 1-5. ISSN: 19317573 (2013).

74. Nguyen, Q. M. Technological status of nickel oxide cathodes in molten carbonate fuel cells - A review. Journal of Power Sources 24, 1-19. ISSN: 03787753 (1988).

75. Zhong, L. et al. In Situ Transmission Electron Microscopy Observations of Electrochemical Oxidation of Li 2 O 2. Nano Letters 13, 2209-2214. ISSN: 1530-6984 (May 2013).

76. Seriani, N. Ab initio thermodynamics of lithium oxides: from bulk phases to nanoparticles. Nanotechnology 20, 445703. ISSN: 0957-4484 (Nov. 2009).

77. Desimoni, E., Paniccia, F. \& Zambonin, P. G. Solubility and detection (down to 30 p.p.b.) of oxygen in molten alkali nitrates. Journal of Electroanalytical Chemistry 38, 373-379. ISSN: 00220728 (1972).

78. Kwak, W.-J. et al. A Mo 2 C/Carbon Nanotube Composite Cathode for Lithium-Oxygen Batteries with High Energy Efficiency and Long Cycle Life. ACS Nano 9, 4129-4137. ISSN: 1936-0851 (2015).

79. Dullien, F. A. Porous media: fluid transport and pore structure (Academic press, 2012).

80. Pikul, J. H., Gang Zhang, H., Cho, J., Braun, P. V. \& King, W. P. Highpower lithium ion microbatteries from interdigitated three-dimensional bicontinuous nanoporous electrodes. Nature Communications 4, 1732-1735. ISSN: 20411723 (2013). 
81. Bauer, J., Schroer, A., Schwaiger, R. \& Kraft, O. Approaching theoretical strength in glassy carbon nanolattices. Nature Materials 15, 438-443. ISSN: 14764660 (2016).

82. Wendy Gu, X. \& Greer, J. R. Ultra-strong architected Cu meso-lattices. Extreme Mechanics Letters 2, 7-14. ISSN: 23524316 (2015).

83. Meza, L. R., Das, S. \& Greer, J. R. Strong, lightweight, and recoverable threedimensional ceramic nanolattices. Science (New York, N.Y.) 345, 1322-6. ISSN: 1095-9203 (2014).

84. Jang, D., Meza, L. R., Greer, F. \& Greer, J. R. Fabrication and deformation of three-dimensional hollow ceramic nanostructures. Nature Materials 12, 893898. ISSN: 14761122 (2013).

85. Montemayor, L. C., Meza, L. R. \& Greer, J. R. Design and Fabrication of Hollow Rigid Nanolattices via Two-Photon Lithography. Advanced Engineering Materials 16, 184-189 (2014).

86. Liontas, R. \& Greer, J. R. 3D nano-architected metallic glass: Size effect suppresses catastrophic failure. Acta Materialia 133, 393-407. ISSN: 13596454 (2017).

87. Seghiouer, A., Chevalet, J., Barhoun, A. \& Lantelme, F. Electrochemical oxidation of nickel in alkaline solutions: a voltammetric study and modelling. Journal of Electroanalytical Chemistry 442, 113-123. ISSN: 15726657 (Jan. 1998).

88. Grdeń, M., Alsabet, M. \& Jerkiewicz, G. Surface Science and Electrochemical Analysis of Nickel Foams. ACS Applied Materials \& Interfaces 4, 3012-3021. ISSN: 1944-8244 (June 2012).

89. Van Drunen, J. et al. Comprehensive Structural, Surface-Chemical and Electrochemical Characterization of Nickel-Based Metallic Foams. ACS Applied Materials \& Interfaces 5, 6712-6722. ISSN: 1944-8244 (July 2013).

90. Hall, D. S., Bock, C. \& MacDougall, B. R. An Oxalate Method for Measuring the Surface Area of Nickel Electrodes. Journal of the Electrochemical Society 161, H787-H795. IssN: 0013-4651 (Sept. 2014).

91. Van Drunen, J., Barbosa, A. F. B. \& Tremiliosi-Filho, G. The Formation of Surface Oxides on Nickel in Oxalate-Containing Alkaline Media. Electrocatalysis 6, 481-491. ISSN: 1868-2529 (Sept. 2015).

92. Chung, W. J. et al. The use of elemental sulfur as an alternative feedstock for polymeric materials. Nature Chemistry 5, 518-524. ISSN: 17554330 (2013).

93. Thangavel, V. et al. A Microstructurally Resolved Model for Li-S Batteries Assessing the Impact of the Cathode Design on the Discharge Performance. Journal of The Electrochemical Society 163, A2817-A2829. ISSN: 0013-4651 (2016). 
94. McCloskey, B. D. Attainable Gravimetric and Volumetric Energy Density of Li-S and Li Ion Battery Cells with Solid Separator-Protected Li Metal Anodes. Journal of Physical Chemistry Letters 6, 4581-4588. ISSN: 19487185 (2015). 
Appendix A

\section{DETAILED CELL CONSTRUCTION}

All alkali metal nitrate salts were purchased from Sigma-Aldrich, vacuum dried at $120{ }^{\circ} \mathrm{C}$ for 1 week and stored inside an argon-filled glovebox. Typically, a $12 \mathrm{~mm}$ diameter glass microfiber separator (Whatman) was impregnated with 200-300 mg of eutectic mixture and then vacuum-dried at $200{ }^{\circ} \mathrm{C}$ (above the eutectic melting point) for 1 day using an oven (LC Technology Solutions) inside the glovebox. For trace amounts of water in the electrolyte, Karl Fischer titration was performed using dry N-methylacetamide solvent (NMA, 5 ppm of water, Sigma-Aldrich) before and after the addition of the dried binary or ternary mixture of nitrate/nitrite salts. Results show that water content of $10 \mathrm{ppm}$ is typically observed with these electrolytes.

The oxygen positive electrodes consisted of Super P carbon black (Timcal) mixed with PTFE binder (Sigma-Aldrich) in a 95:5 mass ratio (no catalyst). The amorphous carbon was used as received with no pretreatment or surface activation. Super P carbon and PTFE were mixed together in a water-isopropanol mixture and dried in air at room temperature. The mixture was then dry pressed on a $10 \mathrm{~mm}$ diameter stainless steel mesh. Typical carbon loading in these batteries was $3-5 \mathrm{mg} / \mathrm{cm}^{2}$. The nitrate reduction positive electrodes, except for the catalyst search, consisted of nickel nanopowder (MTI Corporation, $\sim 30 \mathrm{~nm}$ particle size, $\sim 10 \mathrm{~m}^{2} / \mathrm{g}$ BET Surface Area). The nanopowder was used as received with no pretreatment or surface activation, dry pressed on a $10 \mathrm{~mm}$ diameter stainless steel or aluminum mesh. Typical nickel loading in these batteries was $10-20 \mathrm{mg} / \mathrm{cm}^{2}$. To improve electrolyte infusion into the porous positive electrodes, electrolyte separators containing the molten salts and cathode were dried together at $180^{\circ} \mathrm{C}$ for 1 day under a vacuum.

Typical battery cells consisted of a hermetically sealed stainless steel fixture (Swagelok) of known volume, which is comprised of a pressure sensor (Omega) and a valve (Valco Instruments) that can easily be connected to a mass spectrometer for qualitative and quantitative gas analysis. See Figure A.1 for a picture of the cell assembly. Together with pressure monitoring, precise concentrations of gas in the head-space can be determined: consumed and evolved oxygen gas during cycling in the case of a lithium-oxygen battery, or checking for side reaction products in the case of a nitrate reduction battery. Batteries are routinely leak tested with helium gas at 


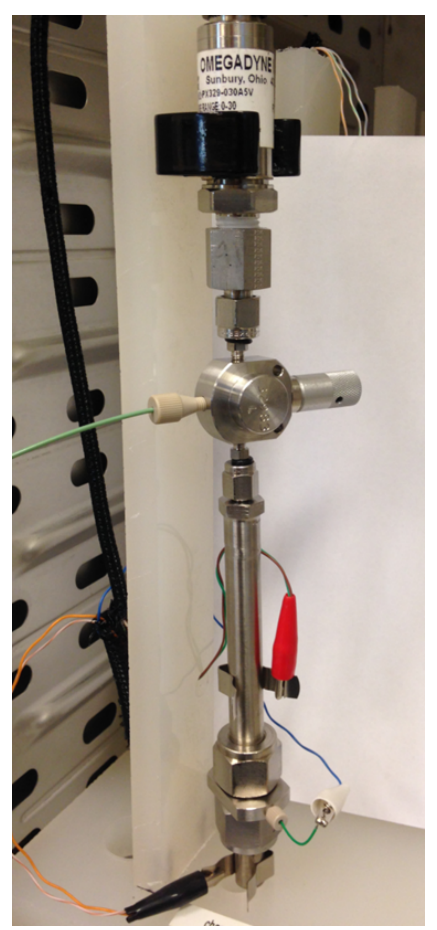

Figure A.1: Picture of Swagelok cell. From top to bottom: pressure sensor (with sticker); valve allowing access to head-space gas; hollow tube holding gas headspace (also connected to for positive electrode contact); Swagelok assembly with spring, current collector, pressed cathode, eutectic-infused separator, lithium anode; negative current collector rod.

$150{ }^{\circ} \mathrm{C}$ prior to use. The anode consists of an $8 \mathrm{~mm}$ diameter lithium metal disc (250 $\mu \mathrm{m}$ thick) used as received (MTI Corporation). Once electrolyte and cathode were added into the battery, a stainless steel spring was used to accommodate volume changes upon electrolyte melting and to maintain good electrical contact. All battery construction was performed in an argon-filled glovebox with oxygen and water levels maintained below $0.1 \mathrm{ppm}$. Batteries were purged with pure oxygen or argon (Research 5.0 grade, Airgas), for lithium-oxygen or nitrate reduction batteries respectively, at room temperature and maintained under positive pressure, typically around $1.1 \mathrm{e}^{5}-1.5 \mathrm{e}^{5} \mathrm{~Pa}(1.1-1.5$ bar). Batteries were then transferred to an oven kept at either 120 or $150{ }^{\circ} \mathrm{C}$ depending on the molten nitrate/nitrite salts used. Opencircuit voltage, with periods of typically 6 or $12 \mathrm{~h}$, was applied to ensure both the battery voltage and the pressure reached equilibrium.

After electrochemical testing, cells were removed from the oven, allowing the molten salt to freeze. After purging the head-space gas with argon, they were then moved inside an argon-filled glove box for further analysis. Typically, positive electrodes 
were extracted from batteries after reheating to melt the electrolyte, and then allowed to cool again before being rinsed with ultra-dry NMA solvent ( $3 \times 30$ minutes) in order to remove excess nitrate salts. If extracting the electrolyte for further analysis was desired, the entire Swagelok fixture was disassembled, allowing access to the salt without having to remelt it. 
Appendix B

\section{ION EXCHANGE CHROMATOGRAPHY CALIBRATION AND CALCULATION}

\section{Calibration Procedure}

Ion exchange chromatography works by measuring the time it takes for ions to pass through a chromatography column. This time will depend on the size and charge of these ions. After passing through this column, the conductivity of the solution is measured, and this conductivity is proportional to the concentration of species in the solution. As this is not a direct measure of concentration, a calibration procedure must be used to determine the proportionality constant.

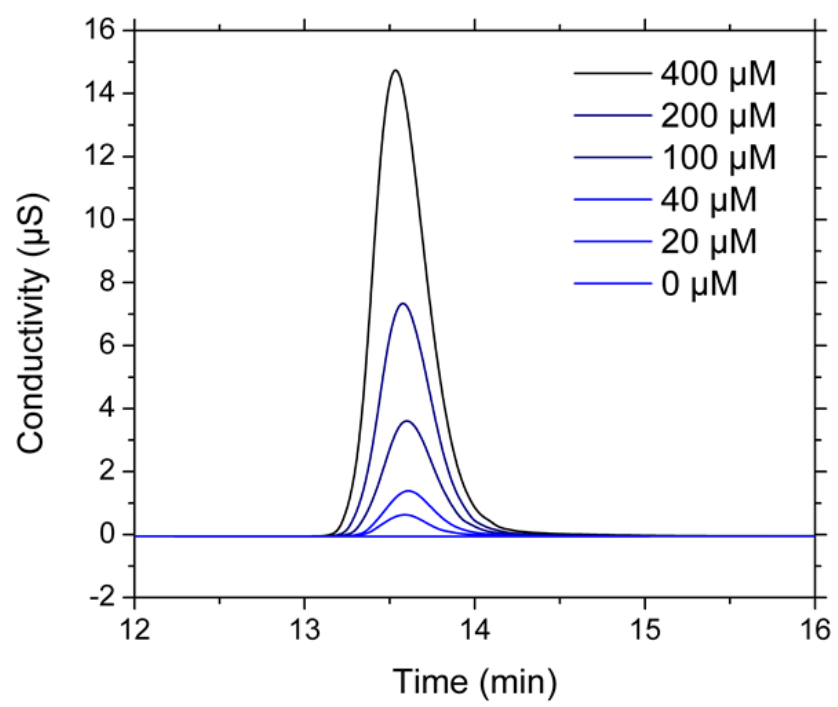

Figure B.1: Ion exchange chromatography nitrate calibration scans.

A Dionex ICS-2000 Ion Chromatography System was used for all experiments. Calibration curves were generated by preparing a series of solutions of know concentration in the range of 5-500 $\mu \mathrm{M}$, and Figure B.1 contains a series of calibration runs from prepared solutions of $\mathrm{LiNO}_{3}-\mathrm{KNO}_{3}$. Similar calibrations were performed for nitrite salts. All alkali metal nitrate and nitrite salts were purchased from SigmaAldrich, and mQ water (ultra-pure water from a Millipore filtration machine) was used in preparation of all solutions. Calibration curves were generated before each set of data was collected to account for any long term drift in the instrument, and 
any error, coming from a combination of machine error and solution measurement error, was generally on the order of a couple percent.

\section{Calculation Details}

The concentration of ionic species was calculated based on the calibration data, and from this a ratio of nitrate to nitrite anions could be calculated. Then, using the initial mass of electrolyte in the cell, the number of moles of each could be calculated. There is good reason to not just take the concentration of ionic species and work backwards through the dilution procedure to arrive at the total amount of a component in the electrolyte. When disassembling the battery to harvest the electrolyte (which is done when the electrolyte is a solid), it is easy to not recover all of the electrolyte, as some will inevitably be stuck in the pores of the cathode or on the lithium anode. This problem is easily avoided by only taking a ratio of ions from the chromatography data and using this with the known amount of electrolyte originally in the battery.

Due to impurities in the electrolyte salts (i.e. nitrite salt containing nitrate impurity), correction factors calculated from ion exchange chromatography data were applied to arrive at the final values. When calculating the number of moles of nitrate and nitrite to attribute to electrochemical behavior, several factors needed to be considered.

First, when using an electrolyte that contains significant nitrate, it is important to note that the reaction described in Equation 3.1 also occurs on the lithium anode as the SEI forms. This process can be seen in cells that sit at OCV and is difficult to account for, so it is hard to make an accurate correction for it when calculating moles of nitrate consumed in an electrochemical process. However, working with a nitrite electrolyte avoids this issue, so studying a purely nitrite electrolyte with a cathode previously discharged is most appropriate for accurate calculations. Many other cells were put through this ion exchange chromatography analysis, such as all the cells of Figure 3.13, but an accurate correction factor for this extra nitrite could not be found. The amount of time a battery sat at OCV was not a stable enough metric to be able to generate a calibration relating the time at OCV to the amount of nitrate generated due to SEI growth. In addition, plating and discharge processes seemed to evolve nitrite from the lithium anode at an even faster rate, making the use of a nitrate electrolyte untenable.

Second, nitrite is not generally pure, but it is thermodynamically favorable for $\sim 1 \%$ 
of it to convert to nitrate in the presence of oxygen. However, throughout all of the nitrite calibration series performed across all of the samples run, this impurity proved to be a constant, and it is therefore easy to account for it in calculations. 
Appendix $C$

\section{NANOSCRIBE SPEED OPTIMIZATION}

Before discussing how long it takes to write a structure using the Nanoscribe, it is necessary to give more detail on the operation of the instrument. As mentioned in the main text, Nanoscribe employs two-photon lithography, a lithography process in which a photoresist is polymerized by a laser of photons with half the energy needed for the polymerization reaction to occur (i.e. twice the wavelength of light that would be used in a normal lithography process). This laser is focused to a small volume, or voxel, such that the probability of two photons interacting with the same molecule is high enough that the polymerization process takes place. This voxel is then rastered in space, allowing the direct writing of polymer throughout the photoresist.

It is this rastering process which dictates the length of time to fabricate a sample. The instrument is assembled on an optical table with the laser stationary, and there are three mechanisms by which rastering can happen. For large translations, the stage which holds the sample substrate and photoresist moves with an electric motor. This is too rough a control to make precise features, so it is only used when necessary to travel a significant distance. The second method also involves stage motion, but now by use of a piezoelectric controller (piezo mode). This gives precise control within a couple hundred micron radius but is fairly slow. Until recently, these were the only means of effectively rastering the laser, limiting the typical sample size to about $100 \mu \mathrm{m}$. However, recently (about three years ago) a new rastering method was introduced whereby a mirror galvanometer moves the laser focal point (galvo mode), allowing the rastering to proceed without stage motion. This is a much faster process, but only achievable in-plane (x,y) and similarly limited to a couple hundred micron radius.

With a good understanding of the rastering methods, it is time to describe how all three of them are used together to make a sample. A structure no larger than $\sim 250 \mu \mathrm{m}$ in any dimension can be made without needing to move the stage with the motors, so any larger sample must consist of smaller units patched together. In the case of the lattice array of Chapter Four, this tiled unit is a $120 \mu \mathrm{m}$ cube. This model is broken down into a series of raster lines as defined by a MATLAB script, where 
due to the size of the structure each beam is rastered across several times. Starting from the substrate, all the raster lines in a plane are written in galvo mode before moving out of plane (up in z) using piezo mode. Then the next plane of raster lines is written, and so on until the single unit is finished. Finally, the motor takes the stage to a new spot to begin the next unit. Because the galvo mode is so much faster than the piezo mode, the out of plane motion plays a large role in determining the amount of time to make a sample.

Based on the detailed description of how to make a sample, there are a few parameters we can tune to affect the speed of writing. One is the rate of motion of the rastering, but that only moves within a fairly small range and thus won't play too large of a role (this was tested, and little impact on time was seen). Another is the spacing between the raster lines. While a close spacing of raster lines within a beam leads to a mechanically robust structure (since the writing voxels significantly overlap), it also takes a longer time. So in order to see what spacing was allowable, several parameter sweeps were performed. The spacing in $\mathrm{x}, \mathrm{y}$ (hatch spacing) and in $\mathrm{z}$ (layer spacing) were varied from $200 \mathrm{~nm}$ to $1.5 \mu \mathrm{m}$. Because the motion in $\mathrm{z}$ is controlled in piezo mode, maximizing the allowable layer spacing was crucial to minimizing the time to fabricate a sample. In addition, the laser power was varied because it plays a role in the extent of polymerization, and thus the mechanical properties of the structure.

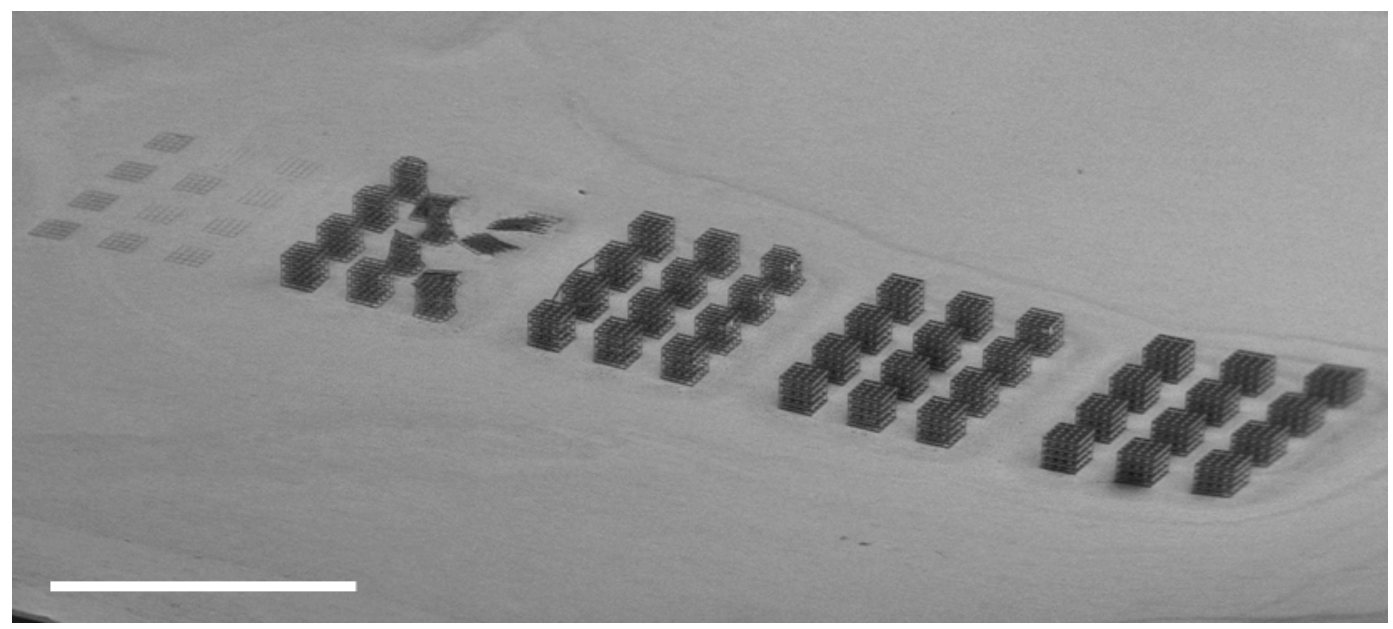

Figure C.1: Nanoscribe parameter sweep. Each group of 12 is performed at a different laser power. Within each group, a matrix of different layer and hatch spacings is used (scale bar: $1 \mathrm{~mm}$ ).

After performing several parameter sweeps similar to the one shown in Figure C.1, 
a maximum allowable raster spacing that still yields a robust structure was found. Such parameters will be different for each photoresist used, and IP-S photoresist was chosen because it has the largest interaction volume, allowing for the largest raster spacing. Implementing this set of parameters for the macroscopic lattice array of Chapter Four results in a write time of 20 hours. Trying to create such a structure before optimization (i.e. implementing typical writing parameters used by other group members at the time) would have taken about 2 weeks, an untenable amount of time for making a single sample. 
Appendix D

\section{WETTING OF ARCHITECTED ELECTRODES}

\section{Wetting for Nitrate Reduction}

When first attempting to use a lattice array as an electrode for nitrate reduction as in Chapter Four, the electrochemical data were noisy and the achievable currents were lower than expected, being worse than the thin film electrode. Based on discussions with collaborators who struggled with similar problems using a molten salt electrolyte, it was suspected that the electrolyte was not wetting the lattice. Because the $\mathrm{LiNO}_{3}-\mathrm{KNO}_{3}$ electrolyte is a solid below $125^{\circ} \mathrm{C}$, directly working with the electrode in the electrolyte was untenable. This required a different approach for pre-wetting electrodes before cell assembly.

At first glance, we assumed that the wetting issue was due to the viscosity of the molten salt. To resolve this, we used a $100 \mathrm{~g} \mathrm{~L}^{-1} \mathrm{LiNO}_{3}-\mathrm{KNO}_{3}$ aqueous solution, hoping the lower viscosity of water would be sufficient. Figure D.1 shows the result of pipetting $100 \mu \mathrm{L}$ of this solution on both the lattice and film electrodes.
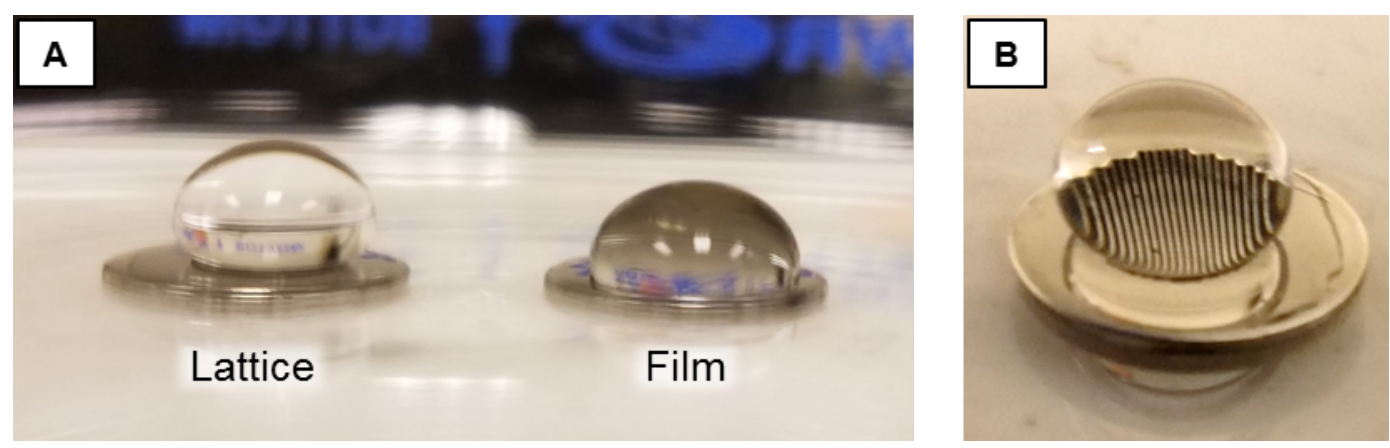

Figure D.1: Wettability of lattice electrode. Aqueous solution of $100 \mathrm{~g} \mathrm{~L}^{-1} \mathrm{LiNO}_{3}-$ $\mathrm{KNO}_{3}$ dropped onto electrodes. (A) Side view of droplet on lattice and thin film electrodes. (B) Lattice electrode viewed through droplet acting as lens (scale: metal disc is $1 \mathrm{~cm}$ in diameter).

Interestingly, it was not the viscosity but that the lattice is fairly hydrophobic, confirming the assumption that wetting was likely the issue with poor nitrate reduction performance, and the water droplet behaved like a lens, allowing observation of the lattice array by eye. In order to encourage the solution to wet the lattice, enough salt solution was added so that the lattice and a bubble within it were completely 
submerged. This was then briefly put into a vacuum oven. The moment vacuum was pulled, a bubbles emerged from the lattice, not unlike the one in Figure D.2c. Once all the bubbles had left (after only about 30 seconds), the filled lattice was taken out of the vacuum oven and dried on a hot plate. Once the water left, salt was impregnated in the lattice, and when put in contact with more molten salt, it readily filled.

\section{Wetting for Surface Area Measurements}

Having determined the viability of a lattice electrode for studying nitrate reduction, it was necessary to know its surface area. Knowing the difficulty of wetting a lattice from the previous section, we decided to study the wetting process, and Figure D.2 shows its evolution using a Keyence VW-9000 high speed optical microscope.
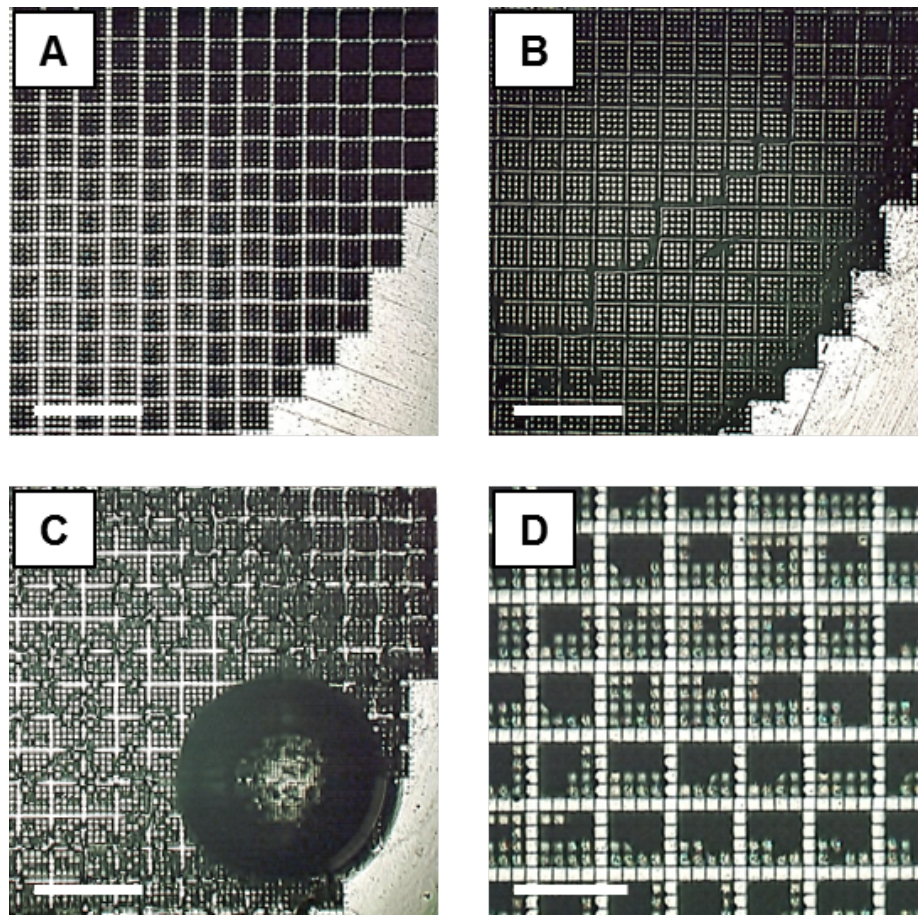

Figure D.2: Wetting of a lattice electrode, by optical microscopy. Images of lattice electrode (A) when dry, (B) immediately after immersion in water, (C) after 15 minutes of immersion, and (D) after CVs of Figure 4.9. (scale bar: (A-C) $500 \mu \mathrm{m}$ and (D) $250 \mu \mathrm{m}$ ).

The entire lattice and its stainless steel substrate were submerged in a shallow bath of DI water. Immediately upon immersion, it appeared that no bubbles were going to leave the electrode, but suddenly a large bubble developed and began to grow over time. Interestingly, the size of this bubble served as a good measure of the extent 
to which air had left the electrode. By simply measuring the size of the bubble and comparing this with porosity values calculated from the SOLIDWROKS model, we could know what fraction of the lattice had been wet. After sitting in the bath overnight, the lattice became fully wet.

As mentioned in Chapter Four, there were some bubbles in the lattice after running the CVs to measure the electrode surface area, as seen in Figure D.2d. It is hard to measure the fraction of space filled with bubble as one can not tell how many unit cells within a column are filled with air, but this observation seems to confirm the slightly smaller measured surface area compared to what was expected from the SOLIDWORKS model calculation. 